Portland State University

PDXScholar

$1-1-2011$

\title{
Coupled Pedagogy: A Study of Sustainability Education and Community-Based Learning in the Senior Capstone Program at Portland State University
}

Emily Erin Bowling

Portland State University

Follow this and additional works at: https://pdxscholar.library.pdx.edu/open_access_etds

Part of the Community-Based Learning Commons

Let us know how access to this document benefits you.

\section{Recommended Citation}

Bowling, Emily Erin, "Coupled Pedagogy: A Study of Sustainability Education and Community-Based Learning in the Senior Capstone Program at Portland State University" (2011). Dissertations and Theses. Paper 260.

https://doi.org/10.15760/etd.260

This Thesis is brought to you for free and open access. It has been accepted for inclusion in Dissertations and Theses by an authorized administrator of PDXScholar. Please contact us if we can make this document more accessible: pdxscholar@pdx.edu. 
Coupled Pedagogy: A Study of Sustainability Education and Community-Based Learning in the Senior Capstone Program at Portland State University

by

Emily Erin Bowling

A thesis submitted in partial fulfillment of the requirements for the degree of

Master of Science

in

Education: Policy, Foundation and Administration

Thesis Committee:

Dilafruz Williams, Chair

Christopher Carey

Stephanie Stokamer

Portland State University

(C)2011 


\begin{abstract}
Sustainability has emerged in mainstream higher education over the last few years, and the fields of community-based learning and sustainability education are closely linked through their emphases on active, experiential learning in place-based contexts. In order to create ecologically literate citizens to more adequately address environmental problems, there is a logical connection between teaching about sustainability and engaging students in the community, which can serve as a relevant forum to address sustainability issues. However, there is a problem in that educational programs and courses dealing directly with sustainability topics across the higher education landscape often do not emphasize or include experiential, community-based elements. Understanding this relationship is crucial to advance the field of sustainability with meaningful community engagement.
\end{abstract}

This research investigated the pedagogical strategies and frameworks that are foundational in undergraduate capstone courses that include sustainability education and community-based learning. A sample of five community-based, interdisciplinary senior capstone courses at Portland State University was examined through semi-structured interviews with course instructors and syllabi review. Three broad themes emerged as common values among the instructors: connectedness and relationships, community and place, and diversity and inclusiveness. Reflection was a tool utilized universally by instructors to personalize the learning process, cultivate understanding of connectedness and relationships, and incorporate feelings into the learning process. Competencies and skills related to sustainability and those related to civic engagement were very similar; engagement in community is a sustainable practice. This study provides cogent support 
for the notion that achieving meaningful, transformative sustainability learning requires community-based learning. 


\section{Dedication}

This thesis is dedicated to my amazing Leadership in Ecology, Culture, and Learning (LECL)/Leadership for Sustainability Education (LSE) family, especially Lacy Cagle, Robert Nathan, Angela Hamilton, Marisa Ferro, Kara Gilbert, Hope Yamasaki, and Lauriel Schuman, for their endless inspiration, steadfast support, hours spent with me imagining the world we want to create and live in, and for reminding me continuously of the power of community and love. 


\section{Acknowledgements}

Heartfelt thanks go out to all who have helped me along this journey of discovery. I have endless gratitude for the many people who have inspired me throughout the writing process. In particular, thanks and appreciation go to the members of my thesis review committee, Dr. Dilafruz Williams, Dr. Christopher Carey, and Dr. Stephanie Stokamer, who each offered useful feedback. My advisor, Dr. Dilafruz Williams, in particular never gave up on me in the many rounds it took me to write and finally finish this project. Dilafruz has been an invaluable resource and source of encouragement. This thesis would not have been completed without Dilafruz's enthusiasm, high standards, and belief in me. I am also deeply appreciative of the insights, support, and guidance from Dr. Heather Burns regarding my research topic and career interests.

University Studies, specifically Senior Capstone Director, Dr. Seanna Kerrigan, has been incredibly supportive of my work. I thank Seanna for her excitement, openness to my ideas, and willingness to provide resources and encouragement to senior capstone instructors to participate in this study. I also have much gratitude for Seanna and Dr. Sukhwant Jhaj, Director of University Studies, for supporting this project through funding of the transcription of the interviews.

I am thankful for the many friends and mentors outside of my graduate program who have helped me to process and make sense of my learning, including Eric Lassahn, Jeff Klein, Christine May, Kimberly Tomaszewksi, Carrie Walker, and Mark Radecke. I am grateful for their undying support, listening to my many ramblings and tangents, and encouraging me to pursue the work I am most passionate about. I have learned much from each of them, appreciate their humor and zest for life, and admire their desire to 
create a more livable world.

Finally, I want to thank the instructors who participated in my study for their willingness to share their time, insight, and perspectives with me. I have learned tremendously from all of them and am in awe of their work. I thank the participants for making this project both an enjoyable and rewarding experience. 
Table of Contents

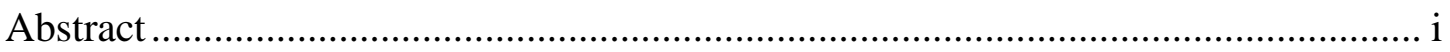

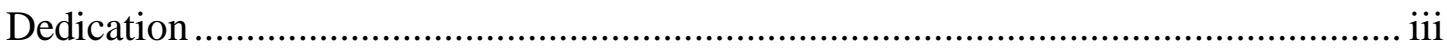

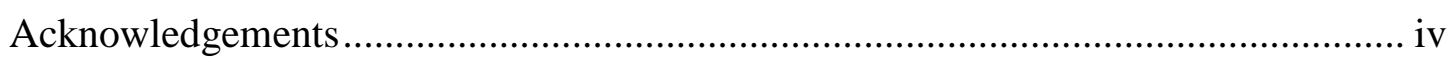

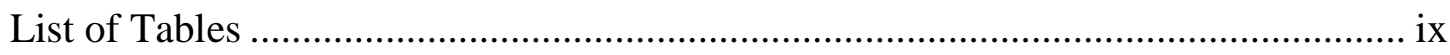

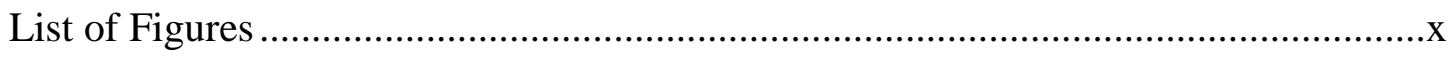

Chapter I

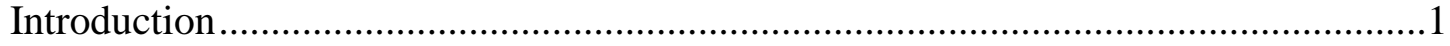

Chapter II

Review of Literature: The Intersection of Sustainability Education and Community-

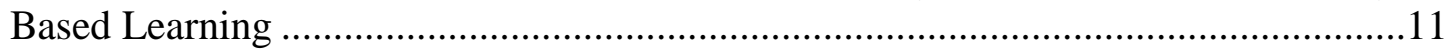

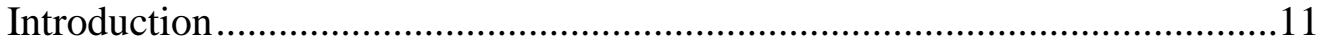

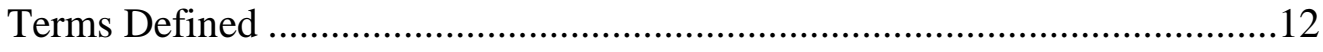

Conceptual Framework ................................................................................13

Context for sustainability education pedagogy in postsecondary

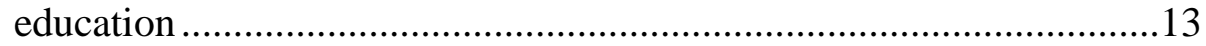

Teaching and learning in postsecondary education: traditional practice and research ........................................................................18

Recent research and trends in sustainability education in

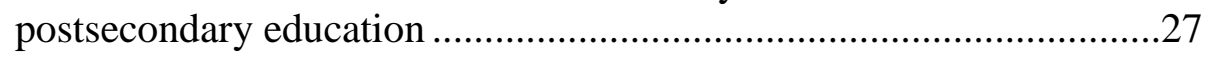

The significance of community engagement to sustainability

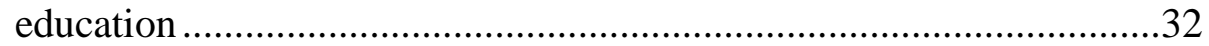

Connecting Schools to Communities: Civic Engagement ................................40

A Critique of Higher Education: The Need for Reform ....................................45

Common Pedagogical Attributes of Community-Based Learning and

Sustainability Education: Process and Context..............................................54

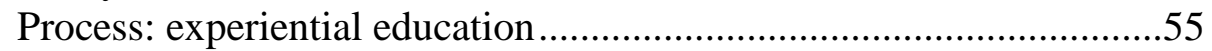

Process: community engagement.......................................................56

Process: community collaboration and reciprocity ...............................59

Context: place-based .....................................................................62

Portland and Portland State University as Context for Research .....................70

Portland's reputation for civic engagement and sustainability .............70

Portland State University's University Studies and senior capstone

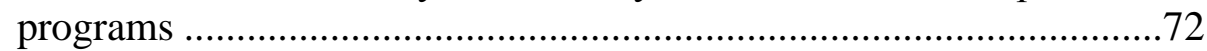

Portland State University's sustainability priority ................................74

Conclusion 
Chapter III

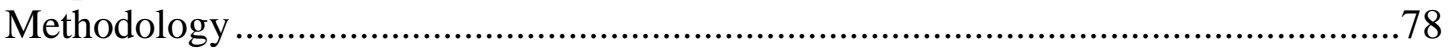

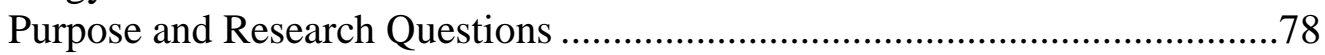

Rationale for Qualitative Methodology .................................................79

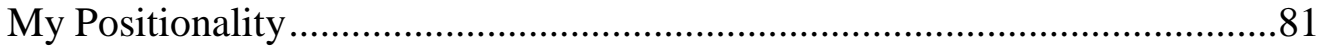

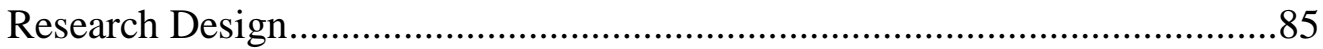

Portland State University and the senior capstone program ...............85

Sampling, subject recruitment, and research participants..................86

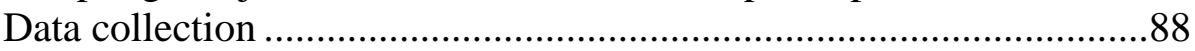

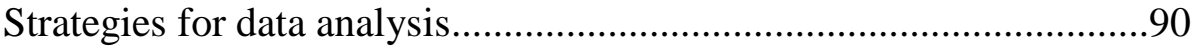

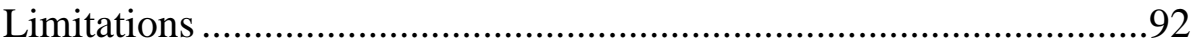

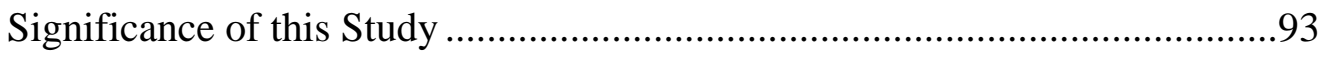

\section{Chapter IV}

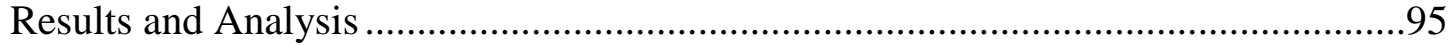

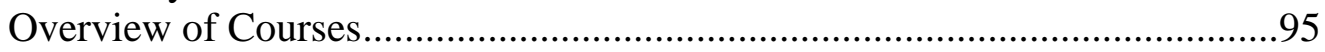

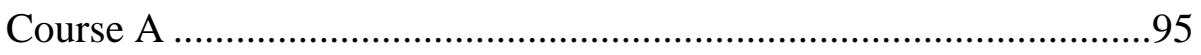

Course B...............................................................................96

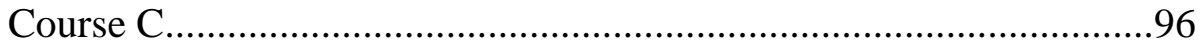

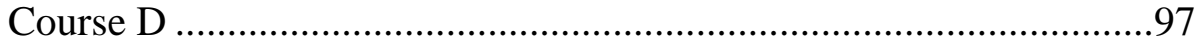

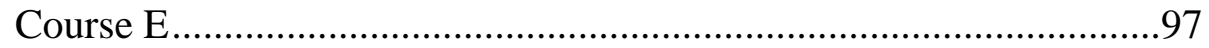

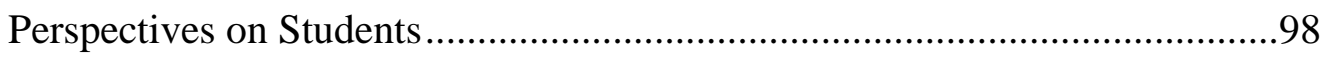

Cooperative learning and personal responsibility .............................98

Holistic student view: multiple senses and affective and cognitive

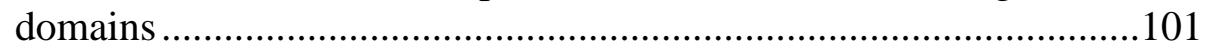

Learner-centered and active learning strategies..............................103

Reflection and Personalizing Sustainability ........................................... 107

Connectedness and Relationships ........................................................111

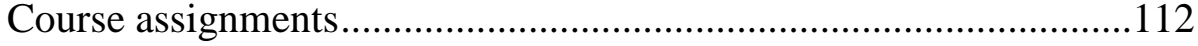

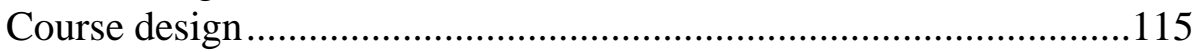

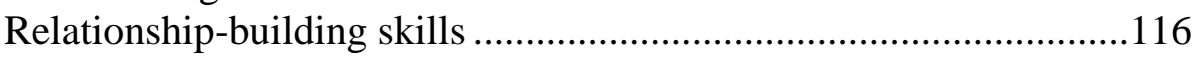

Community partner relationships............................................. 117

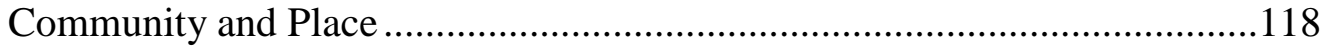

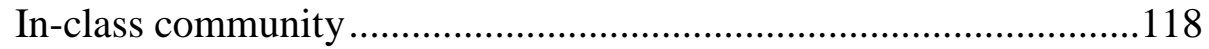

Community as the classroom .......................................................122

Community building to challenge Western culture and capitalism ...123

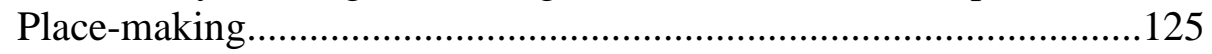

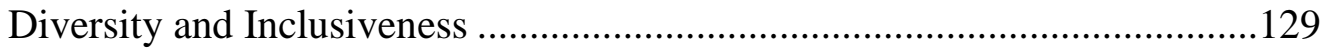

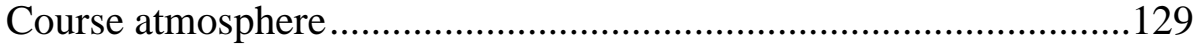

Curriculum and course learning outcomes ....................................131

Instructor Pedagogical Values, Sensitivity, and Intention Related to

In-Class Community Development....................................................... 134

Coupling Sustainability Education and Community-Based Learning ............137

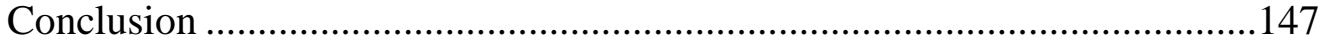


Chapter V

Recommendations and Conclusion

Recommendations for Higher Education Instructors.................................151

Recommendations for Higher Education Administrators ............................156

Potential Institutional Barriers and Opportunities for Recommendations .....158

Suggestions for Further Research .........................................................163

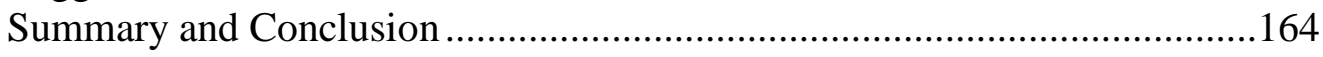

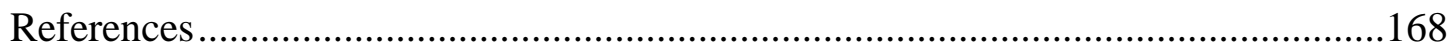

Appendices

A. Interview Themes for Individual Interviews......................................... 182

B. Informed Consent Form for Individual Interviews .................................183

C. Individual Interview Guide for Semi-Structured Interviews.....................185 


\section{List of Tables}

Table

Page

1

Summary of data sources .

.91 


\section{List of Figures}

Figure

Page

1 Instructor pedagogical values, sensitivity, and intention related to strong in-class community development .......... 136

2 Pedagogical model of and values within the coupling of sustainability education and community-based learning .......................................... 138 


\section{Chapter I}

\section{Introduction}

In his forward to Stephen Sterling's book Sustainable Education: Re-visioning

Learning and Change, David Orr (2004b) wrote,

The disorder we see all around us reflects a prior disorder grounded in the paradigm of human domination that has now nearly conquered the entire world. That paradigm must be replaced by one that places us in the web of life as citizens of the biotic community. We must come to see ourselves as implicated in the world, not simply isolated, self-maximizing individuals. This battle will be won or lost in the schools, colleges, and universities around the world. (pp. 7-8)

Here, Orr (2004b) poignantly draws attention to the undeniable role that education at all levels must play in addressing sustainability. Exponentially greater energy use, resource extraction, population growth, and consumer-driven lifestyles are among several factors that have exacerbated existing ecological and social problems and transformed our world in the last several decades (Edwards, 2005). The need has never been greater for a deeper, more holistic approach to education that sustains the whole person and prepares students to live lives of thought and purpose. If education is going to be part of the solution to the critical problems we face, it must be education of a specific kind: sustainability education. Sustainability education is a framework and approach to education that is meant to prepare students to engage in and work toward solutions for the world's most pressing ecological, social, and economic problems (Sterling, 2004).

Achieving sustainability necessitates a basic shift in the way humans orient themselves within social and economic systems, to each other, and to the natural world. Moreover, "The nature of sustainability, and the prospect of unsustainability, require a fundamental change of epistemology, and therefore of education," according to Corcoran 
(2010, p. xii). Because sustainability requires a way of thinking and knowing that is distinctly different than that which is commonplace in Western culture, creating a more sustainable reality is contingent upon educational systems, including structures, curricula, pedagogy, policies, and practices, that reflect an ethos of sustainability. Such systems can equip and prepare students to perpetuate sustainability ideals and live sustainable lives.

In order for future generations to be able to benefit from the resources that exist today, education must equip people with the knowledge, skills, values, and perspectives needed to practice sustainability (Sterling, 2004). This urgent need requires education to be reoriented to promote sustainable living by integrating the principles of sustainability into existing fields and disciplines; sustainability needs to be brought to the center of the educational enterprise and not be merely an add-on to existing curricula. Sustainability is at the confluence of nearly every subject area and touches social and environmental concerns; therefore, it ought to be woven throughout the curriculum. Because no two places are identical and local conditions are affected by many factors, the solutions to sustainability issues often differ by geographic region and culture; therefore, education for sustainability can be best practiced with locally relevant and culturally appropriate curricula (UNESCO, 2005).

Higher education has a substantial role to play in addressing a shift toward a sustainability paradigm. An undergraduate college education is an optimal opportunity to educate and enlighten young adults about sustainability and sustainable living. During the university experience, students gain knowledge, develop skills, and adopt views that will shape them and consequently shape how they will impact society. According to Cortese (2003), higher education must play a role in creating a sustainable future because higher 
education "prepares most of the professionals who develop, lead, manage, teach, work in, and influence society's institutions, including the most basic foundation of K-12 education" (p. 17). A complete and holistic education should prepare individuals to be productive, active citizens who can contribute to the betterment of society. This must include being knowledgeable about sustainability as a framework, developing skills associated with sustainability, and understanding the values and perspectives of sustainability. Essentially, if sustaining life and the well being of living species as well as the planet itself are priorities and goals, sustainability education at all levels is an unquestionable imperative.

The most "educated" nations produce the largest carbon footprints and are often credited with the most unsustainable lifestyles (Merkel \& Litten, 2007). The most educated populations are destroying the environment, furthering inequities, and generally promoting unsustainable practices to a greater degree than populations with less formal education (Merkel \& Litten, 2007; Orr, 1992). This fact demands the question: what are we educating for? The modern mechanistic schooling paradigm was built out of the Industrial Revolution as a place to prepare youth to participate in the emerging market economy (Bowers, 1999). A prescriptive, mechanistic approach to education simply does not allow individual learning styles, cultural, or other differences to be acknowledged, local community issues or contexts to be considered, or critical, active, or creative modes of inquiry to be employed. A prescriptive, mechanistic approach to education is, in many regards, the antithesis of sustainability education.

A criticism of modern educational approaches by the sustainability and community-based learning fields is that most learning lacks relevancy because it is not 
contextualized, causing students to struggle to understand why what they are learning in the classroom matters (Eyler \& Giles, 1999; Orr, 1992; Orr, 2004c). Postsecondary education is largely de-contextualized from local community issues and values abstract thinking and knowledge over practical knowledge and skills that come from experiential, place-based education. In his book Earth in Mind, David Orr (2004a) focuses on the problem of education and that in fact modern education is inadequate, in part, because it separates humans from nature via promotion of human domination. This type of education has contributed to much of what has gone wrong in the world, according to Orr (2004a). The manner in which a liberal arts education has become explicitly non-practical is an example of privileging abstract thought over practical skills (Orr, 2004a). Education without experiential elements essentially separates theory from practical skill building; it does not intentionally incorporate practical experience in nature and the local community into curriculum. This minimizes opportunities for students to develop a healthy curiosity for the natural world. Within modern Western society, de-contextualized knowledge is separated into high- and low-status knowledge (Bowers, 2000). High-status knowledge is abstract, theoretical, scientific, and removed from context in the physical, natural world. Conversely, low-status knowledge is associated with manual, craft, and trade knowledge (Bowers, 2000). Addressing sustainability issues will require educational institutions to restructure the way abstract and trade knowledge are valued and societies and economies to reconsider the way "high-status" and "low-status" knowledge are valued. Sustainability requires a value of knowledge obtained through community settings and skills that allows one to live well in place. 
Further, there appears to be an inherent disconnect between the dominant values of modern society in the United States and the perspectives and practices that will enable society to respond effectively to individual needs as well as local, national, and global challenges (Lindholm, 2007). According to M. C. Taylor (2010), “College and universities are more isolated from the world and inwardly fragmented today than ever before" (p. 47). Thus, many colleges are not adequately connecting education to larger world issues. Lindholm (2007) posits that undergraduate students are experiencing emotional and spiritual poverty through participating in schools systems that favor positivistic modes of thinking and scientific worldviews brought on in the Enlightenment period. Today, many college environments embody the strong societal emphases on individual achievement, competitiveness, materialism, and objective knowing (Lindholm, 2007). These reductionist and positivistic Western traditions within the academy devalue what is seen as nonintellectual including self-discovery, fusion of the affective and cognitive domains, self-reflection, critical dialogue, and the collaboration that community-based learning and sustainability education utilize as pedagogical cornerstones. The ecological crisis we face is an educational challenge; this challenge calls for higher education institutions to reconsider their missions, values, and priorities. Sustainability and ecological education must create learning experiences that are relevant, meaningful, as well as ones that value practical skill building, experience, and community engagement as essential.

Community engagement and community-based learning is one strategy to promote renewed relationships between human and ecological systems. Paul Hawken (2007) explains that sustainability "is about stabilizing the currently disruptive 
relationship between earth's two most complex systems - human culture and the living world. The interrelation between these two systems marks every person's existence and is responsible for the rise and fall of every civilization" (p. 172). Sustainability requires ecological systems and human societies to be able to exist in synergy. Populations must understand their interdependence with both human and ecological systems in order for a balanced, harmonious relationship to be achieved. Community-based learning, or direct experience in nature and/or civic organizations, is a prime conduit for fostering stewardship, a connection to place, and an understanding of ecological and human systems.

Sustainability education literature emphasizes the necessity of experiential learning in the community in order to create effective, meaningful education for sustainability (G. A. Smith, 2002; Sobel, 2004; Sterling, 2004). Yet, many educational institutions have not prioritized sustainability education or experiential, community-based education. Even fewer institutions are explicitly merging their community engagement and sustainability initiatives. Community-based learning and service-learning are well supported as educational techniques for preparing students to engage most effectively in their communities and participate in democracy (Battistoni, 2002; Colby, Ehrlich, Beaumont, \& Stephens, 2003; Eyler \& Giles, 1999). Collaboration and community engagement are sustainable practices.

Meaningful experiential learning and the need for education to represent sustainability in process are stressed in literature on sustainability education (Sarkissian, Hofer, Shore, Vajda, \& Wilkinson, 2009; Sterling, 2004; Stuteville \& Ikerd, 2009). Sarkissian et al. (2009) frame their central argument around the proposition that a 
commitment to community engagement processes will achieve sustainability outcomes because they provide the space for communities to communicate and engage in the dialogue needed to achieve change. Communication is critical in achieving sustainability outcomes: effective communication can make the difference between natural resource devastation and sustainable resource management (Sarkissian et al., 2009). Sarkissian et al. (2009) detail many reasons why community engagement is central to achieving sustainability including the following: (1) in a democratic society, those whose lives and environments are impacted should be involved in decisions that affect them; (2) community processes and projects empower citizens to take action in local community progress; (3) community engagement encourages citizens to develop a holistic sense of sustainability by allowing decisions to be made using local wisdom, values, and knowledge; and (4) community processes that address local social and cultural needs allow small scale policy approaches to be developed that fit the community's resources, skills sets, and work styles. Sarkissian et al. (2009) claim community engagement is an optimal strategy to achieve sustainability. Thus, it is clear how community involvement is vital in making sustainable progress.

There is consensus around the fact that educational reform is imperative in order to create ecologically literate citizens, educate students about sustainability, and more adequately address the current global environmental crisis (Gadotti, 2008; Orr, 1992). There is also agreement that educational systems often times do more to perpetuate the existing ecological problems than to prepare students to work for and imagine solutions (Gadotti, 2008; Longo, 2007; Orr, 1992; Sterling, 2004). Sustainability education pedagogy calls for experiential and collaborative learning environments that are 
connected to local communities (Burns, 2009; Orr, 1992; Sterling, 2004). Community engagement is a means to achieve sustainability in general but also within the context of education where community-based learning represents a path toward both community engagement and sustainability. Yet, many educational programs and courses, even those dealing directly with sustainability topics at both Portland State University and across the entire higher education landscape, do not emphasize or sometimes even include experiential, community-based elements (L. McBride, personal communication, October 12, 2009; Sipos, Battisti, \& Grimm, 2008; Stuteville \& Ikerd, 2009). Leslie McBride, Associate Vice Provost for Teaching, Learning, and Assessment at Portland State University, noted that of the 39 graduate or upper division courses with sustainability content that were examined for the types of assignments they included in 2009 , only five courses (12.8 percent) included any community-based learning projects (L. McBride, personal communication, October 12, 2009).

Moreover, there has been a significant rise of service-learning and community engagement in the last two decades in education at all levels (Eyler \& Giles, 1999; Sandy \& Holland, 2006). Further, educational institutions have made and are able to receive increased financial commitments for civic and community engagement work in recent years through grants, foundations, and other avenues (Hollister, Wilson, \& Levine, 2008). Community service and community engagement work at the higher education level is completed largely to meet environmental and social needs and to address environmental and social problems, such as pollution, food insecurity, homelessness, struggling school systems, and other problems related to marginalization, inequities, and injustices. These same problems also represent obstacles in achieving sustainable societies. While 
sustainability is quickly becoming a banal trend on college campuses, community engagement initiatives at the higher education level are often not explicitly linked to issues or an understanding of sustainability (Stuteville \& Ikerd, 2009). The time is ripe to explore community engagement as it relates to sustainability in higher education.

The fields of community-based learning and sustainability education are related by their emphases on active, experiential learning within a place-based context. This link is crucial in order to advance the field of sustainability with meaningful community engagement. However, there is a paucity of research that examines the overlap of these two formally distinct fields and provides an understanding of the relationship between sustainability education and community-based learning. This empirical study aims to fill this void. The goal of this research is to elucidate better the nexus of community-based learning and sustainability education within the senior capstone program at Portland State University. Sustainability is one of the four cross-cutting themes of Portland State University and is part of the institutional mission and learning outcomes; thus, logically sustainability ought to be integrated into its education program. This research will explore course frameworks and strategies for exemplary sustainability senior capstone courses and investigate connections between community-based learning and sustainability education as understood by undergraduate instructors. At its core, this study will discern how instructors who have successfully integrated community engagement into sustainability learning view linking a community-based approach to sustainability course content. Ways in which the two formally distinct fields of service-learning and sustainability education are closely linked and related are explored and described. Thus, this study provides relevant information for practitioners in the fields of community- 
based learning and sustainability education as well as for administrators and instructors across institutions of higher education.

The literature review in chapter II will provide an overview of the fields of community-based learning and sustainability education in postsecondary education and an understanding of the vitality for community engagement in sustainability education. The qualitative, interview, and syllabi review methodology that was employed to answer the research questions will be detailed in chapter III. The similarities in pedagogical framework, strategy, priorities, and values within the courses examined and among the senior capstone instructors interviewed will be revealed in chapter IV. Lastly, chapter V provides recommendations for the coupling of sustainability education and communitybased learning. 


\section{Chapter II}

\section{Review of Literature: The Intersection of Sustainability Education and Community- Based Learning}

\section{Introduction}

A review of relevant postsecondary education, sustainability education, and community-based learning literature is necessary to provide a conceptual framework and context for this research study. David Orr, Stephen Sterling, Gregory Smith, and Dilafruz Williams are scholars that have provided the theoretical frameworks for ecological and sustainability education. Further, David Sobel, Gregory Smith, and David Gruenewald have been integral to the closely related place-based education movement. My intellectual ancestors in the field of community and civic engagement include John Dewey, Ernest Boyer, Thomas Ehrlich, Janet Eyler, Dwight Giles, Ira Harkavy, and Harry Boyte. Further, scholars including Paulo Freire, Mark Tennant, Philip Pogson, Ernest Boyer, and Jack Mezirow have contributed critical work to the literature on how adults and undergraduates learn best, and thus their work contributes significantly to the conceptual framework of this study. These strands of literature are explored with a view to situate the empirical research and look for convergence between community-based learning and sustainability education.

First, the key terms in this thesis are defined. Next, current trends and changes within postsecondary education are discussed, vis-à-vis the emergence of sustainability education and community-based learning. Third, a summary of traditional practices of teaching and learning at the postsecondary level shows that research on adult learning supports a shift from mechanistic, transmissive learning to learner-centered, active 
learning. Fourth, recent trends in sustainability education pedagogy in higher education are discussed. Finally, Portland and Portland State University as relevant contexts for this research are described in the latter part of this chapter.

\section{Terms Defined}

The essence of sustainability boils down to one idea: enough for all, forever. Sustainability means sustaining the planet's ability to support all forms of life and includes societies' ability to provide for the welfare of all their citizens (Merkel \& Litten, 2007). Senge, Smith, Kruschwitz, Laur, and Schley (2008) explain the term "sustainability" to mean living in the present in a way that does not put the ability of future generations to meet their needs in jeopardy. Sustainability must include environmental, social, and economic elements because they are interconnected intricately. The health and equity of human systems, economy, and environment must be in balance in a sustainable society. A sustainable future is only possible with ecological, economic, and social shifts away from current paradigms.

Sustainability education is an approach to education that is meant to prepare students to engage in and work toward solutions for the world's most pressing ecological, social, and economic problems (Sterling, 2004). Sustainability education includes addressing knowledge, skills, values, and perspectives as well as the content, process, and context of education (Burns, 2009; McKeown, 2002). Community-based learning is pedagogy that integrates learning, community service, and community organizations in order for students to apply classroom knowledge to address issues of local concern (Eyler \& Giles, 1999). 
The terms "sustainability education," "education for sustainable development," and "education for sustainability" are often used interchangeably because they suggest many of the same goals. "Sustainability education" is the term that will be used in this study because of the study's focus on the pedagogy, process, and context of education and to reflect education as sustainability. Furthermore, "community-based learning" and "service-learning" are terms that are often used interchangeably. "Community-based learning" is the term that has been chosen for this study because this is the language used by University Studies and the senior capstone program at Portland State University.

\section{Conceptual Framework}

\section{Context for sustainability education pedagogy in postsecondary education}

Postsecondary education enrollment is rapidly expanding and henceforth university students are increasingly diverse in terms of their demographics and experiences they have upon entering the classroom. Research on diverse adult learners coupled with an increased demand for employability and practical skills exert pressures for institutions to update and expand curricular content and pedagogical process. Furthermore, the increasing impacts of globalization are also forcing higher education institutions to be reshaped. Room for, acceptance of, and support for sustainability education at the postsecondary level have taken place as part of a larger wave of changes within postsecondary education in recent decades.

Morrison (2003) summarized many of the most prominent changes within postsecondary education when he wrote, "American higher education is undergoing substantial change in terms of the way colleges and universities are organized and function. This change is being driven by the combined forces of demographics, 
globalization, economic restructuring, and information technology (IT) - forces that will, over the coming decade, lead us to adopt new conceptions of educational markets, organizational structures, how we teach, and what we teach" (p. 6). Perhaps the most distinguishing change is that postsecondary education has seen noteworthy increases in enrollment numbers. In 1970, there were only about six and a half million undergraduate students in the United States, and this number rose to over 15 million by 2005 (Institute of Education Sciences, 2008). This number will continue to rise dramatically. The global demand for higher education is expected to grow from 97 million students in 2000 to 263 million students in 2025 (Ruby, 2008).

Postsecondary students are more diverse than ever before. Increased federal financial aid has increased access to lower socio-economic status students as well as historically underrepresented groups in the United States (Pascarella \& Terenzini, 2005). Today's students are diverse in terms of age, ethnicity, nationality, race, socioeconomic status, sexual orientation, and part-time or full-time status (Morrison, 2003). The number of international students has sharply risen in the last decade (Ruby, 2008). In addition to these demographic differences, students also vary greatly in terms of the lived experiences they matriculate with as well as their expectations, attitudes, intellectual abilities, and learning styles (Morrison, 2003; Tennant \& Pogson, 1995). Just 40 percent of college students being educated for future careers are 21 years of age or younger; serving older, nontraditional students for initial or recurrent education is clearly a major challenge for the higher education system (Geiger, 2002). The expansion of technological advances, namely computers and the Internet, as well as the increased number of nontraditional and part-time students has resulted in a higher demand for distance learning 
and online classes and for institutions of higher education to be more flexible in their approach to education (Morrison, 2003; Pascarella \& Terenzini, 2005). Institutions have also put more energy into research on and implementation of programs to increase student persistence and retention as a way to augment student satisfaction and learning, institutional reputation, and fiscal responsibility (Pascarella \& Terenzini, 2005).

Globalization has continued to have an increasing impact on higher education. Curriculum, faculty recruitment, student recruitment, food sources for campuses, endowments funds, as well as the value of higher education are all affected by globalization (Ruby, 2008). Globalization is presenting at least five major challenges for universities, particularly those in the United States, according to Ruby (2008). These challenges include a growth in global demand for higher education, diversification of students, growth of private providers, diversification of the delivery of education, and implications for the content of research and learning (Ruby, 2008). Every previous phase of globalization has resulted in increased disparities between the rich and poor (Ruby, 2008); globalization has historically created societies that are more unsustainable and inequitable. Thus, the research at postsecondary institutions should begin to address how distribution of capital and access to education and other public services can promote equality even in the face of globalization. Furthermore, the impact of globalization on the content of research and learning raises difficult questions about what kind of curriculum will prepare global citizens. Ruby (2008) argues that institutions of higher education ought to explore how the current wave of globalization is changing the skills and knowledge required to participate effectively in social institutions of the twenty-first century. Because the content of research and learning needs to be reconsidered within 
global contexts as a result of globalization, a sustainability lens can and should be used in creating curriculum to prepare global citizens with the knowledge and skills necessary to ameliorate many of the negative outcomes of globalization.

The totality of the pressures that Morrison (2003), Pascarella and Terenzini (2005), Ruby (2008), and Tennant and Pogson (1995) note has contributed to changes in approaches to teaching and learning. Globalization in combination with other educational, economic, and political factors have demanded more career skills like critical thinking, reflection, and teamwork from college graduates (Morrison, 2003; Tennant and Pogson, 1995). A more diverse world, globalized economy, and competitive job market require increased skills and competency among college graduates. Further, the more concerted focus of institutions of higher education on student engagement, persistence, and retention have resulted in more participatory, high-impact programs and techniques including internships, problem-based learning, and civic education like service-learning; these practices are associated with increased student engagement and retention in addition to critical thinking and practical skill cultivation (Pascarella \& Terenzini, 2005). Further, educational research suggests that high-impact practices, such as collaborative assignments and projects, writing-intensive courses, learning communities, diversity and global learning, service-learning, community-based learning, internships, and capstone courses and projects, increase rates of student retention and student engagement (Kuh, 2008). The high-impact practices linked to student persistence and retention are largely those centered on active, learner-centered practices and engaged pedagogies; they are many of the same practices and pedagogical strategies 
recommended for sustainability education (Burns, 2009; Cotton \& Winter, 2010; Sipos et al., 2008; Sterling, 2004).

Furthermore, as a result of many of the factors and influences described above, the tangible learning outcomes for students in higher education have been under more scrutiny, review, and revision in recent decades. The National Leadership Council for Liberal Education \& America's Promise (LEAP) is an organization focused on the quality of teaching and learning in postsecondary education as well as preparing students to meet the challenges of the twenty-first century through affording them empowering liberal educational experiences (The National Leadership Council for LEAP, 2007). The National Leadership Council for LEAP (2007) identified essential learning outcomes that support the report's recommendation that all college students have an "education that intentionally fosters, across multiple fields of study, wide-ranging knowledge of science, cultures, and society; high-level intellectual and practical skills; an active commitment to personal and social responsibility; and the demonstrated ability to apply learning to complex problems and challenges" (p. 4). The essential learning outcomes identified by LEAP consist of four key areas including: (1) knowledge of human cultures and the physical and natural world, (2) intellectual and practical skills, (3) personal and social responsibility including local and global civic knowledge and engagement, and (4) integrative learning demonstrated by application of knowledge and skills to complex problems (The National Leadership Council for LEAP, 2007). These learning objectives must be integrated not only within the general education programs but also within major programs, according to The National Leadership Council for LEAP (2007). The LEAP learning outcomes share significant similarities with the goals of sustainability education. 
Yet, the purpose of a liberal education at the higher education level does not explicitly include or address sustainability. Instead, the focus of a liberal education is on preparing students to for responsible work, citizenship, and life within the current global economy.

The compilation of changes in postsecondary education, including growth, increased diversity, expanded technology, a focus on student retention and persistence, a demand for more tangible work-related skills, the implications of globalization, and revisions on learning outcomes focused on meeting the needs of a global society and economy, has called for institutions of higher education to reconsider and reshape both how and what they teach; it has also provided room for sustainability education to emerge within the postsecondary education landscape. Among the population of more diverse learners exists a need for higher education that acknowledges the diversity of its students and the complex global and local sustainability issues they face. There is a need for sustainability education to enter the forefront of higher education.

\section{Teaching and learning in postsecondary education: traditional practice and research}

Making progress toward sustainability education within postsecondary education requires a fundamental shift from traditional practices and assumptions about teaching and learning. Basic beliefs about teaching and learning have gone largely unchallenged within higher education. One of the longest standing assumptions about learning is that students should subsume knowledge from a teacher who is wiser, be able to repeat and show that they have obtained this knowledge, and then move on to a new topic (Bowers, 2000; Freire, 1970; hooks, 1994). Freire (1970) coined this the "banking" method of education. According to Freire (1970), "In the banking concept of education, knowledge 
is a gift bestowed by those who consider themselves knowledgeable upon those whom they consider to know nothing. Projecting an absolute ignorance onto others, a characteristic of the ideology of oppression, negates education and knowledge as processes of inquiry" (p. 72). Here, Freire (1970) describes how the banking method of education is in a sense oppressive to students who are treated largely like sponges. Moreover, hooks (1994) posits that this pattern reinforces the power of the teacher and dulls the enthusiasm of and objectifies students. Barr and Tagg (1995) argue that this paradigm treats students like passive vessels that are to merely ingest knowledge for recall on tests. This perspective is largely positivistic and assumes students have little or nothing to contribute to the learning process. This modern, mechanistic, instructorcentered paradigm of education emerged from the Industrial Revolution as a place to prepare students for the market economy (Bowers, 2000). Under this educational paradigm, students are seen as better and more successful if they are able to memorize and master information that has been pre-determined as valuable by the instructor (Freire, 1970).

However, instructor-centered education and the traditional method of lecture style teaching are contrary to most research about the strategies that allow students to learn best. Much literature agrees that learning should not be teacher-centered but should be learner-centered or student-centered whereby students are continually engaged in their learning and can apply the course's content to their own lives and the world (Barr \& Tagg, 1995; The National Leadership Council for LEAP, 2007; Steiner \& Posch, 2006; Sterling, 2005; M. L. Taylor, 2006; Tennent \& Pogson, 1995). According to The National Leadership Council for LEAP (2007), “The key to educational excellence... lies not in the 
memorization of vast amounts of information, but rather in fostering habits of mind that enable students to continue their learning, engage new questions, and reach informed judgments" (p. 30). This excerpt aligns with the argument of Freire (1970) regarding the inability of memorization to represent valuable student learning. Excellence in undergraduate education comes when students cultivate the skills that allow them to think critically and conjunctively, continue to ask healthy questions about how they make meaning and find truth, and form judgments about what it means to be an active, contributing citizen in society.

Furthermore, Barr and Tagg (1995) suggest that a paradigm shift is pervading higher education, and that is a paradigm shift from the view that college exists to provide instruction to the idea that college is an institution to produce learning; it is a shift from an instruction paradigm to a learning paradigm. Barr and Tagg (1995) argue that the dominant instruction paradigm mistakes a means for an end and that a learning paradigm is needed because it frames learning holistically, recognizes the primary player in the process as the learner, and requires students to be active discoverers and constructors of their own knowledge.

The view of experience as an essential foundation for adult education practice is widely held and experiential education allows educators to meet the growing demand to link education and vocation (The National Leadership Council for LEAP, 2007; Tennant \& Pogson, 1995). Tennant and Pogson (1995) support learner-centered, active education as a way to develop self-aware learners who have the ability to frame their own purposes and continually use classroom material to understand the world. Lecture-based courses and instruction tend to induce passivity rather than activity within students (Orr, 1992). 
The lecture-style, instructor-centered approach also ignores the diverse needs of an increasingly diverse student population. Educators benefit all students when learning environments balance instructional strategies, different cultural norms, and perspectives and value various learning styles (Chávez \& Guido-DiBrito, 1999). hooks (1994) argues that engaged pedagogies are a requirement for creating inclusive learning environments. Native American pedagogy also makes a sharp distinction between teaching and learning based upon the principle that when something is taught to someone, the person has been robbed of the experience of learning it (Margolin, 2005). Making progress toward learning that is transformational and best prepares students to participate in sustainable change requires challenging basic assumptions about how teaching and learning has occurred historically in order to allow engaged, learner-centered pedagogies to be readily integrated into higher education. A shift in assumptions about learning and new pedagogies is necessary in order to move away from traditional teacher-centered forms of education.

Ardent support for active learning exists in literature about the most effective strategies for enhancing learning and increasing engagement for college students; pedagogies of engagement have far reaching applications for higher education. Some active learning strategies include problem-based learning, community service-learning, critical emancipatory pedagogy, participatory action research, pedagogy for eco-justice, and environmental education (Sipos et al., 2007). Generally speaking, active learning means that students must do more than listen to lectures and take notes and that there is more focus on what the students do rather than what the instructor does. In active learning, students must engage in higher-order thinking tasks to learn content in ways that 
allow them to apply new knowledge outside the classroom walls in ways that students receiving traditional instruction are not asked to do (Nardone \& Lee, 2011). Recent research in writing in the disciplines, critical thinking, and problem-based learning all have one thing in common, and that is support for making students more active in their role as learners (Nardone \& Lee, 2011). Active learning and developing students' problem-posing skills allows them to wrestle with course content and leads to deeper understanding of course content and improved critical thinking (Nardone \& Lee, 2011).

In one study, Knight and Wood (2005) found promising learning gains through employing a more interactive course structure rather than a traditional lecture-based style. By decreasing lecturing and increasing student participation, cooperative problemsolving, and more in-class assessment of student understanding, significant learning gains and better conceptual understanding were indicated by the students when compared to students in the same course that was taught in the traditional lecture method (Knight \& Wood, 2005). Active learning exercises increase student engagement, encourage critical thinking, and lead to improved student attitudes about learning (Moravec, Williams, Aguilar-Roca, \& O’Dowd, 2010). Murphy (2010) reports that increased independent thinking skills and enhanced active citizenship capacities result from an active learning strategy called "open spaces for dialogue and enquiry" that the author likens to the service-learning strategy.

Service-learning is one popular active learning strategy with well researched student learning gains. M. C. Smith (2008) supports service-learning as a pedagogy that contributes to the cognitive, moral, and psychosocial growth of adult learners. Waldstein and Reiher (2001) report that students who participated in intentional service-learning 
were significantly stronger in their ratings of likelihood of participating in future service, stronger in their attitude that personal and community service involvement is important, and statistically significant differences were apparent for increased self-efficacy and tolerance for diversity among students in the study. Students who participate in community service or service-learning are more likely to develop a long-term commitment to the betterment of the communities in which they live (Perry \& Katula, 2001). Battistoni (2002) notes the ability for service-learning to lead to increased communication and collaborative skills as a result of the work with peers and the local community. Further, Eyler (2000) reports that service-learning impacts student growth in the areas of interpersonal skills, confidence, self-efficacy, increased moral reasoning, and personal and social responsibility. Stronger impacts are experienced when students are encouraged to reflect on their learning and when the service-learning components are linked explicitly to coursework (Eyler, 2000; Eyler \& Giles, 1999). The academic, cognitive, and problem-solving skill gains, positive civic attitude shifts, and the moral and psychosocial growth from service-learning experiences among higher education students evidence the many strengths of this active learning method.

The age, lived experiences, class, and racial and ethnic diversity of students must be considered in designing and implementing service-learning programs (Largent \& Horinek, 2008). Work schedules and life commitments and responsibilities outside the classroom can impact students' availability for service-learning and other activities that take place outside of class time. Further, younger and older adults approach communitybased projects with varying levels of expertise and lived experience which impacts the way reflection unfolds; adult learners tend to find the process of reflection particularly 
meaningful (Largent \& Horinek, 2008). Largent and Horinek (2008) found that adult learners need to have more understanding of what is expected, more attention to the need for learning to meaningful, and more connection to life experiences in service-learning programs than traditional aged students. There are limited studies that examine the impact of non-traditional and adult learners in service-learning (M. C. Smith, 2008). Nonetheless, Prentice and Robinson (2010) found that when faculty related the servicelearning experience directly to the curriculum, community college students learned more in service-learning courses than those without service-learning and that the servicelearning component added stimulation and passion to courses, increased retention of academic content among students, afforded students increases in reasoning, logic, leadership, and confidence, and was a motivator for higher degree attainment. Furthermore, Yeh (2010) found that service-learning participation can facilitate academic growth, psychosocial growth, personal and spiritual growth and sociocultural and sociopolitical growth among low-income, first generation students; all four areas contribute positively to persistence. Despite the challenges and diverse needs of diverse students, service-learning program development has been increasing at community colleges and among non-traditional students (Prentice, 2002).

Active learning techniques, such as service-learning, are especially relevant to and effective with Millennial students. Students in the Millennial Generation have been raised in an entertainment and multimedia-focused environment in which they are accustomed to shifting their attention quickly from one source of information to another (Roehling, Kooi, Dykema, Quisenberry, \& Vandlen, 2011). Consequently, these students have a low tolerance for boredom and passive learning that is associated with lectures; Millennial 
students report that active learning helps them focus better, makes it easier to pay attention in class, and prevents them from zoning out (Roehling et al., 2011). Because of the unique needs of the current generation of students, active learning techniques are more needed now than ever before.

Moreover, research supports the notion that education for sustainability ought to be more centered on learning than on teaching, that it be more learner-centered rather than teacher-centered. Scott and Gough (2003) posit that learning for sustainable development must transcend schools, colleges, and universities and include learning in, by, and between organizations and communities. This creates a view of learning that is inclusive in order to encompass all the learning that a person does between birth and death and not just within formal education. Scott and Gough (2003) further support an emphasis on learning rather than instruction or teaching within sustainability because "we do not yet know what we shall need to learn in relation to sustainable development, it is hard to be definitive about what needs to be taught except, perhaps that we need to be taught how to learn and how to be critical in order to build our collective capacity to live both sustainably and well" (p. xiv). Here, further support is provided for active, learnercentered education specifically as it relates to promoting sustainability.

Experiential, active learning is a core element in transformational learning (Mezirow, 1991). The way that one makes meaning out of the world is changed in some way by transformational learning. In essence, traditional education in adulthood adds to what one knows, however, transformational learning changes how one knows (Mezirow, 1991). Because of its powerful impacts, transformational learning has become a more researched phenomenon and is becoming a more commonplace goal for adult education. 
Transformation cannot be taught because it requires students to be active and the creators of their learning; transformation is not a passive process or knowledge that an instructor can give to student (Cranton, 2002). Education as sustainability is defined as transformative by Sterling (2004). Therefore, experiential, active learning is critical for education as sustainability rather than education about sustainability or education for sustainability (Sterling, 2004).

Addressing sustainability through education requires more learner-centered education, active learning, and pedagogies of engagement. Postsecondary education must move away from transmissive, instructor-centered strategies in order to embrace the active learning methods that provide opportunities for transformation more readily. Active, engaged pedagogies allow students to develop the problem-solving and critical thinking skills, self-efficacy, and ability to apply knowledge to real world contexts that are needed for understanding the complex relationships between social and environmental systems. Learner-centered education challenges some of the most longheld beliefs about the nature of learning and places students and learning at the center of education rather than the instructors and teaching. Pedagogies of engagement are especially pertinent for students of the Millennial Generation. Further, hands-on, experiential, collaborative opportunities are imperative in order for students to be better equipped to understand and address the complexity and magnitude of sustainability issues. Research supports the notion that active, experiential learning leads to enhanced learning and cognitive skill development. Sustainability education pedagogy needs to include active, student-centered learning to best prepare students to engage in sustainability work. 


\section{Recent research and trends in sustainability education in postsecondary education}

Sustainability education as a field is a relatively new area of research.

Consequently, the literature on teaching and learning focused on sustainability is fairly limited yet rapidly growing. To date, most higher education practice around sustainability has focused on "greening” campuses. Many questions and uncertainties remain about what learning outcomes best represent sustainability learning and how sustainability can best be taught and learned. Research about classroom related practice of sustainability education is still limited and more research is needed to provide more empirical evidence about the process of teaching and learning within sustainability education, according to Corney and Reid (2007). However, this section includes some preliminary examples of research and literature that present insights into the current state of and best practices for sustainability education within postsecondary education.

Unfortunately, a vast majority of institutions of higher education in North America are only addressing sustainability through facilities and operations by improving environmental management and reducing ecological footprints rather than considering how the institution could best address sustainability through research, curriculum, professional development, and community outreach and partnerships (Wals \& Blewitt, 2010). Within a sustainability context, there is a clear need to rethink the relationship between research, learning, and teaching as well as the meaning of the term "research" itself (Wals \& Blewitt, 2010). According to Wals and Blewitt (2010), sustainability in higher education "above all means the creation of spaces for transformative learning: learning that helps people transcend the 'given,' the 'ordinary,' and the often 'routine 
ways of doing' to create a new dynamic and alternative ways of seeing and doing" ( $\mathrm{p}$. 66). The ability to view the world through multiple vantage points, switch between various mindsets, and engage in innovative thinking that crosses or transcends disciplinary boundaries are needed in sustainability. According to Wals and Blewitt (2010), "we need to be able to switch back and forth between disciplinary perspectives, time perspectives (past-present-future), space perspectives (local-regional-global), cultural perspectives and perhaps even between human and other or more-than-human perspectives" (p. 66). Sustainability requires pluralism and diversity in teaching and research as well as "blurring the boundaries between science and society" (Wals \& Blewitt, 2010, p. 66). The result of development of the abilities described above represents transformative learning for sustainability.

Barth, Godemann, Rieckmann, and Stoltenberg (2007) found that both formal and informal education settings, or both curricular and co-curricular experiences, provide desirable forums for undergraduates to develop key competencies for sustainable development. In their study, Barth et al. (2007) defined key competencies for sustainable development as competency in foresighted thinking, interdisciplinary work, participatory skills, planning and implementation, self-motivation, reflection, and cultural models, as well as participatory skills and a capacity for empathy and compassion. Developing sustainability competencies at a higher level involves a variety of contexts, formal and informal, and requires a learning culture that allows interaction and engagement beyond the walls of the classroom (Barth et al., 2007). Barth et al. (2007) suggest blurring the boundaries between formal and informal learning to provide a variety of learning contexts and more comprehensive sustainability learning. 
Steiner and Posch (2006) note that interdisciplinary points of view, problemsolving skills, analytic capabilities, creativity, social competencies, and communication skills are required to address the complex problems of sustainable development and the dynamic changes that characterize the relationship between society and nature. Further, Hopkins and McKeown (2001) found that the following six learning outcomes were most desired within education for sustainable development: literacy, aesthetic appreciation and creativity, communication and collaboration, information management, responsible citizenship, and personal life skills, values, and actions. Engaging in sustainability work requires the "competence to integrate, connect, confront, and as much as possible, reconcile multiple ways of looking at the world" (Wals \& Blewitt, 2010, p. 70). Thus, systems thinking, critical thinking, problem-solving skills, and an appreciation for diversity and interdisciplinarity are needed outcomes of sustainability education, according to Wals and Blewitt (2010). Across the literature, the most commonly cited skills that are desired outcomes for sustainability education seem to be include systems thinking, comprehension of interdisciplinary perspectives, oral and written communication, interpersonal and intrapersonal, collaborative, and creative thinking skills (Cohen, 2007; McKeown, 2002; Senge et al., 2008; Svanström, Lozano-García, \& Rowe, 2007; Wals \& Blewitt, 2010).

Cotton, Warren, Maiboroda, and Bailey (2007) completed a case study at the University of Plymouth in England to determine lecturers' understandings of sustainable development, their attitudes toward sustainable development, and their beliefs about incorporating sustainable development into higher education curriculum. The beliefs of the lecturers about incorporating sustainable development into the curriculum were very 
positive. Lack of a shared understanding and language of sustainability education hinders the ability to engage instructors (Cotton et al., 2007). Cotton and Winter (2010) also note that the complexity and lack of clarity around the terms sustainability and sustainable development limit sustainability education by many in academia. The findings from Cotton et al. (2007) indicate a potential predisposition the environmental aspects within the sustainability framework rather than social or economic aspects among the lecturers. The belief that sustainable development is important and relevant among lecturers from a myriad of disciplines is encouraging for advocates of sustainability education in higher education. The range of answers concerning appropriate pedagogies shows that there is not one clearly accepted method for teaching education for sustainable development (Cotton et al., 2007). However, the majority of respondents believe that education for sustainable development requires non-transmissive teaching methods such has experiential learning through problem-based or hands-on learning as a result of the complexity associated with sustainability.

Cotton and Winter (2010) review ways to incorporate sustainability into curricula and the academics' understandings of sustainability pedagogies. Different pedagogies are required for sustainability because of the often controversial nature of sustainability issues; further, different pedagogies are needed to allow cultivation of skills and exploration of values in addition to the standard acquisition of knowledge that are all part of sustainability education (Callenbach, 2005; Orr, 1992; Sterling, 2004). The interdisciplinary nature of the framework of sustainability and the need for students and staff alike to view the world from multiple viewpoints also necessitates unique and innovative pedagogies (Wals \& Blewitt, 2010). Sustainability seems to invite interactive, 
innovative, and fluid teaching methods as a result of the complexity and controversial nature of many sustainability issues (Cotton \& Winter, 2010). The emerging pedagogical approaches for sustainability promote inclusive forms of communicating knowledge that are based largely on discussion and experience (Scott \& Gough, 2003). Domask (2007) found that various experiential learning approaches, including internships and visiting local communities, most effectively meet educational goals in international sustainability courses. Underlying the wide range of suggestions for approaches to sustainability education is support for active, experiential, and collaborative learning, interdisciplinarity, and the use of the local environmental for educational purposes (Cotton \& Winter, 2010). Teaching strategies that have been advocated for environmental education or sustainability education include: participative inquiry, action research, roleplays and simulations, group discussions, stimulus activities, debates, critical incidents, case studies, reflexive accounts, personal development planning, critical reading and writing, problem-based learning, fieldwork, and modeling good practice (Cotton \& Winter, 2010).

While considerable support exists for non-transmissive approaches to sustainability education, there is not one universally agreed upon pedagogy for sustainability education. However, there is increasing evidence that generally speaking good sustainability education pedagogy is often simply good pedagogy; thus, sustainability education pedagogy will likely be an attractive option for higher education administrators and instructors within a broader shift toward more learner-centered, constructivist educational methods across the higher education landscape (Cotton \& Winter, 2010). Moreover, much existing research on sustainability education pedagogy 
indicates that community engagement and community context are critical to sustainability education and sustainable progress.

\section{The significance of community engagement to sustainability education}

An extensive body of literature calls for sustainability education to be rooted in locale and community (see for example: Burns, 2009; Eflin \& Sheaffer, 2011;

Gruenewald, 2003b; Orr, 1992; Otto \& Wohlpart, 2009; G. A. Smith, 2002; Sobel, 2004;

Steiner \& Posch, 2006; Sterling, 2004; Wals \& Blewitt, 2010). Further, many researchers and practitioners within higher education have documented and support the importance and effectiveness of community engagement to sustainability education programs (see for example: Allen-Gil, Walker, Thomas, Shevory, \& Elan, 2005; Alvarez \& Rogers, 2006; Burns, 2009; Fagan, 1996; Keen \& Baldwin, 2004; Krasny \& Tidball, 2010; Moore, 2005; Niesenbaum \& Gorka, 2001; Sarkissian et al., 2009; Sauvé, 2005; Sipos et al., 2008; Stuteville \& Ikerd, 2009; Zaferatos, 2007). Sustainability requires permeability between disciplines, cultures, and the university and wider community (Wals \& Blewitt, 2010). Service-learning and community-based learning are common educational strategies and pedagogies requiring community engagement and campus-community partnerships. This section summarizes the significance of community engagement in sustainability education pedagogy and community engagement as a means to achieve sustainability.

Moore (2005) presents seven recommendations for creating sustainability education at the university level based on her research. Many of these recommendations are at least loosely related to community engagement and community service while two of them explicitly call for improved community relationships and engagement. Moore's 
(2005) recommendations include: (1) infuse sustainability in all decisions, (2) promote and practice collaboration, (3) promote and practice interdisciplinarity, (4) focus on personal and social sustainability, (5) integration of planning, decision-making, and evaluation, (6) integration of research, service, and teaching, and (7) create space for pedagogical transformation. The final two recommendations are strongly related to community engagement.

Moore (2005) recommends a more equal integration of research, service, and teaching because research is acknowledged and rewarded heaviest by most institutions. Service and teaching ought to be considered as bigger factors for tenure and promotion and the community should be incorporated into the everyday practices of the university, according to Moore (2005). Moore (2005) also urges creating space for pedagogical transformation that promotes, enhances, and rewards community service-learning, participatory group learning, experiential learning, problem-based learning, et cetera. Moore (2005) argues that academics engaged in alternative pedagogies and community work must be rewarded for their efforts in the same manner that top researchers are rewarded for research publications if universities are serious about sustainability education. Community engagement, community service, and community-based learning are clearly a vital part of Moore's (2005) findings on what will allow universities to create effective sustainability education.

Further, Alvarez and Rogers (2006) argue that learning about sustainability ought to not be exclusively prescriptive and that the sustainability education agenda must allow learning about sustainability to occur as discourse with students, instructors, and community members. Students must be taken into the community to facilitate a process 
where learners are "exposed to different understandings of sustainability and are able to recognize the messy and complex reality of sustainability on the ground" (Alvarez \& Rogers, 2006, p. 182). Students and teachers are challenged to think about sustainability as a complex practice and idea that is woven throughout places and people's lives; learning about sustainability in community gives meaning and legitimacy to student learning (Alvarez \& Rogers, 2006).

Fagan (1996) gets at the heart of the matter of local community related to sustainability in stating that

Agenda 21, the 'Earth Action Plan' that resulted from the Rio Earth Summit of 1992, recognized that any pretence at sustainability practice that failed to embrace local people and their aspirations, fears and needs for the future was doomed to failure. Local people were at the core of sustainability for the earth and its people: anything less could not be sustained. (p. 136)

Education is no exception to this statement; if education aims to be a sustainabile practice, it must embrace the local people and local community (Fagan, 1996). Fagan (1996) goes on to argue that community-based learning is essential to help students make sense of the world, to seek and engage in local opportunities, to challenge and change local conditions, and to allow them to engage in problem solving and seeing problems inside other problems. Community-based learning is needed in sustainability education because it "is about understanding the local to make sense of the global" (Fagan, 1996, p. 147). To this end, Fagan's (1996) central argument is that education cannot be a sustainabile practice without being community-based.

Eflin and Sheaffer (2011) also provide rationale for linking sustainability education to the local community and environment. Solutions to local environmental 
problems must be place-based. Eflin and Sheaffer (2011) poignantly describe the necessity of the local context to learning:

Sustainable communities require people with differing opinions and worldviews to communicate about issues in which each has a stake. For this reason, education for sustainability must take place in the context of civic engagement. Sustainability lends itself well to the increasing emphasis on 'service-learning' in higher education because it helps students bridge local and global issues, academic with residential communities, and theory with praxis. In the detached university setting, students learn technical skills that eventually can help them become agents of community development. (p. 34)

Here, compelling support is offered for why civic engagement and an understanding of local issues and stakeholders' opinions are imperative for students to engage in sustainable local solutions. College students learn about a wide array of problems facing the natural environment and local communities but often they are the problems of far away places or nations (Elfin \& Sheaffer, 2011) rather than the ones in their own backyards. Eflin and Sheaffer (2011) found many positive outcomes of their servicelearning project with watershed management planning with geography students. These successes included that students learned that individuals on the same side of an environmental issue do not always agree on strategies for action, students were immersed in a real-world environmental issue, and students were exposed to political processes and social concerns that surround such issues. Students also quickly realized the need to build bridges between stakeholders.

Otto and Wohlpart (2009) posit that service-learning can be used to advance sustainability education by using service projects to develop ecological perspectives among students. Service allows students to feel bound and connected to the local human community. Service-learning allows students to understand that their education is 
relevant and their actions make a difference (Otto \& Wohlpart, 2009). Service-learning emphasizes to students that their actions have a real impact and that they are the ones who can change the world. Making sustainable progress requires students and citizens alike to realize and accept their ability to create change where they are. Service-learning can help enhance the agency students have in creating sustainable community change and progress.

Sarkissian et al. (2009) devote an entire chapter in Kitchen Table Sustainability: Practical Recipes for Community Engagement with Sustainability to the idea that community education is a requirement to achieve sustainability. Education can only be a leverage point in working toward a sustainable future if the education allows us to be informed about the local challenges we face, search for the root cause of those changes, and integrate theoretical knowledge with community knowledge to promote "wise action" to address the sustainable challenges (Sarkissian et al., 2009). Democratic societies depend on citizens who are engaged and involved in the decisions that directly affect them; community-based projects empower people to take action (Sarkissian et al., 2009).

Sipos et al. (2008) present an argument for integrating heads, hands, and heart in education in order to achieve transformative sustainability learning and name community service-learning and problem-based learning as two pedagogies that can provide transformative sustainability education. Community-based learning fits into both of these categories. Burns (2009) presents a model for sustainability education that deems placebased education and learning in the community as essential to sustainability education. Burns (2009) states, "Service-learning, due to its participatory and experiential nature 
with goals of civic engagement and leadership, serves as an excellent application of sustainability pedagogy” (p. 46). Sauvé (2005) also notes that a central role of education is in enhancing human-environment relationships and that experiential approaches rooted in local community are vital to accomplishing learning around several concepts in environmental education, including a complete understanding of the human-environment relationship.

Stuteville and Ikerd (2009) feel that global sustainability and service-learning are paradigms for the future; the underlying principles of sustainability should and will guide new economic and educational paradigms that shifts from a neoclassical capitalist model that is not sustainable. Service-learning is powerful because it guides our relationships with other people and the earth by emphasizing interconnection and demonstrates to students that "the global has local feet." Students can engage with the community to understand how local actions have global social, political, economic, and environmental consequences via community engagement and service-learning. According to Stuteville and Ikerd (2009),

Service-learning, as an educational model that is intimately integrated with society, is poised to respond to the global transformations that are taking place. It is a responsive and responsible pedagogy that promotes the core values of social trust and interdependence as well as the skills that will be essential for success in the future. Through service-learning, social networks are strengthened, students are academically enriched and education is informed and renewed. (p. 21)

Because service-learning is an educational model that is informed by both the changing society and the academy, it is a promising type of education to respond to the global environmental and social crises. Education can foster the development of sustainability principles including a respect for other living beings, respect for the environment, and 
responsible stewardship of human, economic, and environmental resources through service-learning education (Stuteville \& Ikerd, 2009). Service-learning is a means for developing social capital, fostering development of the core values of sustainability, and creating an educational paradigm that is rooted in collaborative construction of knowledge (Stuteville \& Ikerd, 2009). "Service-learning uses real-time information to promote both a social and civic agenda - and even a sustainable agenda," according to Stuteville and Ikerd (2009, p. 11). Stuteville and Ikerd (2009) present a cogent argument for service-learning being the most effective teaching method of our time to address sustainability.

Keen and Baldwin (2004) make use of community-based research and servicelearning programs to encourage students to promote economic development and environmental sustainability at Allegheny College in Meadville, Pennsylvania. The community-university collaboration and partnership resulting from this project allowed the Allegheny College to become part of the local community and strengthened relationships where little connection existed previously (Keen \& Baldwin, 2004). This particular program allows students to work with one of seven community partner organizations in the areas of water quality analysis, energy efficiency, and forest management. Community partners and students alike commented that the program was effective and beneficial because of the new networks and contributions they were able to make to either the community (students) or the students' learning (community partners). Interviews with the community partners and alumni of the program revealed that they felt the ability to achieve positive environmental and sustainability results for the community was greatly enhanced by the community-university partnership. Keen and Baldwin 
(2004) recommend using community-based research for universities to address structural injustice, economic well-being, and environmental degradation, practice sustainability, model collaborative decision making, and take on a leadership role in the community. Allen-Gil et al. (2005) formed a community partnership to enhance education in sustainability at Ithaca College in Ithaca, New York. The Environmental Studies program and a local EcoVillage formed a partnership around issues of community sustainability to explore and teach systemic solutions to the environmental and social crises of our time including those related to communities, energy, agriculture, housing, land use, green spaces, forest conservation, et cetera. Community partnerships offer unique and valuable educational opportunities. The place-based approach allowed the student to appreciate the interrelatedness of the living systems, including human communities, as a vital common ground for sustainable action (Allen-Gil et al., 2005). Allen-Gil et al. (2005) provide an example of how colleges can partner with community organizations, particularly local EcoVillages, to further sustainability education at the higher education level and to strengthen ties with the local community.

Community engagement is critical to sustainability education. Community-based learning innately cultivates community engagement. Solutions to local environmental problems must be place-based and be derived from conversations with stakeholders within local communities. Service-learning is a method that allows students to feel connected to their community while allowing them to understand they have the ability to impact change. It is clear that community engagement via community-based learning is one way more readily to achieve and advance effective sustainability education programs, strengthen university-community relationships, and then consequently improve local 
communities and environments. The potential of the sustainability education and community-based pedagogies to achieve transformative results is dependent largely upon the process and context implicit in these strategies. The vitality of community engagement to sustainability education merits a look at how the relationship between schools and universities has developed over time.

\section{Connecting Schools to Communities: Civic Engagement}

Because civic and community engagement is so critical to sustainability and sustainable communities, it is important to provide a brief history and context of the relationship between schools and communities and how this relationship has evolved and been viewed by various scholars. Educators have called for schools to recognize their connection to community for over a century. John Dewey's educational philosophy is named as one of the biggest influences on the community engagement and communitybased learning fields. Dewey (1902) presents a theoretical foundation that has contributed to schools understanding that their roles and functions are connected to communities. Dewey (1902) argues for schools to act as social centers by connecting their educational missions to the local community. Schools are public institutions that are financed by the public and therefore owned by the public (Dewey, 1902). Dewey held the belief that education was more than schooling and that all parts of life should be educational.

Dewey's initial vision of the school as a social center did not explicitly call for colleges and universities to be institutions for community improvement or enhancement of democracy. Dewey actually never articulated a vision for the university to be a social center in the community. This was likely largely due to the limited access to higher education during the early part of the twentieth century. However, Dewey's call for all 
schools to act as social centers applies directly to colleges and universities and how he would have envisioned the role or mission of institutions of higher education.

Federal acts or legislation have called for institutions of higher education to see their mission as connected to the public and local communities for nearly 150 years. The federal Morrill Act of 1862 called for institutions of higher education to connect their mission with the broader public and gave federal land to each state for the creation of public land grant universities (Longo, 2007). The Hatch Act of 1887 and the Smith-Lever Act of 1914 created the cooperative extension system in land grant universities to help bring higher education to farmers in rural communities (Longo, 2007). Historically, service to democracy has always been an important function for higher education.

Ernest Boyer also called for a larger public purpose in higher education. Boyer (1987) urges campuses to adopt a scholarship of engagement that connects the many resources of the university to pressing community problems. A scholarship of engagement prevents universities from becoming or existing as islands isolated from the community. Boyer (1987) stresses that universities cannot ignore the social problems that surround them and erode the educational foundations of the country. General education at the collegiate level should introduce students to essential knowledge but also to connections across the disciplines and application of knowledge to life off campus (Boyer, 1987). Boyer views education as a seamless web.

In his renowned book, Scholarship Reconsidered, Ernest Boyer (1990) further supports a scholarship of engagement and offers a new paradigm for higher education that recognizes scholarly activity by university faculty outside of research and publication, including discovery, integration of knowledge, teaching, and service. Boyer 
(1990) questions the widespread faculty reward system that pushes faculty away from teaching and toward research. Boyer (1990) expands the concept of scholarship, traditionally viewed as the discovery of new knowledge, to include the scholarship of integration, the scholarship of application, and the scholarship of teaching. The scholarship of application involves using knowledge to address pressing societal issues; it asks how knowledge can be helpful to both individuals and institutions. Application involves the use of knowledge for creative activities for development and change. A scholarship of application allows groups, organizations, community, government, or current societal issues to define the agenda for scholarship, rather than only the university scholars as takes place in the scholarship of discovery.

Boyer (1990) also presents full support for the scholarship of teaching. The scholarship of teaching involves developing the knowledge, skill, character, or ability of others. Teaching is not merely transmitting knowledge but transforming it as well. According to Boyer (1990), teaching stimulates "active, not passive, learning and encourages students to be critical, creative thinkers, with the capacity to go on learning....Pedagogical procedures must be carefully planned, continuously examined, and relate directly to the subject taught" (p. 23-24). This characterization of scholarship expands the traditional role of teaching from a routine task to a vital element in a professor's academic life. Furthermore, Boyer (1990) argues that the academy should reward all four components of scholarship. The scholarship of universities ought to be applied to the local community's most pressing problems. Civic engagement and community-based learning pedagogy clearly emphasize both the scholarship of application and scholarship of teaching that Boyer (1990) calls for. Academic and civic 
cultures must value all four types of scholarship equally and communicate more frequently and creatively to be able to fully address the issues that stand as obstacles in achieving a more sustainable future.

In The Basic School: A Community for Learning, Boyer (1995) proposes that community, curriculum, coherence, and character should be the four priorities that are the building blocks for successful schools. Classrooms are communities themselves but must be connected and have a shared purpose with the other classrooms in the school (Boyer, 1995). Schools must have core virtues that are taught in word and deed and the curriculum, school climate, and service should encourage students to apply classroom lessons to the world around them (Boyer, 1995). Boyer (1995) sees the four priorities as providing a path for successful school and community renewal.

Ira Harkavy is another educator who has been a long time supporter of connecting schools to their communities and for community-university partnerships being an integral part of higher education. Harkavy and Blank (2002) call for systemic reform for education and policy makers that work to connect schools to community through resource sharing that will improve both education and community life. Harkavy and Blank (2002) demonstrate this view when they state:

A strategy needs to be developed that connects schools and school system change to a process of democratic community change and development. The strategy should be directed toward tapping, integrating, mobilizing, and galvanizing the enormous untapped resources of communities, including colleges and universities, for the purpose of improving schooling and community life. (p. 22)

Harkavy and Blank (2002) show how connections between schools and communities are mutually beneficial, maximize school and community resources, and promote democracy. 
Community-based learning presents an ideal way to connect schools and communities and promote reciprocity.

Boyte (2004) calls for public work, work with public meanings and purposes, to promote civic engagement. Public work is a tool to create civic change and help citizens see themselves as part of community rather than "outside fixers." Activities based in the community can reconnect citizens to purposeful and responsible public life at times other than Election Day. Boyte (2008) asks everyone to join a "citizen movement" to achieve change in American communities' problems by focusing on issues close to home. Concentrating on local issues is a tenet of sustainable change as well. The most effective way to create change is to work for change from the ground up, not the top down, according to Boyte (2008). Being involved in one's local community allows citizens to feel like they are part of their community and a part of positive civic change that addresses social problems.

Community engagement for institutions of higher education is on the rise. The Campus Outreach Opportunity League (COOL) and Campus Compact began in 1984 to promote civic engagement in higher education (Learn and Serve America's National Service-Learning Clearinghouse, 2008). These efforts began with community service and by the 1990 s included attempts to incorporate community service into the academic curriculum through "service-learning." Campus Compact has grown from a few hundred members to over 1,000 institutions with state affiliates in over thirty-one states (Longo, 2007). The current push for civic engagement within universities has been called the "fourth wave" of higher education civic engagement initiatives; this wave is moving beyond efforts focused on individual classrooms and toward a fully engaged university as 
a whole (Learn and Serve America's National Service-Learning Clearinghouse, 2008). In 2005, Princeton Review and Campus Compact published Colleges with a Conscience, which is a guide for high school students to use civic engagement as a criterion for college selection. U.S. News and World Report also now includes a listing of the country's best service-learning institutions. Today, more than $83 \%$ of Campus Compact

member schools house a Community Service or Service-Learning Office while only 50\% did in 1995 (Longo, 2007). Colleges and universities are beginning to focus on a civic mission and explore the ways that they can meaningfully connect to their local communities with an increasing frequency over the last few decades. While it is encouraging that these initiatives are on the rise, much education at the postsecondary level remains devoid of community context and an experiential process.

\section{A Critique of Higher Education: The Need for Reform}

There is considerable consensus around the fact that educational reform is needed to prepare students better to be citizens that are able to work toward better communities and social and environmental solutions (see for example: Battistoni, 2002; Bowers, 2000; Colby et al., 2003; Gadotti, 2008; Gruenewald, 2003a; Longo, 2007; Orr, 1992; Orr, 2004a; Stuteville \& Ikerd, 2009; M. C. Taylor, 2010). Stuteville and Ikerd (2009) argue that addressing the sustainability challenges of our time will require a re-evaluation of our current educational institutions that are grounded in the past and on mechanistic systems. Campus support for service-learning and community-based learning has been connected to a concern about a "crisis" in American civic education from the beginning; this concern has only grown over the past two decades (Battistoni, 2002). In Educating Citizens: Preparing America's Undergraduates for Lives of Moral and Civic 
Responsibility, Colby et al. (2003) recognize that most institutions of higher education have not implemented educational practices that make undergraduate moral and civic education a priority. However, because global interdependence is becoming more pronounced, old social problems still persist, new social and environmental problems are surfacing, increasing racial and ethnic diversity have brought new tensions to societies, and since the complexity of political, economic, social, and environmental worlds is increasing, moral and civic education is needed more than ever before (Colby et al., 2003). Educational reform that will address the ecological and civic crises must honor the interplay and relationships between ecological and human and social systems.

Many colleges and universities remain detached from their public missions. Faculty members have three main roles including teaching, research, and service. The faculty reward and tenure systems are designed at most institutions to reward research and publications much more heavily than their quality of teaching or their commitment to public work and the community, particularly at research I institutions. Many of the world's "best universities" are located in urban neighborhoods or towns with some of the largest community problems (Longo, 2007). M. C. Taylor (2010) describes the unbalanced focus on research and autonomy within the academy as contributing to a "culture of expertise that leads to overspecialization among faculty members who are more interested in pursuing their narrow research agendas than they are in teaching what students need to learn and addressing pressing practical issues" (p. 57). Having a predominantly research focus detracts from the ability of many colleges and universities to effectively fulfill an institutional civic mission and provide students with learning experiences that prepare them to deal with the complexity of pressing problems in their 
local communities, state, nation, or world. These examples illustrate a disconnection between higher education and a concern for public responsibility.

Community decay, disengagement in politics, and poor academic performance are not currently being successfully addressed by government policy or schooling (Longo, 2007). It is apparent that any one institution alone cannot address these interrelated issues. Any isolated institution is powerless to make the needed civic improvements. Educators must look at how the ways education in the community and civic engagement overlap to educate youth for social change and democracy. Reciprocal relationships must be fostered, intentional emphasis should be placed on education being made comprehensive, relational, and public. Learning must be made relevant to people's everyday lives, and commitment must be made to making change over long periods of time for education to be successful in addressing community ills. Community-based learning offers an opportunity to cultivate this type of education for students.

However, various critiques of and concerns about community-based learning and civic engagement at the higher education level exist. Westheimer and Kahne (2004) claim that service and service-learning are political by nature because service-learning is often completed in the pursuit of an improved world; thus, the goals and motivations that underlie service-learning must be carefully sorted out. According to Boyte (2004), community service has limitations for increasing political engagement because it is based on apolitical notions of volunteerism where too little effort is made to connect involvement in community with notions of power and root causes of community problems. Boyte (2004) claims that community-based learning and service-learning 
initiatives must be intentionally connected to politics and an understanding of power relationships to promote a more robust democracy and create better communities.

Further, Butin (2006) presents political, pedagogical, and institutional limits to service-learning. He posits that service-learning has a progressive and liberal agenda under the façade of a universalistic practice because of its push to have a justice orientation, creating a challenge in being politically balanced. Additionally, soft fields such as education, sociology, English, psychology, communications, and health utilize service-learning with a much higher frequency than hard fields such as physics and chemistry because of the way knowledge is valued within the field (iterative, qualitative in the soft fields rather than cumulative and quantitative in the hard fields) (Butin, 2006). Moreover, service-learning programs would need to promote additional studies on nontraditional and more diverse students because much research on student gains related to service-learning has been dominated by students with high cultural capital who are of traditional age and are middle class, according to Butin (2006). Service-learning is limited institutionally because it attempts to subvert the disciplinary rules that have traditionally governed higher education and dictated academic legitimacy (Butin, 2006). He also argues that service-learning must become "disciplined" as an academic department to overcome the limits he describes.

Several authors have written about the importance of having a justice rather than a charity or a critical rather than a traditional approach to service-learning that includes analyzing social structural issues (Boyte, 2004; Eby, 1998; Illich, 1990; Mitchell, 2008; Westheimer \& Kahne, 2004). Illich (1990) cautions that service runs the risk of damaging communities or creating divides when assumptions are made about community needs and 
students are not aware of their privilege related to power, money, or education.

Furthermore, Mitchell (2008) expresses concerns about the possibility of service-learning programs recreating power differences that could reinforce racism and other forms of oppression if students are not asked to analyze the interplay of power, privilege, and oppression. Mitchell (2008) supports a social change orientation for service-learning whereby work is done to redistribute and share power and develop authentic relationships as well as critical service-learning programs that encourage students to see themselves as agents of social change and use the experience of service to address injustice in communities. Despite these critiques and concerns, there is ample support for and documentation of the benefits of community-based learning for students and communities alike. The fact that civic engagement and service-learning is on the rise in higher education suggests that these critiques and concerns related to the field need to continue to be teased apart and addressed in order to sensitively and thoughtfully move the field forward. The field offers the possibility to transform the academy and our classrooms (Butin, 2006).

The interests of often conflicting stakeholders including teachers, administrators, school boards, parents, youth, community residents, community organizers, elected officials, policy makers, college presidents, faculty, staff, and college students will have to be organized for effective public action and civic education to occur (Longo, 2007). The power relationships among these constituencies will also have to be altered in order to honor the needs and maximize the talents of all stakeholders. In order to address community decay, Longo (2007) calls for an "ecology of civic learning" that puts the community at the center of civic education rather than the school or school system as in 
the traditional educational approach. The "ecology of civic learning" approach sees the interconnections between community systems and school systems and promotes comprehensive and public dimensions of education (Longo, 2007). Longo (2007) expands on his vision for education addressing civic renewal when he states that taking a new path, however, involves rethinking where education takes place; seeing people of all ages, backgrounds, and professional status as educators and resources; thinking more comprehensively, relationally, publicly about learning; developing neighborhood learning community networks; and making civic learning a public priority. All this can only be accomplished by making, and then maintaining, a commitment to creating educative communities in pursuit of democracy. (p. 142)

Here, support for education taking place in the community and university-community partnerships that value diversity in all facets is emphatically supported. There is increasing recognition of the connections between schools and communities by scholars such as Colby et al. (2003), Longo (2007), and Putnam (2000). The current educational paradigm is broken, at least partly, because of the failure to understand how problems are interrelated and failing to address issues ecologically and holistically through civic education.

Longo (2007) argues that it takes a village to educate a citizen and proposes an ecological approach to education through the "ecology of civic learning." Longo's (2007) proposal for an ecological approach to education and civic learning suggests that community engagement is an essential pathway for civic renewal. The ecological approach represents a framework within which people can educate for a different type of politics, a type of politics that moves beyond a model of scarcity. The conception of learning and civic life needs to include education for democracy as a responsibility of whole communities. Longo (2007) states that, "Schools and communities are inexplicably 
linked: solutions to the problems in each must be addressed by harnessing the many talents in the "ecology of education"' (p. 4). Because schools and communities are so intimately related, the problems of the community must be addressed by the schools and vice versa. Educational reform at all levels must acknowledge the ways schools and communities are connected.

Bowers (1995) presents an urgent call for educators and environmentalists to understand how current educational ideals and practices undermine efforts to create a more sustainable future. This occurs through repeated reform efforts that focus on the individual and discount the fact that the individual is embedded within culture, and culture is in turn nested within and dependent upon natural ecosystems. Bowers (1995) asserts that direct experience in the learning process and acknowledgment of local culture is imperative for creating an ecologically sustainable culture.

David Orr $(1992 ; 1994)$ presents one of the most compelling critiques of higher education's inability to educate for ecological literacy and a more sustainable world. Orr (2004a; 2004c) warns of the dangers of continuing to privilege abstract, theoretical knowledge over practical competence and education; this sends the message that education is to provide upward mobility and success in the form of careers and income. Orr (1992) harshly criticizes higher education and Alan Bloom's (1987) proposal for the content of a liberal education. Bloom (1987) and higher education trends to date greatly value a liberal education that includes reading classic texts to provide ancient wisdom and mere knowledge acquisition whereby education is an end in itself. A purely academic mind is closed off to ecological issues, and when education is regarded as an end in itself it cannot serve any transcendent purposes that are needed in a time of global and 
environmental turmoil, according to Orr (1992). One of Orr's (1992) arguments centers around the fact that Western culture and education have failed to offer much direction on the appropriate relationship between humanity and its habitat. The relationship between humanity and habitat is of the utmost importance in a shift toward sustainability. Institutions of higher education have continually missed the mark in providing an education that leaves students understanding their relationship with their environment and locale.

Another central argument of Orr's (1992) critique of higher education is that its traditional priorities on immersion in text books and a focus on scoring well on written tests value second-hand knowledge of the world rather than the first-hand knowledge and experience that ought to be the priority of educational institutions. Orr (1992) notes that, "The aim of education is life lived to its fullest....The purpose of a liberal education has to do with the development of the whole person" (pp. 99-100). The development of the whole person requires experiential education and integration of students in a holistic sense. Developing balanced, whole persons necessitates that the mind and feelings be connected through an active learning process (Orr, 1992).

Orr (1992) calls for reformed liberal arts education that will develop balanced, whole persons, connect disciplines and subjects through interdisciplinary knowledge in order to keep knowledge within its larger context, provide a realistic view of the world without inducing fear or despair, and equip students to live well in a place. A genuine liberal arts education will foster connectedness, implicatedness, and ecological citizenship and will provide the agency to act on this knowledge (Orr, 1992). Most liberal arts colleges put students in environments where they learn separation rather than 
connectedness and where they learn practical incompetence by never being required to solve problems that have real consequences (Orr, 1992). "The conventional campus has become a place where indoor learning occurs as a preparation for indoor careers" (Orr, 1992, p. 105). This statement explains why ecological literacy is in sharp decline during a time when it is needed most. Practical competence, problem solving, and outdoor education and careers are imperative in addressing the pressing ecological and sustainability concerns we currently face. Orr (1992) posits that the mediocrity of higher education to date is rooted in its failure to achieve the type of liberal arts education described above. Persons with a genuine liberal arts education will make themselves relevant to the crisis of our time and work for the care, nurturing, and enhancement of life, in all of its forms (Orr, 1992). Orr (1992; 1994) presents convincing support for community elements, place-based, problem-solving, active, experiential, and practical skill building elements of higher education to produce ecologically literate citizens to join the fight for a more habitable and humane world. Orr's (1992) critique of higher education makes it clear that place-based approaches are imperative in creating ecologically literate citizens.

Higher education is facing an educational challenge to prepare citizens to work toward solutions of our current ecological and sustainability crises. The priorities of our current educational paradigm are largely ineffective in meeting the needs of a sustainable future as result of its foci on the individual, test scores, disciplinary bound learning, and abstract thought rather than collaborative teams, applied projects, placed-based, interdisciplinary learning, and applied, practical competence. Place-based education has inherent characteristics in both its process and context. Successfully linking community- 
based learning and sustainability education holds great potential for providing the type of liberal arts education that Bowers (1995), Longo (2007), and Orr (1992) deem necessary because of the pedagogical characteristics related to the process and context for education within sustainability education and community-based learning. The next section builds further support for place-based education in the form of community-based learning for sustainability education by reviewing the pedagogical similarities of these methods.

\section{Common Pedagogical Attributes: Process and Context}

Community-based learning and sustainability education are closely linked through the context and process of their pedagogies. By definition, community-based learning is participatory, experiential, occurs in the community, and both necessitates and fosters community-campus partnerships, collaboration, and reciprocity. Sustainability education emphasizes both the process and context of learning (Burns, 2009; Orr, 1992; Sterling, 2004). In fact, Orr (1992) argues that how we learn is just as important as what we learn; education should be locally relevant, participatory, and change the way people live. Sterling (2004) urges educators to shift from a transmissive paradigm (mechanistic view) to a transformative paradigm (ecological view) of teaching whereby education as sustainability can occur via actively engaging students in their own learning through collaboration, discussions, reflections, and being able to view learners as teachers and teachers as learners. Furthermore, the Burns model of sustainability pedagogy includes five dimensions of sustainability education pedagogy (Burns, 2009). Two of the five dimensions that are deemed imperative for education as sustainability are process and context. The process of learning should be participatory and experiential and the context of learning ought to be place-based (Burns, 2009). The process and context of learning 
are undeniably distinguishing attributes of both sustainability education and communitybased learning.

The fields of sustainability education and civic engagement both desire transformational change within society in order to develop student leaders who have the ability lead social change to address our community's most onerous concerns. Much literature supports the idea that grounding learning in locale or community affords students the best opportunity to develop abilities to work for social change (Astin \& Astin, 2000; Otto \& Wohlpart, (2009); G. A. Smith, 2002; Sobel, 2004). Context and process are key elements of educational pedagogy that can foster an individual's ability and capacity to work for social and sustainable community change.

\section{Process: experiential education.}

Both sustainability education and community-based learning are forms of experiential education. Learning from experience, reflective activity, citizenship, community, and democracy are the ideals that undergird Dewey's educational philosophy presented in his work Democracy and Education (1916) and Experience and Education (1938) (Carver, 1996; Carver, 1997; Giles \& Eyler, 1994; Saltmarsh, 2007). Actionoriented, collaborative, real world, problem-solving education was emphasized by Dewey (1916) as the most powerful means to increase the intelligence of individuals, communities, societies, and humanity at large. Dewey suggested that community problems could only be solved through the creation of educated citizens and that citizens must be engaged in thought and action to be able to participate in a democracy and democratic solutions (Cress, 2005). Experiential education was strongly supported by Dewey (1938) as a means through which people could develop skills and practical 
competence as well as a connection to their community and place. Dewey argued for the need for an explicit connection between education and public problem solving (Saltmarsh, 2007). Further, Dewey was one of the first educators to recognize the importance of reflection in the educational process. Dewey argues that it is through reflection that people come to understand their experiences (Collier \& Williams, 2005). Reflection allows for meaning making, and the experiential characteristic increases the relevancy of education.

Experiential education allows students to learn directly from interactions with the environment and also embody the principle of continuity (Dewey, 1938). In describing the principle of continuity, Dewey (1938) states “every experience both takes up something from those which have gone before and modifies in some way the quality of those which come after" (p. 35). Thus, experiential education helps to facilitate a connection between generations and an understanding of the interdependence of generations; interdependence and intergenerational connections are tenets of sustainability education (Kiefer \& Kemple, 1999; Meadows, 2005; Orr, 1992; Smith \& Williams, 1999; Sterling; 2004).

\section{Process: community engagement.}

Cress (2005), Giles and Eyler (1994), and Saltmarsh (2007) all credit Dewey with serving as a foundational figure in the emergence of service-learning as an educational pedagogy and practice. Further, Sterling (2004) cites Dewey as both a key figure in development of humanistic, experiential, and holistic education as well as a precursor to sustainable education itself. Orr (1992) also references Dewey's work for its emphasis on the local community, place-based education, and as providing an understanding for both 
environmental and sustainability education. Dewey's work is commonly cited as forming the theoretical framework for community-based learning and service-learning.

Learner-centered pedagogies or pedagogies of engagement are the most effective for educating citizens (Colby et al., 2003). Service-learning, community-based learning, problem-based learning, and collaborative learning are examples of such pedagogies. Moral judgment, moral interpretation, and knowledge are all part of students' moral and civic development in the college years (Colby et al., 2003). The motivation of individuals to be morally and civically responsible is often impacted by their undergraduate education. Values, goals, attitudes, moral and civic identity, political efficacy, moral and civic emotions, and civic or political skills can all be motivators for moral and civic responsibility and also can all be impacted by education (Colby et al., 2003). Colby et al. (2003) provide a compelling argument for civic and moral education for undergraduates to be learner-centered and experiential.

Sustainability education is education that embodies the ideals and values of sustainability and engages students in learning that promotes lifestyles that do not compromise the ability of future generations to meet their needs. Sustainability education includes the process, content, location, scale, and scope of education. Sustainability education encourages students to look at the world in a way that examines the network of dependent relationships that exist between the environment, the economy, and culture (Callenbach; 2005; Capra, 2005; Orr, 1992; Sterling, 2004). Students come to understand that these interrelationships exist on the local, regional, and global levels.

Community-based learning is a pedagogy of instruction that integrates community organizations, community service, and academic learning; it requires students to 
participate in the community in a way that meets a community's social or environmental need while simultaneously allowing students to learn about and apply course content in a real world setting. Community-based learning allows students to engage in community activities with intentional academic and learning goals with reflection opportunities that connect the community experience to academic work (Cress, 2005; Eyler, Giles, \& Schmiede, 1996). Service-learning researchers and practitioners widely agree that reflection is the essential link between community experience and academic learning (Cress, 2005; Eyler \& Giles, 1999; Eyler et al., 1996). Reflection offers the opportunity to make meaning of the experience. Community-based learning is collaborative and experiential and often is problem-based and interdisciplinary (Cress, 2005).

Because of their experiential quality, sustainability education and communitybased learning stress learning as both an outcome and a process and place students at the center of the learning experience. Community-based learning and sustainability education are concerned with the outcomes of attainment of knowledge and the development of skills and values, making the experiential nature essential (Eyler \& Giles, 1999; Orr, 1992; Sterling, 2004). Sterling (2004) calls for sustainability education to be transformative rather than transmissive by being student-centered, or learner-centered, rather than instructor-centered. Democratic, participatory, and experiential practices are cited as part of an ecological view of education (Sterling, 2004) and of service-learning (Eyler \& Giles, 1999). Orr (1992) also proposes that ecological education stress both content and process with the process being experiential. Orr (1992) shows further support for experiential learning when he states that, "Real learning is participatory and experiential, not just didactic" (p. 91). Kiefer and Kemple (1999) discuss the need for 
sustainability education to include integrated learning that is connected to local community concerns. Sustainability education as a theory calls for experiential learning. Community-based learning is inherently experiential because of the inclusion of service in a community setting as part of the educational approach. The fact that sustainability education is characterized by experiential learning connected to the local community helps explain, in part, why some of PSU's senior capstone courses address sustainability issues given the PSU's focus on community-based learning.

\section{Process: community collaboration and reciprocity.}

Collaboration, building relationships and community, and reciprocity lie at the core of community-based learning and sustainability education. Because sustainability is dependent upon all people and organizations being able to live well together, both individuals and organizations will need to share the responsibility in creating more sustainable communities through civic participation, new policy, commitment, and true democratic government (UNESCO, 2005). Collaboration is stressed as imperative in decision making for sustainability education and in moving toward sustainable change within schools (Barlow, Marcellino, \& Stone, 2005; Comnes, 2005). Valuing input and perspectives from all constituencies and stakeholders was found to be successful in developing sustainability education programs and developing learning communities by Alvarez and Rogers (2006), Barlow et al. (2005), Comnes (2005), Eflin and Sheaffer (2011), Fagan (1996), and Sarkissian et al. (2009). Sterling (2004) also emphasizes a collaborative and democratic approach for sustainability education as well as collaboration and inclusion of all people as core values of sustainable education. Sustainable progress is only possible with the collaboration of individuals, communities, 
organizations, and governments at the local, regional, national, and international levels; no one entity can fully address sustainability issues (Lappé, 2007; Senge et al., 2008).

Native American and indigenous education and indigenous knowledge systems are instrumental in much research and work on sustainability. Indigenous education and knowledge systems are known for their valuing of active learning and participation from children as well as valuing input from all community members, collaboration, oral history and storytelling, and reciprocity between people and with the land (Margolin, 2005). The indigenous decision making process is also collaborative, involves seeking input from everyone in the community, and is based on valuing all forms of life and causing as little harm as possible (Armstrong, 2005). Further, the indigenous way of living is based on valuing the land and environment and on a relationship of mutual care and reciprocity with the land (Cajete, 1994). Indigenous forms of teaching and living are often cited as being the essence of sustainability (Orr, 1992; Sterling, 2004). Bowers (1999) and Krapfel (1999) argue that ecological education must preserve and celebrate diversity and prevent the creation of a monoculture; collaborative approaches can ensure just that. Additionally, Williams and Taylor (1999) suggest that a sustainability education model or school must have permeable boundaries and develop relationships with the local community through partnerships, service, and intergenerational learning. Cajete (1994) and Margolin (2005) also stress learning from the environment and intergenerational learning as necessary for sustainable progress. Relationships and community building are building blocks for sustainability (Orr, 1992). Collaboration, social trust, relationships, and reciprocity are core values for a sustainable future. 
Community-based learning and service-learning require collaboration between a community partner, a school administrator or instructor, and a class of students. Effective partnerships necessitate collaboration between the community agency, the instructor, and the students (Dorado \& Giles, 2004; Reitenauer, Spring, Kecskes, Kerrigan, \& Cress, 2005). Thus, permeable boundaries that are essential to the sustainability model described by Williams and Taylor (1999) are intrinsically part of community-based learning because of the community engagement that is cultivated through the communityuniversity partnership. Sterling (2004) calls for the ecological view of education to have fuzzy borders and include the local community as part of the learning community; community-based learning does just that.

Community-based learning and sustainability education call for people, schools, and communities to establish collaborative, reciprocal relationships built on trust. Sandy and Holland (2006) found that relationships are a foundation for community-based learning models; sustainability is contingent upon the ability of people and communities being able to live well together (Sterling, 2004). Community service results in students being more invested in the health and vitality of the community and community organizations being more invested in the education of the students. Society is strengthened by the creation of new social bonds and reciprocity via community-based learning (Stuteville \& Ikerd, 2009); this alone builds sustainability. DeLind and Link (2004) found that "Often the messy and meandering process of building interpersonal trust was the key to sustainable change" (p. 134). The process of collaborating is often as valuable as any "product" that can be created. Engaging in any activity, particularly service, in the community through reciprocal relationships leads to students being 
connected intimately to the community and in community building, increasing social capital, and enhancing social trust; these elements are foundational for sustainable communities (Stuteville \& Ikerd, 2009). Increasing social capital is one measure Putnam (2000) calls for to revive American communities. Reciprocal relationships are a vital part of sustainable communities. The collaboration and relationship building that characterizes both sustainability education and community-based learning likely contributes to the explanation of why some of PSU's senior capstone courses would be linked to sustainability issues.

\section{Context: place-based education.}

A criticism of conventional educational approaches by the sustainability and community-based learning fields is that most undergraduate learning lacks relevancy and that students often do not have context for their learning or understand why what they are learning in the classroom is important (Eyler \& Giles, 1999; Orr, 1992; Orr, 2004a). Closely tied to being experiential, community-based learning and sustainability education are also place-based. Emerging in the 1990s, place-based education has the following qualities: (1) as its name suggests, it is education that is rooted in place and is primarily concerned with providing students a quality educational experience in local settings (Knapp, 2005); (2) it helps to provide context and relevancy for student learning; (3) while it always includes experiential learning, it is unique because of the context it provides for learning; (4) it can be distinguished from many conventional educational methods by the attention of its practitioners to both natural and social environments; (5) it is an educational approach that embraces both human and non-human communities in an attempt to reach social justice and ecological sustainability goals; (6) it strives to reach 
these goals through creating permeable boundaries between schools and their environments and communities by directing students' "experiences to local phenomena ranging from culture and politics to environmental concerns and the economy" (G. A. Smith, 2007, p. 190).

Because communities and local environments have diverse issues and problems, place-based education has the ability to be connected to virtually any discipline and it in fact often promotes multidisciplinary thinking because of its problem-solving nature. Further, place-based education engages learners through positioning of a curriculum within the context of participants' own lives, communities, and regions; thus, place-based education takes advantage of students' and communities' natural interests in locale (Gruenewald, 2003b; G. A. Smith, 2002). G. A. Smith (2007) identifies five main patterns or approaches in place-based education including cultural studies, nature studies, real-world problem solving, internship and entrepreneurial opportunities, and induction into community process or decision-making. Place-based education is linked or closely associated with cultural journalism, expeditionary learning, problem-based learning, contextual teaching and learning, environmental education, outdoor education, experiential education, service-learning, civic education, and project-based learning (Knapp, 2005; G. A. Smith, 2007).

Place-based education curriculum can take a wide range of forms, despite the diversity in models: since local phenomena serve as the foundation for curricular development, students are allowed to become creators of knowledge; students' questions and concerns play a central role in determining what is studied; teachers act as experienced guides rather than the sole provider of knowledge; students work toward 
understanding multiple perspectives within the class and community; students are involved in real-world problem solving, and communication and relations between the school and community are enhanced; it is multidisciplinary and integrates self, others, and place as well as multicultural dimensions into the curriculum (Gruenewald, 2003b; Knapp, 2005, G. A. Smith, 2007). Further, Gruenewald (2003a) urges that all place-based education must include perspectives of critical pedagogy whereby students learn to question and challenge perspectives that harm both their own lives and the lives of others. While place-based curriculum unfolds uniquely in each distinct locale, the above characteristics unify this broad pedagogical technique.

Place-based education is credited with many benefits for both students and communities: it leads to increases in academic achievement, social capital, and environmental quality; test scores increase as a function of the increased enthusiasm for learning that results from place-based educational techniques; it cultivates stewardship and responsible environmental behavior; and it can adapt to the unique characteristics of particular places and becomes relevant to all locales (Sobel, 2004). As mentioned earlier, sustainability education must be both locally relevant and culturally appropriate because the solutions to sustainability problems differ by region and culture (UNESCO, 2005). This fact posits place-based education as an ideal technique for sustainability education because being locally relevant is an embedded element of a place-based approach; it stresses that the context of knowledge is situational and best understood through investigation and learning in place (Gruenewald, 2003a). Therefore, this educational technique can help assuage the typical disconnection between schools and students' lives to provide higher levels of relevancy and context for students' learning. Place-based 
education views students as a resource to the community (Sobel, 2004). Further, an assumption undergirding the place-based approach is that students should not be prepared for tomorrow, rather that they should be prepared to solve local problems today (Sobel, 2004). To this end, place-based education serves as a source of empowerment and agency for students in working for positive social change in their communities. Creating social change and solving problems is transformation for the students and communities alike. G. A. Smith (2007) actually calls place-based education a "transformational agenda" (p. 593). Place-based education provides ample opportunity for transformational learning for students.

Much education occurring at the higher education level today lacks relevancy and context for student learning (Eyler \& Giles, 1999; Orr, 1992). Dewey (1938) argues that education placed in the local community inspires the desire to steward and preserve. Place-based education occurs in the community and inherently promotes interdisciplinary thinking, cooperation and collaboration between students, instructors, and community organizations. It uses the local community to provide context for learning and improves the health and vitality of communities (Smith \& Williams, 1999). Hass (2005), Kiefer and Kemple (1999), Michael (2005), Stone (2005), and Williams and Taylor (1999), provide examples of effective sustainability education programs that are place-based. Berg (2005) argues that a sense of place and knowledge of one's bioregion are imperative for living sustainably. Kiefer and Kemple (1999) discuss the need for sustainability education to include integrated learning that is connected to local community concerns. Orr (1992) argues that one must know where one comes from in order to know oneself best; placed-based education is therefore necessary to know the community and oneself. 
Sustainability education emphasizes education rooted in place to instill a sense of place in students through the study of local knowledge in nearby natural and human communities as well as to foster an affinity and attachment for the local community and natural world (Louv, 2005; Orr, 1992; Smith \& Williams, 1999). Place-based education is advocated for by sustainability educators largely to foster an understanding in learners of their connection to the natural world.

Orr (1992) supports place-based learning and the integration of locale into education for several reasons. This approach necessitates the fusion of experience with intellect, which allows observation and experimentation, and more fully incorporates the whole person. Another benefit of learning in place is that it allows people to feel more connected to place, appreciate the art of living well where they are, and to act as stewards of their locale. Further, the concerns of overspecialization and disciplinary-bound or fragmented learning are ameliorated because learning experientially in place is naturally interdisciplinary and focuses on understanding connections. Knowledge of place results in people being "inhabitants" rather than "residents" in a community; inhabitants are less likely to vandalize their place and more likely to feel rooted in the community with a sense of care and duty (Orr, 1992). Inhabitants are more likely to be both good neighbors and honest citizens (Orr, 1992). Good neighbors and active citizens are goals of ecological education (Orr, 1992; Sterling, 2004) and community-based learning (Carver, 1997; Eyler \& Giles, 1999). Orr (1992) eloquently describes the impact of place-based learning when he writes, “...knowledge of a place - where you are and where you come from - is intertwined with knowledge of who you are. Landscape, in other words, shapes mindscape" (p. 130). Learning in community allows learners to better understand 
who they are, but also value the places they live and thus to value themselves within the context of that place.

DeLind and Link (2004) created the course "Our Place on Earth" at Michigan State University using place as the focus point in order to explore using the concept of place to teaching for a more sustainable future. Place was used in course development in order to create a collaborative learning culture and also bridge the scientific and technological views of sustainability with the humanities and social sciences. According to DeLind and Link (2004), responsible citizenship is tied to the ecological and social fabric of the local community. The Michigan State campus was used to foster an awareness of place and be a living-learning laboratory.

Course objectives focused on providing students with an opportunity to experience discovery of their relationships to place and the world, an understanding of connections that bind students not only to each other but to all places and life forms, opportunities to exercise both a sense of empowerment and engagement at home, and creating a mobile experience that allows students to take their placed-based values and responsibilities to new locations. The two-credit course invited fifteen diverse scholars, practitioners, and activists from around the country who all were united by their passion for the earth, social justice, and democratic process. The course also required the students to attend two tours of the Michigan State University campus, one indoor and one outdoor, in order to expose students to areas and operations that they had not seen before, encourage the students to consider the relationships between the areas and operations on and off campus, and finally to reflect on the sustainability of these relationships. The student evaluations were overwhelmingly positive and reflected that students wanted to 
find more lasting ways to connect and belong to something greater than themselves; they wanted to reinhabit their places. The course successfully blurred traditional intellectual and physical boundaries and introduced students and community members to alternative ways of knowing, ways that are humanistic, qualitative in nature, and open-ended (DeLind \& Link, 2004).

A connection to place is an ideal springboard to motivating citizens to have a stronger sense of identity, an ethic of care for their communities, an understanding of cultural geography, and a commitment for sustainability work. Exploring our connection to place challenges us in ways that strengthen our sense of self, respect for our communities, and also our ability "to lay claim to the term native and the songs and dances, the beads and feathers, and the profound responsibilities that go with it" (Snyder, 1995, p. 236). DeLind and Link (2004) write:

Yet place is a concept of many dimensions - a shape shifter of sorts. It can be tangible, sensual. It can exist under our feet; it can literally ground us, anchor us, give us roots. But place can also be social and spiritual. It can be as intangible as history, as creative as culture, as mystical as creation myths. Instead of something absolute, place can be a matter of shifting identities, shared understandings and relationships not only among ourselves but among all living creatures. Place is also particular, unique. There are no two places exactly alike, just as there are no two snowflakes or human beings exactly alike. And this makes it necessary for us to cooperate as well as make choices. (p. 124)

The concept of place can anchor citizens in place and provide additional social and spiritual context for citizens' lives. Because sustainable solutions must be locally relevant, all citizens who want to be successfully involved in sustainability work must understand the concept of place. Additional support for place-making as means to promote sustainability is articulated by DeLind and Link (2004) when they state, 
If we want to be sustainable, then we need to know our place in every sense of this word. But where are we to begin? Perhaps the best answer we have found is uncommonly simple. We begin with the local, with the embodied, with the personal and the familiar. We begin where we are and where we live. We begin with what we know and what we see before us, and out of this eventually comes the stuff of a greater and deeper wisdom. (pp. 124-125)

Living sustainably is dependent upon knowing our place intimately. Sustainability begins at home with knowledge and wisdom of place. Place is both deep and wide and when we start to understand place we also must learn to think and act deep and wide (DeLind \& Link, 2004). Education in place allows students to both feel and practice sustainability. Place-based education provides legitimacy for ideas and ways of being that are not easily codified and are too easily marginalized in society. Becoming native to a region is a forever process; place-based education can serve as the impetus for this process. According to DeLind and Link (2004), "Daily life is not a backdrop to education but education itself' (p. 127). Place-based education is a necessary characteristic of education in order to allow daily life to be education itself rather than merely a side note to education.

Community-based learning is a type of place-based education as a result of the engagement element that often takes place in the community surrounding the school. Community-based learning and place-based learning can be utilized to restore context and meaning to citizens' lives (Eyler \& Giles, 1999). Like sustainability education, community-based learning aims to instill an ethic of care and responsibility for the local community through a place-based approach which develops a sense of connection to locale. Kiefer and Kemple's (1999) call for sustainability education to include learning that is connected to local community concerns; community-based learning does exactly 
that. It is imperative that students learn about their immediate surroundings, communities, and environments to develop an appreciation for their local environment. Understanding of and experience in local communities and natural systems will allow for students to develop an attachment or relationships that will likely lead to them feeling a heightened responsibility in caring for both the community and environment. Thus, it is clear how the place-based approach for community-based learning can contribute to building sustainability through fostering connection to place and understanding of the local community's social and environmental needs. The place-based and context qualities are common denominators for sustainability education and community-based learning. The way in which community-based learning connects students and participants to place helps to build sustainability through cultivation of connection to community and environment and therefore enhancing the likelihood of both community and environmental stewardship. Portland and Portland State University represent ideal contexts for studying place-based education or community-based learning as it relates to sustainability education because of the reputation of both Portland and Portland State University regarding community engagement and sustainability initiatives.

\section{Portland and Portland State University as Context for Research} Portland's reputation for civic engagement and sustainability.

Portland, Oregon is well known for its civic engagement and social networks (Putnam \& Feldstein, 2003). In February 1974, the city council of Portland, established a new Office of Neighborhood Associations and within the next year recognized roughly 90 neighborhood associations. These types of initiative are a key way to create civic engagement in contemporary America (Putnam \& Feldstein, 2003). In the early 1970s, 
many measures of civic engagement in Portland, such as attendance at public meetings in town or school affairs, writing letters to editors, signing petitions, et cetera, were essentially identical to that of comparable cities, but 20 years later, Portlanders of all demographics were three to four times more likely to be involved in civic life as their counterparts elsewhere in America (Putnam \& Feldstein, 2003). Proximity, communication, spaces and parks serving as the commons, large numbers of neighborhood associations and civic organizations, government officials that respond and adapt to its citizens are all qualities of Portland that have increased civic engagement. Involvement is the norm in Portland while disengagement is the norm in many other American communities (Putnam \& Feldstein, 2003). Achieving communal objectives is easier with strong social networks; building social capital is an effective strategy for building community and working toward solving social problems. Society as a whole benefits enormously when there are many social ties among residents working toward common goals (Putnam \& Feldstein, 2003). The spirit for and reputation within Portland for high civic engagement and community participation position the city as an ideal location for a study about community engagement and community-based learning.

The Portland Bureau of Planning and Sustainability, with support from Mayor Sam Adams, is active in sustainable planning for the city of Portland (City of Portland, 2010). Work by the Bureau of Planning and Sustainability is done around energy, food, green building, climate protection, waste and recycling, purchasing policies, and economic development and green jobs (City of Portland, 2010). Mayor Sam Adams has also vowed to make Portland "the most sustainable city in the world" (City of Portland, 2010). These initiatives and programs speak to the priority of sustainability in the city of 
Portland. Therefore, Portland is an ideal locale for a research study related to community engagement and sustainability.

\section{Portland State University's University Studies and senior capstone programs.}

The senior capstone program at Portland State University (PSU) is the culmination of the University Studies program, which is the interdisciplinary general education curriculum at PSU. University Studies was implemented as a comprehensive general education reform in 1996 after intensive work by a General Education Working Group charged with developing purpose and goals for general education at PSU and creating a curricular model that would achieve those goals (White, 1993). University Studies was created because PSU wanted a general education that would achieve designated goals rather than simply setting student requirements, help increase student retention, and integrate course material and student learning (White, 1993). University Studies includes a year-long freshmen inquiry course exploring one theme, three sophomore inquiry courses, three junior cluster courses related to one of the sophomore inquiry courses, and one senior capstone course. The four goals of all University Studies courses are inquiry and critical thinking, communication, diversity of human experience, and ethics and social responsibility (Portland State University University Studies, 2009). Courses in University Studies examine topics and issues using an interdisciplinary approach to show how they can be understood from different perspectives. The senior capstone course is the fruition of the University Studies program for all undergraduate students at PSU. 
The senior capstone program was established in 1996 with a focus on experiential education and community engagement. Instructors design the six-credit senior capstone courses to build cooperative learning communities by taking students out of the classroom and into the community. Students are able to utilize the knowledge, skills, and interests developed through their entire undergraduate education to work on a community project. The goals of the senior capstone courses are to enhance student learning while cultivating critical life skills that are important academically and professionally, to establish connections within the Portland and larger community, to develop strategies for analyzing and addressing community problems, and to work with others trained in fields different from one's own (Portland State University University Studies, 2009). Senior capstone courses provide students the opportunity to apply their learning to community problems and work in interdisciplinary teams as well as empowering students to become engaged in their communities (Portland State University University Studies, 2009). Senior capstone courses bring students from diverse majors and backgrounds together to work collaboratively as a team with faculty and community leaders to both understand and propose solutions for issues that are important for an engaged citizenry.

The senior capstone program was not developed with issues of sustainability in mind: the program was developed with a focus on community engagement, collaborative learning, and application of course knowledge and skills to real world issues. However, as the years have progressed, more and more senior capstone courses are incorporating sustainability into the course title, course description, or course content (S. Kerrigan, personal communication, October 21, 2009). Currently, there are senior capstone courses that address, among others, the following issues related to sustainability: food systems, 
watersheds, solid waste reduction, oral histories, education, indigenous knowledge systems, environmental education, and social justice. The incorporation of sustainability issues into the senior capstone courses has happened organically. There has been no written or otherwise communicated incentive for instructors to integrate issues of sustainability into their courses (S. Kerrigan, personal communication, October 5, 2009). Additionally, there has been little study of how the community engagement aspect of the senior capstone courses is being connected to sustainability issues within the courses that are addressing sustainability topics (S. Kerrigan, personal communication, October 21, 2009). Thus, it is a prime time to undertake a study to investigate how community-based learning and sustainability issues are being connected. Further, hundreds of universities across the United States include a senior capstone or culminating experience that include community engagement or community-based learning elements (Colby et al., 2003). Additionally, a growing number of institutions of higher education are interested in incorporating sustainability into both their operations and curriculum, including capstone programs (AASHE, 2010). Hence, what will be learned from this study will be beneficial to programs across the United States that are similar to PSU's senior capstone program.

\section{Portland State University's sustainability priority.}

Portland State University (PSU) has a commitment to sustainability as an institution. The priority for sustainability has been shown by PSU through a number of avenues, including its learning outcomes and its sustainability grant awards.

Sustainability is one of the eight campus-wide learning outcomes of PSU and was adopted in the spring of 2009, demonstrating PSU's institutional focus on sustainability. The sustainability learning outcome states that "students will identify, act on, and 
evaluate their professional and personal actions with the knowledge and appreciation of interconnections among economic, environmental, and social perspectives in order to create a more sustainable future" (Portland State University Institutional Assessment Council, 2009). Further, the rationale for the sustainability learning outcome according to the Portland State University Institutional Assessment Council (2009) is as follows:

Understanding sustainability is essential to join the international discourse and work cooperatively in the closely interconnected world of the new millennium. PSU is a leader in local, regional, and global knowledge creation and practice of sustainability, and therefore has the opportunity and challenge to publicly support, inform and lead students and communities in creating a sustainable future, and can provide a place for students who have this inclination to get an education. (para. 8)

The faculty senate's approval of sustainability as a learning outcome shows general acceptance of the need for sustainability education for PSU undergraduates by instructors. All courses at PSU ought to be at least loosely aligned with the campus-wide learning outcomes. For these reasons, it logically follows that PSU instructors would be interested in incorporating issues of sustainability into the community-based learning of the senior capstone courses.

PSU has been awarded grant monies for sustainability as a result of its previous work and promise in the field of sustainability. The Miller Foundation presented a \$25 million challenge grant to PSU for sustainability-related projects in September of 2008. The gift came with the challenge for PSU to raise an additional \$25 million over the next ten years to create a total sum of $\$ 50$ million. This is the largest gift ever presented to Portland State University and the largest grant ever given to a university for sustainability in the United States. The Miller Grant is intended to support programs that promote sustainability at Portland State and within the larger community. Enhancing the student 
learning experience related to sustainability, enhancing research and curricular programs, and community engagement are foci of the grant. Part of PSU's vision is to become an internationally renowned university recognized for its excellence in the field of sustainability (W. Wiewel, personal communication, September 13, 2009). The Miller Grant sustainability monies and the adoption of sustainability as a learning outcome are two prime examples of how PSU's growing commitment to sustainability over the last few years is coming to fruition. An institutional commitment impacts and permeates institutional culture. Therefore, more senior capstone courses are likely integrating sustainability issues into the curriculum as a partial result of institutional priority and culture for sustainability.

\section{Conclusion}

In summary, in order to advance toward a sustainable future, institutions of postsecondary education must prioritize sustainability education. In order to make progress toward sustainability, education must move away from teacher-centered, transmissive education that values abstract, theoretical knowledge over and at the expense of experiential, contextualized knowledge and learning. Most modern education lacks relevancy for students and fails to develop agency in students that allows them to take action and engage in the communities and world around them more successfully and meaningfully. Sustainability education and community-based learning are two approaches that acknowledge and honor the relationships and interconnectedness between schools and local community concerns. Both sustainability education and community-based learning have the potential to model the ecology of civic learning that 
Longo (2007) calls for to improve communities and create the ecologically literate citizens that Orr (1992) deems as imperative for a shift toward sustainability.

Colleges and universities have the potential to become one of the single most important institutions in the pursuit of improved, more sustainable communities because of their unique abilities to both leverage community engagement via collaboration and educate citizens and future professionals. Institutions of higher education can both engage with the local community and prepare a generation of active, democratic community participants. Further, community engagement is a sustainable practice and has a monumental role to play in achieving sustainable communities. The fields of communitybased learning and sustainability education are closely linked by their emphases on an active, experiential process for learning as well as on a place-based context for learning. For these reasons, understanding the relationship between sustainability education and community-based learning at the higher education level is crucial to enhancing the abilities of institutions of higher education to improve communities and prepare students to work for a more just, humane, and sustainable future after graduation. Portland and Portland State University are optimal contexts for this study because of their priorities on community engagement and sustainability. 


\section{Chapter III}

\section{Methodology}

This chapter provides an overview of the research project. The purpose of this study and research questions are presented first. Next, a rationale is provided for using qualitative methodology for this study. My positionality as a researcher and my relationship to the research process are then acknowledged. The research design section provides information on the participants, sample selection, data collection and analysis strategies, and limitations of this research. Lastly, the significance of this study is discussed.

\section{Purpose and Research Questions}

Texts on sustainability education stress the necessity of experiential learning in the community for successful and meaningful education for sustainability (Sarkissian et al., 2009; Sterling, 2004; Stuteville \& Ikerd, 2009). Sustainability has found its way into mainstream media and higher education at increasing rates over the last several years. PSU has an institutional focus on sustainability and sustainability education. Community engagement and service-learning initiatives have seen extensive growth at the higher education level over the last few decades. Yet, the intersection of community-based learning and sustainability education has been explored minimally at PSU and within the higher education community at large (S. Kerrigan, personal communication, October 5, 2009; Stuteville \& Ikerd, 2009). Little understanding exists on how some of the community-based learning curricula in the capstone program are being linked to sustainability issues; research around the convergence of PSU senior capstone's community-based learning curriculum with sustainability education is thus pertinent and 
timely. Specifically, this study explores the question, What are undergraduate instructors' perspectives on the relationship between sustainability education and community-based learning? This research also investigates the following questions: (1) Is the communitybased learning approach beneficial in courses dealing with sustainability issues? and (2) What pedagogical strategies or frameworks undergird courses that incorporate both sustainability education and community-based learning?

This research seeks to further develop and operationalize the concept of community-based learning as it relates to sustainability education. It also elucidates the nexus between the community-based learning and sustainability education fields by examining sustainability courses that successfully integrate community-based learning elements, and by highlighting best practices employed by Portland State University senior capstone instructors for connecting sustainability education with community-based learning for undergraduate students. The research explores community-based learning as a delivery mechanism for sustainability education at the undergraduate level. A goal of this research is to disseminate knowledge about the confluence of the community engagement and sustainability education fields, according to undergraduate instructors. Because commitment to sustainability education is on the rise within higher education (AASHE, 2010), the results will also serve a broader audience of educators.

\section{Rationale for Qualitative Methodology}

Qualitative research methods are used for this study because they allow new constructs to emerge in a way that is not limited by a researcher's bias or predispositions. Participants are encouraged to discuss factors that they deem important and relevant in qualitative methods. Qualitative methods are the collection and interpretation of non- 
numerical narrative and visual data (Gay, Mills, \& Airasian, 2009). This methodology seeks to obtain deep understandings about the way things are, why they are that way, and how the participants in the context perceive them.

This project set out to gain an in-depth understanding of why and how senior capstone courses are incorporating sustainability issues into the curriculum and how the selected capstone instructors perceive the connections between sustainability and community-based learning. Semi-structured interviews and syllabi review were selected as the forms of qualitative data collection. As a data collection strategy, semi-structured interviews allow the researcher to explore the participants' purposes, experiences, feelings, interests, and attitudes (Gay et al., 2009). Thus, the interviews I conducted provided space for senior capstone instructors to express, explain, and expand upon their experiences with community-based learning as it relates to sustainability issues. Also, indepth interviews were chosen to gather data because they provide the opportunity for context-specific information and stories or narratives to be shared. Narratives about the connections between community-based learning and sustainability education are desired outcomes of this research making in-depth interviews an ideal data collection strategy. Examining records, documents, archival documents, such as course syllabi and senior capstone program documents, allowed me to collect data that was naturally occurring in an educational setting (Gay et al., 2009).

This research was conducted primarily from the interpretive paradigm. Meaning was created through interaction with the senior capstone instructor participants in the form of interviews. Research from an interpretive approach is based on what is going on within and between individuals as well as understanding behavior and perspectives 
through analysis (LeCompte \& Schensul, 1999). The role of the researcher is involved and informed by personal experience via interaction with study participants within the interpretive paradigm. Further, historical and social contexts are important in informing research in the interpretive approach (LeCompte \& Schensul, 1999).

\section{My Positionality}

In quantitative research objectivity is a goal. However, qualitative researchers must acknowledge that the nature of the data gathered and the analytic process is grounded in subjectivity (Morrow, 2005). This makes an understanding and acknowledging of as well as reflection upon my positionality and relationship with the research critical to limiting subjectivity.

My origins as a researcher for this project reach back into my experience as an undergraduate college student at Susquehanna University where I experienced servicelearning programs for the first time in 2005. I was a participant in service-learning programs focused on homelessness issues as well as disaster relief projects; these experiences were transformative and empowering for me. I quickly became an ardent supporter of community-based learning and service-learning as educational strategies to empower students to work for social justice and become engaged in their communities. Community-based learning and service-learning are educational approaches that integrate community service or community work into academic learning by having students participate in the community in a way that requires them to apply course content to meet a community need (Eyler \& Giles, 1999). Community-based learning is a pedagogy that recognizes that valuable knowledge is found in many places, both in and outside the classroom. 
Later, as an AmeriCorps VISTA (Volunteer in Service to America) for two years, my passion for civic engagement and social justice work was intensified when I coordinated civic engagement events and service-learning trips for students at Susquehanna University, a small undergraduate institution. AmeriCorps VISTA is a community service program similar to Peace Corps that addresses poverty issues and places participants in community service sites across the United States. When Susquehanna University was considering eliminating the recycling program on campus, I developed a heightened interest in environmental issues and worked to help create a “Guide for Sustainable Living” and a "Refillable Mug Program” at Susquehanna. Upon being immersed in this experience, I began to become aware of the strong connections between social inequity, economic policy, and environmental exploitation.

In selecting graduate programs, I wanted to find an institution that combined education with social justice, environmental justice, and community engagement work. The Leadership in Ecology, Culture, and Learning (LECL) program at PSU allowed me to gain an earnest understanding of global sustainability issues and the need for education to address these issues. At PSU, I held a graduate assistantship in Residence Life where I helped to create a civic leadership and a sustainability living-learning community. I also engaged in a research project about community-campus partnerships. At the end of my first year in my graduate program, I began to explore the overlap between servicelearning or community-based learning and sustainability education. In the course “Sustainability Education," I wrote a paper about utilizing a service-learning project for sustainability education. This paper became the impetus and starter to my understanding of the significant connections between these two fields that are formally distinct. 
Thus, I am well steeped in this work. My lived experience has resulted in my enthusiastic support for the impact of community-based learning for students and communities alike. I come to this research with a strong grounded experience working with students on several campuses and I have seen the importance of community-based work to the lives and learning of students. Over the years, I have worked to garner support for connecting campuses and students more to local problems and needs. This experience has certainly shaped the lens though which I explore this topic and also why I am interested in the research in the first place, particularly as I became more and more aware of environmental problems and their connection to social and economic issues. Because of my experience coordinating service-learning for students and base knowledge in the subject area, my worldview also likely allowed me to understand and analyze the syllabi and interviews more deeply and empathize more with the participants in this study than someone who had not had these experiences. While this is a strength is one aspect, this is also acknowledged in the limitations of the study.

I recognize that various critiques of community-based learning exist. However, my support for community-based learning is rooted not only in my lived experience but also in research and literature that demonstrates the benefits of community-based learning, particularly when executed after thoughtful, intentional planning and student preparation. I agree with the notion that there are undeniable links between schools, communities, and social and environmental needs. In my opinion, engaged pedagogy that integrates the head, hands, and heart and includes the affective and cognitive domains leads to the most transformational learning experiences for students. Engaged pedagogy should be utilized to achieve education for citizenship and sustainability. I believe that 
the splintered approach to solutions for many of the social, environmental, and economic problems plaguing communities is a result of the largely fragmented approach to education that permeates most school systems. K-12 schools and universities are not currently successfully addressing community problems and political disengagement. Yet, school reform is imperative to address the pressing social problems of present day. Any one institution alone cannot address these interrelated issues. Civic improvements rely on collaborations between schools and communities and placing community at the center of education. I believe that when the community is put at the center of the educational experience, the interconnections between communities and schools are honored and the holistic, intergenerational, relational, and civic aspects of education are promoted. Additionally, I believe that institutions of higher education are positioned uniquely to become one of the most powerful and effective organizations for improving communities because of their economic, social, and intellectual resources as well as their ability to educate future citizens and professionals. Many students explore their identity, values, and goals during their undergraduate education. It is an ideal time to provide learning experiences for students to question their role in addressing social and environmental problems and their role within their communities and democracy.

My dedication to sustainability education and community-based learning is rooted in my educational and professional experiences where I have witnessed that current postsecondary educational practices in the United States generally do not encourage practical skill building, whole systems thinking, or a deep understanding of complex, interconnected, local and global issues. Higher education is a critical time to educate learners about their responsibilities in promoting sustainability or equipping them with 
the skills to work for a more sustainable, livable, and humane world. This research is a natural extension of my personal and professional interests in the practices of sustainability education and community-based learning.

\section{Research Design}

\section{Portland State University and the senior capstone program.}

All courses in the Portland State University senior capstone program include an embedded experiential, community-based learning requirement. Senior capstone courses aim to bring diverse students and perspectives together to address a community problem through applied learning and community engagement. Further, as learned from the senior capstone director, an increasing number of senior capstone courses are starting to incorporate issues of sustainability into their course content (S. Kerrigan, personal communication, October 21, 2009). There are senior capstone courses that explore sustainability issues including food systems, climate change, water and watersheds, waste reduction, oral histories, education, indigenous knowledge systems, environmental education, and social justice. Since the senior capstone program is a structured program and has been in existence for over fifteen years, senior capstone courses that utilize community-based learning and included sustainability issues were selected for the sample pool. Further, in order to maximize the possibility that the capstone instructors would be local and available for interview in the Portland area, the 2008-2009 academic year capstone courses were chosen as the sample pool.

PSU credentials around sustainability work and community engagement provided additional support for use of the senior capstone program in this study. In 2009, for the eighth consecutive year, Portland State University ranked among the nation's best 
colleges in the categories of senior capstone and service-learning, both categories which lead to student success according to U.S. News \& World Report in its "America's Best Colleges" 2010 edition (Portland State University References, 2010). Further, Portland State University is among one of the nation's greenest universities, according to "The Princeton Review's Guide to 286 Green Colleges” (Portland State University References, 2010). Additionally, PSU was awarded a Gold STARS rating for sustainable practices in 2010. STARS is the Sustainability Tracking Assessment and Rating System, sponsored by the Association for the Advancement of Sustainability in Higher Education; the STARS rating is based on sustainability programs and performance, including curriculum and research, human resources, and energy consumption. PSU scored high in cocurricular education, public engagement, research, and transportation (Portland State University References, 2010). These commendable community-based learning and sustainability rankings provided additional rationale for using the senior capstone program for this research. Consequently, PSU senior capstone courses that were offered during the 2008-2009 academic year and their corresponding instructors were considered for selection.

\section{Sampling, subject recruitment, and research participants.}

The base sample pool consisted of the senior capstone courses offered during 2008-2009; this included 194 total senior capstone course sections offered over the course of summer, fall, winter, and spring terms. Of these sections, 103 different course titles with 108 different course-instructor combinations were represented. Of the 103 different capstone courses offered and eligible for selection in this study, 54 were offered during only one term, 19 were offered during two terms, 18 were offered during three 
terms, and 12 were offered during all four terms that include the summer. Five courses with the same title were taught during the 2008-2009 year by two different instructors. The courses that were selected for this study had robust sustainability content based on their course descriptions and syllabi.

Non-randomized criterion sampling was utilized. Criterion sampling is a type of qualitative sampling that selects cases that meet some set of criteria or have some characteristic (Gay, Mills, \& Airasian, 2009). Courses with robust sustainability content, for the purpose of this study, incorporate sustainability themes broadly categorized as environment or nature; economy; politics or policy; and community, society, or civic affairs. These four broad thematic areas were utilized to identify the sustainability capstones. The course descriptions and syllabi were screened for these broad sustainability thematic areas. Senior capstone courses offered during the 2008-2009 academic year with at least three of the four identified sustainability thematic areas in their course descriptions or syllabi were included in this study. Through this process, a total of 11 courses were identified as having robust sustainability content from the base pool of 103 courses.

Once the sustainability capstone courses were identified, courses that scored in the highest third on the student evaluations for all capstone courses offered during the 2008-2009 academic year were selected for participation in this study due to their documented success, effectiveness, and meaning, according to the student participants. The student evaluation data was obtained from the senior capstone program director. Of the 11 sustainability courses identified, five capstone courses met the student post-course evaluation criterion. Four of the eleven sustainability courses did not score in the top 
third on the student post-course evaluations and two of the sustainability courses did not have any documented post-course student evaluations, leaving five courses that met both the sustainability content and student evaluation criteria.

Three of the five courses that were identified as courses with robust sustainability content and as exemplary based on the post-course student evaluations were offered during the 2008-2009 year by more than one instructor. Two of these three courses had one instructor receive post-course evaluations in the top third and one instructor not receiving post-course instructor evaluations in the top third. For these two courses, the instructor with the post-course evaluation in the top third was selected for the study. Two different instructors who had both received evaluation scores in the highest third had taught one of these courses that met the sustainability content criteria. Because one of these instructors for this course is a member of my thesis committee, the other instructor was asked to participate in the study to avoid a conflict of interest.

Thus, five capstones were eligible for the study. I contacted the instructors via email and explained the purpose of the study. All five of the recruited senior capstone instructors agreed to participate in the study.

\section{Data collection.}

Before I began this research, I submitted an application to the Human Subjects Research Review Committee at Portland State University. Once I received approval, I began the research. This project utilized qualitative data collection via semi-structured interviews with senior capstone instructors and content analysis on course syllabi. Prior to conducting the interviews, I reviewed the purpose of the study with the participants, how their comments would be used, and what risks were associated with the study. 
Further, I provided a copy of the interview themes to all participants several days before the interview for them to review and ask any questions. The interview themes can be found as Appendix A. I presented each participant with an informed consent form that detailed the study's purpose and potential risks before the interview began. The informed consent form can be found as Appendix B. All participants were given the option to request that their answers be kept confidential or non-confidential. Non-confidential participants allowed for the use of their names. One participant wanted his or her interview to stay confidential. Hence, pseudonyms are used for all participants.

Semi-structured interviews took place with senior capstone instructors. Semistructured interviews are those that involve a script but allow for prompts to be added for elaboration purposes (LeCompte \& Schensul, 1999). The interviews were held at preferred locations of the interviewees in order to bring initial comfort to each interview participant via setting and also to help establish trust. My goal was to say as little as possible in order to learn as much as possible and reduce the chances for any research bias to impact the interviews. Each interview started with a factual question so that the participants could feel at ease and relaxed. The same general questions were asked to every interviewee and room was provided to ask questions prompted by the flow of the interview. While the same content was covered in each interview, the question order varied by interview. I asked the interview participants opening questions that were broad and introductory. From there, direction of the questions throughout the interviews was dependent upon the themes of each participant's answers, their willingness to share, and the length of their responses. The interviews included questions on course content, course approach, course activities related to community engagement and sustainability issues, 
how sustainability process, learning outcomes, skills, knowledge, and/or values are incorporated into the course, why the course includes sustainability issues, and tools or tips for connecting community-based learning with sustainability. The interview guide can be found as Appendix C. Interviews generally lasted between 45 and 80 minutes depending on the speed of the participants' speech and the lengthiness of individuals' chosen answers. The interviews were audio recorded to aid in the transcription process and to help ensure accuracy. Immediately after the interviews, I recorded my own initial impressions and reflections in the form of memos.

Senior capstone syllabi were collected from the instructors and senior capstone director. The syllabi were reviewed for course content and specifically sustainability issues and learning outcomes as well as community-based and sustainability activities, assignments, and/or projects.

\section{Strategies for data analysis.}

Interviews were transcribed verbatim. Each interview participant was given a letter code for the transcript and corresponding syllabus. The five courses were each assigned a letter (A, B, C, D, and E) and the transcripts were denoted with the number one (1) and the syllabi were denoted with the number two (2). These codes aided in the data analysis as well as the reporting phases of this study. For example, B1 represents information from the interview with Instructor B while E2 represents information from the syllabus for Course E. Table 1 summarizes the data sources that are referred to in chapter IV.

A grounded theory (Strauss \& Corbin, 1998) analytic approach was utilized for the interview data in order to allow meaning to arise from the data itself. Interview 
transcripts were coded for themes. Themes were clumped into categories and subcategories. Coding highlighted themes allowed me to see how frequently certain themes showed up. Each level allowed me to see the data in a more abstract, theoretical way. Inductive reasoning was a primary method used in analysis. Identifying themes, coding, and concept mapping were the analytic techniques used for analyzing the syllabi. Course descriptions, stated learning outcomes, grading, course activities, course readings, and course assignments were all reviewed and coded in the syllabi document analysis. I strived to pay close attention to the voice and narratives from each interview to be sure that each instructor's perspectives on the relationship between sustainability education and community-based learning could be clearly understood. Once themes were identified, the literature was reviewed to check for corroboration. Member checks were done for accuracy, validity, and credibility.

Table 1. Summary of data sources

\begin{tabular}{|c|c|c|c|}
\hline Course & Major Course Themes & $\begin{array}{c}\text { Data from } \\
\text { Interview } \\
\text { Transcript }\end{array}$ & $\begin{array}{c}\text { Data from } \\
\text { Course Syllabus }\end{array}$ \\
\hline A & $\begin{array}{c}\text { Food systems and garden-based } \\
\text { education }\end{array}$ & A1 & A2 \\
\hline B & $\begin{array}{c}\text { Indigenous cultures and } \\
\text { environmental education }\end{array}$ & B1 & B2 \\
\hline C & Food systems and business practices & C1 & C2 \\
\hline D & $\begin{array}{c}\text { International environmental } \\
\text { activism and community } \\
\text { engagement }\end{array}$ & D1 & E2 \\
\hline E & $\begin{array}{c}\text { Learning gardens, food systems, and } \\
\text { civic affairs }\end{array}$ & E1 & \\
\hline
\end{tabular}




\section{Limitations.}

As a result of limited time and resources I had as a researcher as well as a narrowly defined sample pool, the sample size was limited. The results were generated from the study of only five courses at a single university and thus the results will not necessarily be generalizable to all postsecondary institutions or courses. Furthermore, given the limited resources, students and community partners were not interviewed to obtain any data or glean their perspectives on the relationship between sustainability education and community-based learning. The data collected in this study was from the perspective of capstone instructors and does not include the perspectives of students or staff from community organizations. The only student input came in using their evaluations of the courses as part of the sample selection criteria.

Furthermore, I recognize the limitation resulting from the use of student evaluations as a way to designate or judge successful capstone courses. The norms of the institution, based on my conversations with the senior capstone director, were that the use of student evaluations has been reliable for identifying successful, effective capstone courses at the institution both in terms of quality instructors and quality community-based learning instruction. While this is only one way of defining success, it fits the norms of the institution.

Another limitation is that because I identify as a keen supporter of both community-based learning and sustainability education, I needed to carefully monitor how my own biases, feelings, assumptions, and expectations influenced the data collection and interpretation process. My efforts to ask only open-ended questions and do limited talking during the interviews served to reduce potential research bias. Constant 
reflection on my assumptions and expectations throughout the study also served as an asset in this process. The memo writing that I did immediately after the interviews was a way to balance subjectivity and objectivity as well.

\section{Significance of this Study}

Growing acknowledgement of social and environmental problems that communities are facing across the country has partially led to increased levels of community engagement and sustainability work at institutions of higher education. Because of these trends, a study examining the intersection of these two fields is both timely and meaningful to instructors and practitioners in both fields as well as community members themselves. This study is significant for institutions of higher education, nonprofits, non-governmental organization (NGOs), community organizations, and communities and citizens at large that are home to colleges and universities who are or could be involved with campus-community partnerships and are interested in sustainability issues. This study is especially pertinent to Portland State University, the University Studies Program, and instructors and administrators in the senior capstone program because the study focuses on this program's courses. Community-based learning and sustainability education have the common goal of fostering positive human interaction to create a more humane and just world. This study should be of interest to any university instructor or administrator who seeks to execute community engagement work through a sustainability lens or create sustainable models for community-based learning work.

This research contributes new knowledge and understanding of how communitybased learning and experiential education can incorporate elements of sustainability in 
order to be a successful delivery model for sustainability education. Effective strategies for linking community-based learning and sustainability will contribute to both the fields of service-learning or community engagement and sustainability education. Reasons supporting the convergence of these two formally distinct fields are discussed and elucidated by this study. This research reveals new ways in which professionals and educators in the fields of sustainability education, environmental education, community engagement, service-learning, and community-based learning, especially at PSU, can collaborate in postsecondary education to achieve outcomes and goals that are mutually desirable. 


\section{Chapter IV}

\section{Results and Analysis}

This chapter is organized according to the results from the data collection and analysis process in relationship to the research questions that directed the study. The chapter is divided into sections according to themes that emerged from the grounded theory analytic process. First, an overview of each of the five courses is presented to provide context for the results. Then, the themes of the responses are presented; the themes are categorized as follows: perspectives of students; reflection and personalizing sustainability; connectedness and relationships; community and place; and diversity and inclusion. Next, models summarizing the major results are illustrated and explained. Finally, the relationship between and coupling of sustainability education and community-based learning are reviewed.

\section{Overview of Courses}

\section{Course A.}

Course A focuses on sustainable food systems and garden-based education. The course has been taught each year between 2007 and 2010 and was developed initially to get more students at PSU engaged in gardening and topics that support gardens and farms (A1). The first class is held in a classroom at PSU, and all remaining classes are taught at a local food-based garden. The course content includes food systems, food issues facing urban citizens, food and farm culture, food security, personal connection to food and land, food impacts on diverse communities, relationships between food and the land, ecological processes, biocultural diversity, local economics, education, and food politics. Major assignments for the course include participation, reflective journal, a vegetable 
project (involving harvesting, cooking, and research), hands-on demonstration, and community service project.

\section{Course B.}

Course B emphasizes indigenous ways of knowing and environmental education. The course analyzes traditional environmental education that focuses on scientific analysis and social policy and considers cultural shifts that may be needed to create a more sustainable world. The course emphasizes integration of all five senses and explores the relationship of the students to the world around them. The course content includes environmental education, Native American perspectives, heritage, cultural transformations, food, crafts and arts, storytelling, policy making, and rituals. The instructor interviewed has taught the course for two full years after serving as a community partner for the course prior to teaching it. About seven of the class sessions are held in the community or outside the classroom and the rest are held at PSU. Major assignments for the course include participation, roundtable discussions and reflection papers, a community project, and a final paper for reflection and synthesis of the course material.

\section{Course C.}

Course $\mathrm{C}$ began in 2006 and has been taught about 24 times to date. The course focuses on the food industry and business practices. The course content includes food systems, healthy communities, cooperative business models, financial analyses, marketing studies, health and nutrition, food security, food politics, community development, urban design, and environmental sustainability. About half of the class sessions are held at PSU while the other half are held in the community. Major course 
assignments include written reflection assignments, group or class participation, engagement with the community and community partner organization, and the final project and group report with reflection.

\section{Course D.}

Course D was taught as a summer course that included a study abroad component. The course has been taught only once to date and is focused on environmental activism and community engagement. The course examines how demographic, economic, and technological pressures impact environmental quality while providing the opportunity for students to work with urban and rural communities. The course includes two community partners in Portland and several international community partners and focuses on promoting environmental protection via community action and also explores issues of forestry practices, ecotourism, food, language, and globalization. Major course assignments include attendance and participation, writing assignments, and a final group project and presentation to the community partners. The class structure includes three pre-trip classes, a two-week international trip, and several post-trip meetings.

\section{Course E.}

Course $\mathrm{E}$ has been taught for four years by three different instructors and explores the relationship between learning gardens and civic concerns. Issues of food security, community involvement in civic affairs, food systems, place-making, community and place, food, culture, food ethics, justice, power, and choices as consumers and citizens are discussed as part of Course E. Major course assignments include attendance and participation, reflection journals, roundtable discussions, a meal plan diary project, and a 
final project and presentation to the community partner. The course includes about four sessions at the community partner site, and the rest of the courses are held at PSU.

\section{Perspectives on Students}

In this section, I explore the instructors' views of students since these impact the classroom structure and pedagogy. Based on the data analysis, I categorize the perspectives into three areas: cooperative learning and personal responsibility; holistic student view; learner-centered and active learning strategies.

\section{Cooperative learning and personal responsibility.}

All five of the courses explicitly call for cooperative and/or learner-centered projects that require students to take some amount of personal responsibility for their own learning and work collaboratively to create a final project or presentation. A2 and B2 state that students are to explore their personal connection to food and the land, participate in cooperative learning, and engage in the local situation. A2 and B2 explicitly list in their syllabi that cooperative learning is an instructor expectation:

Cooperative Learning - We see this course learning as a collective process in which we have an opportunity to help each other generate meaning throughout the term. As an instructor, we see ourselves as partners in this learning and expect feedback that may add to the collective process. (A2; B2)

A value on cooperative learning is a value on the unique contributions that each

individual student can offer. Further, during the interview with Instructor C, it was noted that the students are viewed as "consultants in the real world" and that students are to feel empowered as part of a peer-learning group. The roundtable discussions that were a part of Course E allowed student learning groups to work together to discuss course topics in their civic context; the roundtable discussions in Course E promoted peer-to-peer 
learning experiences and giving students leadership roles in critical discourse (E1). Instructor E expressed a desire to create a classroom atmosphere where students are colearners who learn from each other (E2). Instructor A implied a systems view of their class with the statement, "With emphasis on relationships and cooperative learning, each student's participation impacts the learning and experience of the whole" (A1). Here, it is understood that the participation of each individual student is integral not only to the student but to the class as a whole. This epitomizes cooperative learning.

All five instructors structure their course in a way that entrusts the students to work collaboratively to produce a product and/or final presentation for the community partner. This puts the onus on the students and promotes and develops personal responsibility within the students to work collaboratively to provide a meaningful service or product for the community. The cooperative learning approach of all five courses encourages relationship building, trust, and community building within the classes themselves. Class community building will be discussed more extensively later.

Along with a focus on cooperative learning, many of these courses strive to instill a sense of empowerment and personal responsibility in students to take action. Instructor A discussed how meaningful, engaged, authentic experiences in the class allow students to feel "empowered, part of the change, inspired, and hopefully to be able to take responsibility to make the world a better place" (A1). Instructor A stressed the importance of responsibility in sustainability education, stating, "I think sustainability education involves that moral or ethical component of looking at the choices we make and the consequences they have, and what are our inherent responsibilities to take care of each other and to take care of the earth" (A1). In the words of Instructor B, "sustainability 
carries with it a mindfulness that guides behavior, guides decisions” (B1). Instructor C also commented that they want their students to feel empowered as part of a peer-learning group to make a difference in the real world (C1). The syllabi for all five courses state that students have a personal responsibility to be engaged in class, to show up prepared to participate, and to communicate concerns or needs to the instructor (A2; B2; C2; D2; E2). Instructor $\mathrm{E}$ feels that it was important for students not only to feel engaged in but responsible for their own learning (E1). These instructor views on student potentials and abilities require a certain amount of trust or faith in students that is unique. Course D also places a strong emphasis on personal responsibility of the students while valuing the students' ability to contribute to the construction of knowledge. The syllabus for Course D provides the following context for student responsibilities in the course:

Students are responsible for being active, co-producers of learning and insights for self and others. In short, students in the course are expected to put into practice the very elements that contribute to building vibrant communities and developing effective community leaders. (D2)

Questioning the role of the individual, organizations, and institutions within society to serve as community and environmental stewards to address issues of social and environmental inequity undergird every aspect of Course D (D2). This obliges students to examine their role and personal responsibility in working for change around the issues discussed in the course.

In conversing about the community-based learning pedagogy, Instructor D mentioned that a challenge in recruiting more instructors to execute the approach is the faith the instructors must have in students within community-based learning. Instructor D noted that they had never to date had a group of students let them down partially because 
the students knew that the community was counting on them taking their work seriously (D2). When instructors trust and have faith in their students, they are more likely to give students the opportunity to form meaningful peer learning communities, and the students will be more apt to be engaged in and responsible for their learning.

This student view aligns with the sustainability education theory ideals of education including learning communities, an integrative view of the teaching whereby teachers are also learners and learners are also teachers, and a view of the learner that values existing knowledge, beliefs, and feelings (Sterling, 2004). This approach also acknowledges an inherent value of the knowledge and skills of the students as well as self-discovery that is often not included or valued in traditional transmissive lecture-style educational approaches (Lindholm 2007; Sterling, 2004).

\section{Holistic student view: multiple senses and affective and cognitive domains.}

Several of the instructors also emphasized a holistic view of students in terms of wanting to engage students through multiple senses and using the affective and cognitive domains as well as through head, hands, and heart. In essence, the holistic student view acknowledges more than merely the intellectual or cognitive domain of students.

Instructor A demonstrated support for a holistic view of students, stating: "I really try and cater this class to the whole person. Learning about sustainability isn't just about learning it in your head. It's about experiencing and utilizing the whole self' (A1). Instructor A elaborated on this point in speaking about the reflective field journal assignment:

Having them [students] go sit and be present, and observe rather than projecting our ideas onto the land, being able to learn subjectively, which is a challenging thing for a lot of students because we're taught to be so subjective. To value our sensory response to the places we live, that ultimately helps us learn the dialog 
that exists between our bodies and the earth, and that it's just a different way of knowing and experiencing. (A1)

Here, objective and subjective ways of knowing are valued and students are encouraged to be in tune with their senses and emotions to explore their personal connections to the land. Another example of this holistic student view comes from the syllabus for Course B, "Using all our senses, we will taste, listen, feel, smell, see, and express our relationship to the world around us" (B2). Acknowledging the five senses and affective domains lends itself to more interactive, experiential educational strategies, such as community-based learning.

Sustainability and ecological educators call for the integration of multiple senses and the fusion of the intellect and emotion (Krapfel, 1999; Louv, 2005; Orr, 1992; Sterling, 2004). The multi-sensory characteristic is imperative to sustainability education because it acknowledges the learner holistically (Sterling, 2004). A process that includes multiple senses appeals to and reaches learners who represent a variety of learning styles and modality preferences; thus, this approach provides more access and opportunity and is also more inclusive of diverse learners (McKeown, 2003).

Integrating multiple senses promotes self-discovery and results in deeper, more transformative learning (Cajete, 1994; Sterling; 2004). Integrating the head, hands, and heart balances the cognitive, psychomotor, and affective domains and results in more meaningful, transformational learning (Sipos et al., 2008). Sipos et al. (2008) argue that using the head, hands, and heart will facilitate personal experiences for students that will lead to profound changes in knowledge, skills, and attitudes related to environmental, economic, and social justice, all changes which are needed to create sustainable societies. 
Sustainability education is and should be transformative education that results in behavior change and that this can be accomplished through a pedagogy that integrates the head, hands, and heart, according to Sipos et al. (2008). The transformative possibilities of sustainability education coupled with community-based learning will be touched on further later in this chapter.

When instructors view students in a more holistic way, the pedagogy acknowledges the students as people with intellect, emotion, and practical knowledge. Viewing students in this holistic manner encourages instructors to utilize experiential learning and reflective techniques that incorporate more than strictly cognitive functions. A holistic student view is supported by the research here and sustainability and ecological education research as means to create meaningful, transformative learning experiences.

\section{Learner-centered and active learning strategies.}

Community-based learning is a form of experiential learning that requires active student participation and is a pedagogy that is at least partially learner-centered rather than being merely top-town, instructor controlled. Thus, it is logical to extrapolate that instructors who value a community-based approach would also value regular student attendance and higher levels of student engagement. The research here confirms this supposition. C2 includes the notion that the service-learning final projects involve "student-centered learning" whereby the success or failure of projects is in the hands of the students. Instructor B insisted that sustainability education must be experiential and active, "Sustainability education, I think fundamentally is an experience, it's experiential" (B1). Instructor $\mathrm{C}$ commented that it was a goal for students to move from passive to active learners, understand that sustainability is about them, and learn sustainability 
lessons from the community where the work is actually happening. This point was made by Instructor $\mathrm{C}$ as follows:

Making them [the students] work with the community partner makes them go from passive student to active civically engaged student, that opens the doors for them to be more receptive to the sustainability issues, whether it's straight up environmental kinds of sustainability issues, or even more social ones. They're more active, civically engaged... They're [the students] actually out there working on these real issues. That is hugely important... We need to get out of the abstractions and get into the community and be problem solvers. We have so many people studying theory and process. There's so much that can be learned just by closing the door, opening the door and entering the community. (C1)

The necessity for students to work with community agencies in community-based learning provides an automatic avenue through which students move from passive recipients of knowledge to active creators of their learning experience. Community-based learning allows students to be more receptive to sustainability issues by allowing them to enter the community and open the door to real world sustainability issues and problems the community partner is experiencing and addressing. The community-based learning approach is effective in teaching students about sustainability issues because of its applied nature (A1; B1; C1; D1; E1). Additional support is provided by Instructor C's sentiment:

That in itself is important where students go from being passive to active. I think that is the biggest sustainability piece. That has to do with the interconnection so students don't just see themselves as passive recipients of culture and the food they eat. They see they can make a difference, and by having a community partner, by having them leave the classroom, close the books and see the importance of learning from each other in community, I think that has a big impact on their understanding of sustainability. (C1)

The quote above articulates an important message that when students are active participants in their learning via community-based learning, they see themselves as both part of the community and sustainability and that being active in their learning through 
interactions in peer learning groups and with community partners enhances the ability of the students to understand sustainability. Instructor A strives to minimize the lecture portions of the course by creating engaging learning experiences. Instructor A commented, "I don't really lecture about these things [class theory and concepts]. I create experiences" (A1). Instructor A executes sustainable agriculture council role-play and scenarios as one way to create experiences rather than lecture. To this end, Course A continually emphasizes student-centered, active learning as a strategy to promote more meaningful learning experiences for students.

Much sustainability education literature presents similar ideals in terms of promoting student-centered learning, collaboration, teamwork, and active rather than passive learning (Cotton \& Winter, 2010; Orr, 1992; Scott \& Gough, 2003; G. A. Smith, 2007; Sterling 2004). Additionally, general adult education literature supports the argument that learning should not be teacher-centered but should be learner-centered or student-centered whereby students are continually engaged in their learning and can apply the course's content to their own lives (M. L. Taylor, 2006). According to Tennant and Pogson (1995), the view of experience as an essential foundation for adult education practice is widely held and experiential education allows educators to meet the growing demand to link education and vocation. They also support learner-centered, active education as a way to develop self-aware learners who have the ability to frame their own purposes and continually use classroom material to understand the world (Tennant \& Pogson, 1995). Sarkissian et al. (2009) note that environmental education and adult education are more effective when they are active rather than passive. Community-based learning and sustainability education necessitate both active and experiential learning, 
which affords students with the aforementioned benefits. Furthermore, allowing students to interact in the community results in varied class activities and supports learning for students who learn best in different modalities; this benefits all learners and learning styles (Chávez \& Guido-DiBrito, 1999). Community-based learning and sustainability education, including the senior capstone courses examined here, certainly support a shift from a teacher-centered paradigm to a learner-centered paradigm through their emphases on creating a collaborative learning environment where teachers are co-learners and students are able to be creators of knowledge (Knapp, 2005; G. A. Smith, 2007). Placebased education consistently engages students in their learning and allows students to apply learning to their own lives and communities; it also supports learners with a wide range of learning style preferences. The learner-centered attributes of the senior capstone courses are well supported by sustainability, adult education, and community-based learning theory for what creates effective learning environment for learners. Students need to be engaged in and also feel responsible for their own learning; this is encouraged through cooperative, active learning environments such as those created by the five senior capstone courses explored here.

Furthermore, all five classes place a strong emphasis on attendance and active participation in the community as indicated by course assessment and grading. The percentage of each course's total points awarded for attendance and class participation ranged from $15 \%$ to $25 \%$ while the grade for community engagement and participation for each course ranged from $15 \%$ to $30 \%$ of the overall course grade. The total percentage of the courses' final grades representing either class or community participation or engagement ranged from $30 \%$ to $50 \%$ of the overall course grades. The 
high value placed on attendance and participation represents an understanding of the importance of active participation and experience in the learning process. The syllabus for Course B is explicit in denoting the importance of participation and the process of education as shown below:

Evaluation: Because no one part of this class outweighs the other, each of the sections below is weighted equally. This is to say that student participation and involvement (i.e. process) is as important as the final project and papers (i.e. product). (B2)

This view aligns with the sentiment expressed by Orr (1992) that the process of learning is as important as its content. Instructor A views an attendance priority as a priority on cooperative learning and relationships; each student's participation impacts the learning and experience of the whole (A2). The syllabus for Course D notes that student engagement is key to achieving the desired learning outcomes (D2). All five instructors view active participation in the learning process as vital to the educational process.

\section{Reflection and Personalizing Sustainability}

All five of these courses require reflective writing assignments and emphasize personalizing the educational experience to encourage students to consider their personal relationships to the land, the community, the food they eat, et cetera. Grades for reflection ranged from $20 \%$ to $40 \%$ of the overall grades for the courses. Personalizing the topics of sustainability dovetails with the established instructor emphases on the fact that students ought to take personal responsibility for their own learning and engagement as well as their focus on having the students feel connected to the community and their learning. Considering one's own responsibility and role in addressing these societal and 
environmental issues is personalizing the learning experience. Reflection assignments are another way to ensure personalized learning.

Course A includes a reflective journal that asks the students to observe the land and reflect on specific field related issues as well as make connections between their course readings, theory, and field experiences (A2). Course B requires weekly reflections on the course readings, personal insights, and how these relate to environmental education. These reflective assignments help to personalize the learning experience by requiring the students to connect the course material and their experiences to their own lives (B2). Course $\mathrm{C}$ includes five reflection and critical thinking writing assignments that ask students to weave together the course readings, their experiences with the community partner, and their feelings (C2). Instructor C elaborated on this point as follows:

I think with my capstone it's getting students to see that sustainability is about them, to personalize it. I do that with some of the field trips in the curriculum, in these assignments where they're analyzing their own behavior. I think personalizing the issues makes it more real. (C1)

When sustainability is "real" through community interaction and students are required to reflect on their own behavior and their personal relationships to the community, the course readings, and sustainability itself, the likelihood that the students will actualize ways in which they can individually participate in sustainability and community work greatly increases. Course D assigns pre-trip and post-trip reflective papers as well as a reflective journal for the trip itself to ensure students are making meaning out of the readings, their personal experiences, and connecting course experiences to University Studies goals and to past and future life experiences (D2). Instructor D stressed that 
multi-modal, daily reflection was a quintessential element of the course and part of the reason the course was successful (D1). Instructor D expanded on their commitment to reflection as part of the educational process in stating:

During the experience is constant reflection. Multiple modes of reflection, multiple discussions, free writes, debates, presentations, many presentations on little topics they have...Multi-modal reflection and regular, continuous, small and big. We had lots of free writes. At least one free write a day. (D1)

Instructor D views reflection as the thread throughout the course that continually personalizes the learning experience for students and strives to have a nice balance of students and the instructor actively participating and but also "taking time to formally step back and ask ourselves what does it mean, how does it relate?" (D1). Course E asks students to use their journal to reflect on what they have learned and draw connections between course readings, service projects, and civic affairs (E2). A total of five reflective journal entries are assigned in Course E. Course E also assigns a meal plan project which allows the students to connect course themes to their personal food choices and behaviors (E2). Courses $\mathrm{A}$ and $\mathrm{C}$ also require a similar meal plan assignment asking students to analyzing their personal decisions related to food and consider where their food comes from (A2; C2). Instructors $\mathrm{C}$ and $\mathrm{E}$ particularly noted the transformative impacts of the meal tracking on students $(\mathrm{C} 1 ; \mathrm{E} 1)$. Describing the transformational results of the personalized meal plan assignment, Instructor E commented,

That was really transformative for folks to really not only make that [meal] plan, but implement it and see what happened, and how much it affected not only themselves but how much their choices affected their families, their communities, and on a larger scale how it affected ecosystems in the larger communities based on decisions about food. (E1) 
Personalized reflection assignments that ask students to use systems thinking and make connections between their choices and their communities and environments yield promising educational results. Instructor A noted that creating "webs of dependence" and getting students to see the "larger web of relationships that they are connected" to is a goal for their class that is achieved in part through the reflection assignments. The assignments are one way to encourage students to explore these connections and relationships and provide opportunities for the students to deeply reflect and create personal meaning of the course's material (A1; D1).

Research within the sustainability education and community-based learning fields consistently support the role of reflection in the learning process and provides a solid rationale as to why all five of the courses reviewed in this study include such a strong emphasis on reflection. The element of reflection in community-based learning or service-learning significantly contributes to the ability of this pedagogy to serve as a form of sustainability education and build sustainability. Kaza (1999) posits that students must first explore their experiences and values on issues of social importance before they will be able to encourage or inspire others to act. Within the service-learning community, there is general consensus that reflection is necessary to maximize the meaning of the learning experience (Correia \& Bleicher, 2008; Eyler, 2000; Eyler \& Giles, 1999; Eyler et al., 1996; Hatcher, Bringle, \& Muthiah, 2004; Kaza, 1999). Reflection helps to facilitate the process of students making connections between theory and practice. Authentic and interactive experiences, caring about others, and engaging in important work generates questions; reflection offers the opportunity for students to ask questions, discuss their experience, and make meaning of their experience (Eyler \& 
Giles, 1999). Reflection is viewed as the process and skill that allows students to make sense of their community experience (Correia \& Bleicher, 2008). Reflection serves as a bridge between concrete experiences and conceptual understanding (Felten, Gilchrist, \& Darby, 2006) or a bridge between what students learn in the classroom and what they experience in the community (Collier \& Williams, 2005). Completing service is about making the familiar unfamiliar and the unfamiliar familiar (D. Williams, personal communication, May 12, 2009). Reflecting on this process is absolutely essential to deepening the learning process and clarifying one's role or place in the world and addressing the needs of the community. Furthermore, reflection is participatory, collaborative, interdisciplinary, multi-sensory, fuses intellect and emotion, and fosters systems thinking and understanding of interdependence; the reflection component alone has significant similarities with sustainability education. Research shows the essential role of reflection as part of sustainability education and community-based learning pedagogy and in general effective learning processes. Because reflection is an essential part of all five of these courses, the courses can both serve as a model of sustainability education in practice and build sustainability through fostering students' ability to articulate how sustainability is connected to their own lives and communities.

\section{Connectedness and Relationships}

Connectedness, interconnections, interrelatedness, and relationships are all ideals and principles that serve as part of the foundation of the sustainability paradigm (Capra, 1996; Capra; 2005; Meadows, 2005; Orr, 1992). Themes of connectedness and relationships emerged from the data in this study. "Sustainability is a framework, it's a way of thinking, it's a way of viewing the world and the systems that run the world," 
according to Instructor D (D1). While Instructor A views sustainability as a "fundamental shift of putting ourselves within the web of life... and understanding that whole systems perspective of everything is interconnected" (A1). Systems thinking and an understanding of connectedness are further supported by the preceding quotations. Certainly, reflection assignments are centered on exploring connections and relationships. With all five courses stressing reflection, all five courses consequently stress connectedness and relationships. Relationships and connections were highlighted by all five of the courses between the students, the course material, the students with the course material, and the instructor and students with the community. Referring to studentstudent and student-community relationships, Instructor B mentioned that, "What I hear from the students [is that] the relationships turn out to be the most fulfilling" (B1). The relationships the students have with the community partner are an essential component and gateway to sustainability lessons. The importance of student relationship with the community partner is noted here, “They [the students] have particular relationships with the community partner. That is often the entry into what they're going to learn about sustainability" (C1). Because community engagement is a central tenet of all five of these courses, the community partner has a substantial role to play in what the students learn about sustainability with the relationship between the student and the community partner being a primary indicator of the types of sustainability lessons that can and will be learned.

\section{Course assignments.}

Many assignments in the courses involved in this study incorporated themes of relationships and interconnectedness. Course B includes a final paper that asks students 
to discuss environmental education as it was experienced in the class and how it influences their relationships with at least two of the following: people, earth, water, animals, plants, weather, ancestors, future generations, et cetera (B2). Studying food and food systems represent an ideal tool to have students explore their relationships to their food, communities, and environment (Brown, 2005; Capra, 1996). Instructor A feels that food "brings all things together" (A1). Three of the five courses (A, C, E) focus explicitly on food or food systems and the other two courses (B, D) include food issues in some way in the course. The "Very Important Veggie Partners" assignment in Course A encourages students "to develop a direct bodily relationship to their plant as well as a critical understanding of their plant as a commodity of the food system" (A2). Course A also expects students to "Reflect on how our relationship to food and land impacts our lives" (A2). Courses A, C, and E all require a meal plan or diary assignment that asks students to think critically about their food choices and their relationships to the food they eat, food systems, and the environment or land that produces their food. Instructor C explained part of their rationale for including food in their course when they commented, 'Eating touches everything. Studying food systems, we're studying labor issues. We're studying culture and culture change. We're studying access and inequities. We're studying agricultural systems and pollution and corporatism”(C1). Instructor C contended that food systems touch and are connected to social, economic, and environmental systems (C1). The vast potential of having students explore their relationship and connection to food is beautifully articulated with these statements:

What I do is have students do the simple task of becoming aware of the food they eat. I have food assignments and readings to understand a little bit more about where their food comes from. In some ways that is the single most impactful part 
of the class...We study the animal food industry. It's about ethics, and a lot of students start making connections they never thought about. This is a principle of sustainability having to do with interconnection. I think it hits them just by looking at food. I give them opportunities to really consider where their food comes from, and in that process it's a mental shift that happens, or even an emotional shift. That can be very substantial. Depending on the student, it may lead them in a number of different directions not necessarily related to food. Food is just a springboard. You start thinking about where your food comes from, then you might think about where your clothes come from. Where does my computer come from? What am I doing with my life? Where do I want my food to come from? How do I want to use my labor? (C1)

Once students understand the interconnectedness of systems through exploring their relationships with food, they often proceed to consider how they are connected to other items they consume or buy. When students consider where what they consume comes from, cognitive and affective shifts frequently result. Interconnections and relationships are ubiquitous in food systems and thus exploring food and food systems are an ideal educational venture to ensure students practice systems thinking and understand interconnectedness of environmental, social, and economic systems.

Stone (2005) and Brown (2005) present research that supports utilizing food and food systems as a gateway for sustainability education and learning about interconnections and whole systems. Because all people have to eat and eating is a fundamental part of life, food discussions are a quintessential way to learn about sustainability, develop systems thinking skills, and understand the impacts of where food comes from. Food represents millions of simple agreements and actions in a web of relationships that connect people to each other and to the land (Brown, 2005). Based upon the data themes presented here, the fact that three of the five courses in this study have foci on food, and sustainability education literature, food appears to be an optimal 
topic for sustainability education and for coupling sustainability learning with community-based learning.

\section{Course design.}

The design of the course itself should demonstrate interconnectedness in order to provide thematic, holistic learning for students rather than disjointed or fragmented learning that is often the product of disciplinary bound, transmissive education. All five instructors commented on the importance of interdisciplinary learning and connections within course content (A1, B1, C1, D1, E1). Instructor E stated,

When you're teaching a course [a sustainability community-based learning course] like this, really be very careful and intentional about design so that everything is interconnected. It takes a lot of time to work with a community partner both out of class and in class. It takes a lot of time. I always think about stacking functions. Whatever you're doing has multiple purposes. You're gaining skills and working with partners, you're also learning about something connected to the reading or whatever. The design and implementation is very well thought through. (E1)

This passage represents how sustainability courses should not only allow students to investigate and experience interconnectedness and relationships but the course design ought to also embody these ideals. When a course stacks functions and connections are made between course readings, class activities, and community experiences, a holistic, thematic, interdisciplinary, and interconnected learning experience is the product. Literature supports this type of course design for sustainability education and sustainable learning outcomes (Burns, 2009; Kiefer \& Kemple, 1999; Moore, 2005; Orr, 1992; Svanström et al., 2008).

Understanding connections, interdependence, and interrelationships are of paramount importance to sustainability and sustainability education (Kiefer \& Kemple, 
1999; Meadows, 2005; Orr, 1992; Smith \& Williams, 1999; Sterling; 2004).

Interdisciplinary education is needed for students to fully grasp interdependence, interrelationships, and interconnectedness. Interdisciplinary and relationship-based thinking represent yet another way sustainability education and community-based learning are related. Addressing real world issues requires the ability to consider the problem from all angles and possibilities (Orr, 1992). Interdisciplinary perspectives and interconnected course content are needed to see problems in their wholeness as well as to understand one's relationship to the problem (E. W. Taylor, 2006). A stronger base of knowledge results when it is informed by understanding relationships within multiple disciplines and perspectives and courses are designed in an interconnected way.

\section{Relationship-building skills.}

Relationship-building skills were another facet of the relationship theme. All five courses overtly state that students will gain skills related to relationship-building, community-building, or collaboration (A2, B2, C2, D2, E2). A learning outcome for Courses A and B is for students to "practice the skills that will aid them in developing a deeper awareness of and relationship with their environment, whether it be their neighborhood, the woods, a local farm, or school gardens" (A2; B2). Another learning outcome for both Courses A and B is for students to "learn relationship-building skills that can be applied to everyday lives outside the classroom" (A2; B2). Course C also includes a learning outcome of learning skills working with others related to collaboration and communication (C2). The syllabus for Course D informs students that they are to develop and refine skills that allow them to put into practice actions that contribute to building community (D2). Course E is designed so that the students are able 
to practice the skills needed to serve the community partner and participate in civic affairs, such as interpersonal communication, creativity, and collaborative skills (E2). Substantial literature support exists on the need for collaborative and relationshipbuilding skills for both successful civic engagement and sustainability work. Simply put, progress toward a more sustainable society is only possible with the collaboration of individuals, communities, organizations, and governments at the local, regional, national, and international levels (Senge et al., 2008; UNESCO, 2005). Because no one entity can fully address sustainability issues strong relationship and collaborative skills are vital to making any type of sustainable change.

\section{Community partner relationships.}

All five instructors stressed the importance of honoring the needs of the

community partner while Instructors B, C, and D noted that developing personal, trusting, authentic relationships with community partners that are based on egalitarian and reciprocal exchanges is vital to have a successful course (B1; C1; D1). As Instructor D noted, "the community partner has a huge impact on the student experience" and it is imperative to seek out feedback from the community partner and allow a reciprocal relationship help dictate the course's flow, assignments, and assessment. Course D "closes the loop on sustainability" because the international service work was culturally translated and presented to local Portland non-profits (D1). All five courses implement final student projects that are based on the needs of at least one community partner.

Sandy and Holland (2006) found that university-community relationships are a foundation for service-learning models; sustainability is contingent upon people and communities that can live well together (Sterling, 2004). Engaging in service in the 
community through reciprocal relationships leads to students being connected intimately to the community and in community building, increasing social capital, and enhancing social trust; these elements are foundational for sustainable communities (Stuteville \& Ikerd, 2009). Reciprocal relationships are a vital part of sustainable communities. In concert with relationships and connectedness, a sense of community and place is a critical theme from this research. Developing relationships and connectedness is a central element in fostering a connecting to place and community. When relationships and connections are cultivated, a strong sense of community and place result.

\section{Community and Place}

A sense of community and place undeniably are tenets of sustainability and sustainable communities. Community emerged as a theme in terms of the way instructors want community to form in their classes, between their classes and the local community, and the manner in which they want the students to relate to the community. Community cultivation is perceived as a way to counteract negative impacts of capitalism and Western culture. Themes of place and being connected to place also were prevalent in this study due to the connections cultivated as a result of the community-based elements of the courses.

\section{In-class community.}

Community building within the classroom was noted by all of the instructors as an integral part of their course. The courses encourage peer-to-peer relationship formation via peer-based or cooperative learning groups and projects. While all instructors value classroom community, some instructors have been more intentional in their efforts to build community within their classes. Instructor $\mathrm{C}$ noted that they see the 
community as the classroom and community is fostered through consensus decisionmaking practices and through sitting in a circle when class is held at both PSU and in the community. Small class size helps encourage community building and strong relationships within the senior capstone courses. Instructor C stated, "Having the small class size I think is part of having a good community-based learning experience” (C1). Articulating the predisposition for community formation within small classes, Instructor C commented,

I think creating a learning environment that is like all these capstones. It's usually 15 students. They get to know each other. They work together. They become friends. We learn together. We laugh. We have fun. Even though the topic is very serious, we don't lose sight that we're all there together. I think that leads to some success. (C1)

Small class size ensures some amount of community development because of the intensity of capstone courses and the amount of group work. Instructor B expressed similar views about the propensity for senior capstone courses to offer benefits to students as a result of the in-class community. Instructor B noted:

However, the feedback I get from students [is that], 'This is the first class I've had at PSU where I knew everyone's name in the classroom and I actually felt like I took something away with me. I learned something that will apply to my life.' What does that tell us about how we're doing in higher ed?...Capstones offer [the opportunity for students to] feel like they've been part of the community themselves. For some of them it's the first community they have felt at the college. If that can happen in five hours a week for ten weeks, I think it's very exciting. (B1)

Here, the ability of a community feeling in a class to afford students a sense of belonging is articulated. Instructor B also provided a critique on traditional education at the postsecondary level because of its limited attention on providing relevance in course material, opportunity for students to apply learning to the real world and their own lives, 
and ability for students to bond with the other students in the classroom. These attributes characterize the mechanistic view of education (Sterling, 2004).

Instructor $\mathrm{C}$ noted that their classes always meet in a circle to promote positional equity, empower students, and to build trust and community in the classroom (C1). Instructors $\mathrm{B}$ and $\mathrm{E}$ also discussed the importance of having the class members sit in a circle to build community and trust and promote deep listening during class discussions (B1; E1). Instructor E demonstrated unwavering support for class community building during the interview:

Yes. It [creating community in the class itself] makes for better learning. Absolutely. I think in all adult learning situations, we want to be connected to each other. We want to know our co-learners and learn from each other. It's a very intentional part. It should be, and it is in my class, a very intentional part of teaching sustainability. There's a number of ways I think it happens, but I always try to start the class with some kind of activity that engages people and helps them get to know each other. At the beginning there are more activity types. As we get further into the class they check in, talk about their life a little bit. Those pieces really help people feel connected. Then [we do] lots of active learning in class as well, small group discussions, group discussions, different types of activities that help learning [to] not just [be] lecture or one person talking, whether it be me or someone else. There are always people interacting. (E1)

Feelings of connectedness to other class members allow students to experience a sense of community. Intentionality in promoting community building within the class itself not only creates a feeling of connectedness and meaning between the students but also allows for deeper learning opportunities and represents congruence between both sustainability theory and instructional methods. Instructor A also expressed fervent commitment to creating community in their class as shown by the following excerpt:

The way I set up the class is [with] the number one thing I want students to walk away with from the experience [being] the feeling of community and the experience of connection to themselves, their choices, each other, and the land. Ultimately, I design everything around creating that experience. I really work on 
building a community in class first off. That involves doing check ins, lots of sharing on issues, lots of experiential things to get people comfortable, working together, talking about issues, understanding differences. I do a lot in creating a class community, sense of community, and also that feeling of being part of this community here at [the community partner site], and being part of the larger community of this neighborhood and the city, and this bioregion. I feel like I work on creating that connection. I also developed the class around having that direct engagement with the land. (A1)

The previous two interview excerpts evidence a positive relationship between a sense of connectedness and community. Providing class time for check-ins and for students to share things about their personal lives contribute to class community. Community building within the class itself also models the relationship and community development that ought to be occurring between the students of the class and the local community. It is a natural extension for students to build community with local community members and citizens if they have already participated in community development within their class. In sum, in-class community development allows sustainability ideals and goals of community-based learning to be modeled in practice.

Literature support exists declaring the positive impacts of creating a safe class community and having students sit in a circle to build community within classes. Schrader (2004) argues that an intellectually safe, moral climate in a classroom is needed in order to provide optimal opportunities for student learning, reflection, and change. Arranging chairs in a circle was found to be one attribute of classroom format that demonstrates valuing students, respects individuality, prevents distinct hierarchy, and encourages question asking contributing to an intellectually safe, caring learning environment (Schrader, 2004). Burns (2009) also found that relationship building created a class atmosphere of trust that was key for reflections on values and intended lifestyles. 
Furthermore, Roehling et al. (2011) found that familiarity yields comfort and the better students in a class know each other, the more likely they are to participate in classroom discussion. The practices employed by the instructors to allow students to feel intellectually safe and part of a classroom community support a climate for optimal student learning. Robust support from this study indicates that more meaningful learning takes place in a class with an established sense of community. Thus, creating a class community should be an intentional part of teaching sustainability and community-based learning pedagogy.

\section{Community as the classroom.}

The local community is typically viewed as an extension of the classroom by community-based learning and sustainability education pedagogies. Permeable boundaries are an intrinsic part of campus-community partnerships and collaborations. Instructor $\mathrm{C}$ acknowledged this viewpoint when they noted "That's really the success of the capstone program, providing education in the classroom, but then we also see the community as the classroom" (C1). When students are engaged and more aware of with local community concerns, a certain level of community building results. The understanding that there are no distinct boundaries to the classroom or where learning takes place is also demonstrated by Instructor B with the notion that, "The classroom is outside" (B1). Instructor A noted that it is crucial to teach "within context and outside the walls of the classroom" (A1). In fact, all five instructors expressed that the interactions between the students and local community environment were critical to achieving learning outcomes of the course $(\mathrm{A} 1 ; \mathrm{B} 1 ; \mathrm{C} 1 ; \mathrm{D} 1 ; \mathrm{E} 1)$. This theme is further explored in 
the ensuing relationship between community-based learning and sustainability education section.

\section{Community building to challenge Western culture and capitalism.}

Several instructors depicted the importance of building community between students and local citizens or organizations as a means to challenge taken-for-granted Western traditions. Instructor C commented on oppressive, unsustainable impacts that “...where we see colonialism, imperialism, capitalism, we see inequities, competition, hierarchies, degradation of the earth, warfare" (C1). Instructor B spoke at length about the focus of their class on having students cultivate meaningful relationships with community members and elders in part to counteract certain Western societal pressures and capitalism that both promote competitiveness, isolation, and individualism. The competitiveness, isolation, and individualism promoted in most of Western culture and through capitalism are at odds with and possibly even the antithesis of the ideals and values emerging in the sustainability paradigm. The sustainability movement, sustainability education, and the educational approach of the instructors in this study purport that collaboration, connectedness, social trust, and relational living and learning ought to serve as the roots grounding education and communities at large $(\mathrm{B} 1 ; \mathrm{C} 1$; D1; Longo, 2007; Senge et al., 2008; Sterling, 2004; Stuteville \& Ikerd, 2009). In reference to lessons shared by elders with the students, Instructor B stated, "Many of the things they [indigenous communities] share is there are skills like talking circle, or deep listening, respectful listening, celebrating with food, talking with one another, realizing you're not alone. Our mainstream culture in this country is very isolating" (B1). Here, a sense of valuing and honoring everyone's contributions, gifts, and identities is implicit; these are 
values common to indigenous communities (Cajete, 1994). Mainstream culture referred to by Instructor B is Western culture. Instructor D challenges students to subvert the Western educational ideals that value scholarship, research, and the instructor's views as the ultimate source of knowledge over community knowledge, as portrayed below:

My experience working in community-based settings with the "educated class," which is what we'll call students in university settings, is that universities as institutions themselves, along with the faculty, staff and students in general who populate them, tend to see themselves as problem solvers. Answers in search of problems. Solutions in search of problems. I don't want students to view the world that way. I don't think, in terms of sustainability, that is an approach that will go with social sustainability, which is about each of us informing each other and building stronger social networks, building social capital, binding social capital to use some of Putnam's terms. (D1)

The preceding excerpt acknowledges that the university should not be seen as the "fixers" or all-knowing, all-powerful source of knowledge and solutions in part because it is oppressive and is not a sustainable approach to problem solving. Rather, students are encouraged to collaborate, build social networks, and value input and opinions from all stakeholders. This mentality challenges a top-down, hierarchical approach that is typically favored by post-industrial, capitalistic societies and Western educational systems (Lindholm, 2007). A mindset and practice that values input and perspectives from all constituencies, such as the community, were found to be successful in developing sustainability education programs and developing learning communities by Barlow et al. (2005) and Comnes (2005). Valuing the knowledge and views of the community is a sustainable practice.

An extension of challenging traditional Western culture is that certain community building and respectful listening can even offer healing opportunities for populations who have been historically oppressed. Being engaged in the local community offers an 
opportunity for enhancing community and allowing healing through listening (B1; E2). When students, community members, and communities at large begin to understand their relatedness and their pasts, healing and deeper community building is possible. Instructor B noted this prospect in stating, "I think it's the nature of when communities come together with a deeper understanding of the past, and that we are related. I think it's offering opportunities for healing" (B1). Students in Course E read an article "Listening as Healing" and explore authentic listening as a means to be civically engaged, create community, and offer healing. Instructor B noted the positive prospects for community change as a result of listening by stating, "Through healing that past, we can change the future" (B1). This healing is a necessary part of acknowledging the past in order to move sustainably forward.

\section{Place-making.}

Fostering a connection to place is critical in sustainability education because of the way connection to place allows people to move from being "residents" to becoming "inhabitants" of a community and have a higher sense of care and duty, according to Orr (1992). When people feel connected to place they are more likely to be community and environmental stewards (Berg, 2005; Orr, 1992; Sobel, 2004). Place-making is a way of getting in touch with the "wisdom of place" and learning how to "listen to the earth again" because "we are all indigenous to some place," according to Instructor B (B1). A theme of place-making surfaced in all of the courses. Connection to place was an overt goal for Courses A, B, and E and a subtler outcome for Courses C and D.

A guest speaker speaks in Course E on place-making, community, and bioregionalism. Course B actually assigns a mapping activity for students to literally 
draw out and explore their bioregion and where they live, where their water and food comes from, what native animals or plants are in their backyards or neighborhoods, et cetera. Instructor B discussed the sense of belonging students gained in class as a result of place-making and self-discovery:

What's heartening is in just ten weeks, most of the people will share, through reflection, the discovery they've been on about where they belong....they [the students] ask the questions: 'Where do I belong? Who are my ancestors?' It's amazing that within the course of the term, and getting out and seeing where everyone lives, people get a sense of belonging. That's sustainability education. It's so much more, but that's the little piece of the world I'm operating in. (B1)

Effective sustainability education and place-making allows students to gain the sense of belonging described above. Sauvé (2005) identified a typology in the form of currents to map the pedagogical landscape of environmental education; two of these currents are the humanistic/mesological and bioregionalist currents that aim to allow students to know and appreciate their place and to develop a sense of belonging among students through sensorial, affective, cognitive, and experiential approaches. Place-making does exactly this. Course B challenges students to learn how to listen to the earth in a way common to Native American tradition and to explore their relationships with the earth and land because "the water still talks to us...the plants still welcome us singing" (B1); thus, Course B encourages place-making (B1). According to Instructor B, sustainability education should not "happen in a vacuum" and should include the history of our relationships and the responsibility we are born into; this responsibility is similar but unique to each region (B1). Course A includes a reflective journal that asks the students to observe the land and reflect on specific field related issues including how they are connected to the land; this type of reflection and land based experiences "really brings it 
alive" for the students (A1). Instructor A noted that they support service and communitybased work because of the attention these strategies pay to locale:

Ultimately what I really like about the capstone and service based work is it engages students in the local situation. If you look around the world, every place has different circumstances, and different people, and traditions, and ideas, and relationships. Sustainability, there's not a broad solution or practice that can be applied to every place. Every place is different. I think it's important to build that diversity and resilience within places. (A1)

To promote sustainability, education must be locally relevant (McKeown, 2002; Orr, 1992; Sterling; 2004). Education that will lead to sustainability, therefore, will enhance or promote students' connection to place and understanding of their locale. Instructor A elaborated on these ideals:

...just being engaged in the place that people live I think is a huge piece of sustainability education. The more students can learn about the places they live, be invested in them and take care of them, the better they can take care of them. Ultimately we're trying to nurture our communities so that they're resilient, thriving, and working together, connected to the larger whole. (A1)

Being engaged in one's locale or place is a sustainable practice. Instructor A showed agreement with Orr's (1992) and Sobel's (2004) views that students will be more invested and likely to take care of their communities and environment if they have learned about and become connected to their community and place (A1). Sustainability requires citizens who are able to live well where they are, to live well in place (G. A. Smith, 2002). This practice promotes the resiliency of communities.

Instructors A, B, and E communicated that classes ought to be held in the community in order to model what they value in terms of sustainability in the ways they teach and learn (A1; B1; E1). Therefore, it is important to teach within the context of place and community. Course B has a learning outcome for students to "reflect on how 
our relationship to place impacts our lives" (B2). Instructor B explained the impetus for this learning outcome in the following passage:

I think sustainability education, as I mentioned, is about teaching the next generation, passing on the wisdom of a place, practicing the behavior, and practicing the activities of a place, practicing or celebrating the passing, or the seasons of a place. (B1)

Sharing food, dance, and other ceremony rituals is vital to allow multiple groups and cultures to recognize they share a place together and thus is vital to community and sustainable living; a part of the capstone experience is recognizing the interrelatedness of all people but also that all people share a time and a place together (B1). Comprehension of these ideals simultaneously encourages relationship building, place-making, cultural sensitivity, and sustainable communities.

In sustainability education, it is essential to teach within the context of community and place. Being able to live well in place and in community are undoubtedly required skills and abilities for creating sustainable communities and for a shift to a sustainability paradigm. Community building in the classroom itself is an effective vehicle and model for fostering community beyond the class itself. Successful university-community partnerships are one avenue through which to challenge ideals of Western culture and capitalism and to value the knowledge, values, and skills of all stakeholders. If students are "engaged in context" they are more likely to feel "rooted in place" (E1). When people are connected to their communities and place an ethic of stewardship and strong, resilient communities are a promising product. The connectedness and relationships theme supports the importance of developing student-to-student relationships and relationship building skills while the community and place theme emphasizes the importance of 
building community in the class itself to create a sense of belonging for every student and between the class and the local community as well. In addition to community and place, diversity and inclusion are also critical elements of sustainability education.

\section{Diversity and Inclusiveness}

Diversity and inclusiveness are values among all the instructors interviewed. All five courses explore diversity issues in the content but also demonstrate an appreciation for diversity and inclusion through their process, practice, and perspectives. Incorporating diverse perspectives and critical discourse the way that these courses do is an essential part of a shift to a sustainability paradigm (Gruenewald, 2003a; Kaza, 1999). Instructor A commented that "Everyone should ultimately be able to come to the table of sustainability and have a discussion" (A1) while Instructor C stated that "Everyone has something to do with sustainability" (C1).

\section{Course atmosphere.}

Inclusiveness and safe spaces characterize the environments and atmospheres of the courses in this study. Poignantly articulating commitment to inclusion, Instructor C stated: "We want to create a safe space in class so that students don't feel judged....There's certainly principles of equity and inclusion that are written into the syllabus and appear when we meet in the classroom from day one" (C1). Instructor C utilizes consensus-based decision making for empowerment and stressed that the classroom must be a safe space because "students should never feel insulted in their place of learning" (C1). Emphasizing that sustainability is human oriented and must challenge oppressive social systems, Instructor $\mathrm{C}$ further contended that social sustainability ideals of inclusion are represented in their class via inclusive classroom practices, readings, and 
curriculum. Instructor B also teaches consensus building through studying Janet Armstrong's (2005) decision making model that the Okanagan tribes employed (B1). The intentional community building and cooperative learning groups discussed in the earlier sections also certainly demonstrates a commitment to inclusion of all students among all five instructors. Instructors ought to be aware of the demographics of the students coming into the classroom and include sustainability principles in equity and inclusion in the decision making process and through sitting in a circle throughout the course to embody positional equity $(\mathrm{B} 1 ; \mathrm{C} 1)$.

Family members, significant others, and others are involved in Course B as ways to acknowledge students' lives holistically and as a means to promote inclusion and intergenerational learning. Instructor B described this process:

These are senior capstones so they're often more mature students who have other relationships going on, and a lot to juggle. I want to be respectful of their time. I think that is another way the capstone is presented. I invite them to bring their kids, or significant others. I have had mothers come with their daughters or sons on our walks. The response is this is great, recognizing this educational experience isn't happening in a vacuum, but that the family can be part of it. We recognize in the native community that without health programs, our healthcare programs, or recovery programs, that you don't just treat the patient, all those horrible language things. It's a whole family thing. Unless the family is involved, real change becomes tougher. It's great that students can put their 8 month old on their back and come out. The classroom is multi-generational, and I hear positive things about that, that it was inclusive. (B1)

The practice of inviting students' significant others or children to class promotes both an inclusive, multigenerational learning environment but also is a way of viewing students holistically and "honoring the needs of students" (B1). Williams and Taylor (1999) suggest that a sustainability education model or school must have permeable boundaries and develop relationships with the local community through partnerships, service, and 
intergenerational learning. Cajete (1994) and Margolin (2005) also stress learning from the environment and intergenerational learning as necessary for a sustainable future.

\section{Curriculum and course learning outcomes.}

The content and learning outcomes of the courses in this study strongly supported the ideals of diversity and inclusiveness. Inclusion is a principle of sustainability and is critically explored by students in these five courses. Diversity of the human experience is a University Studies goal and is an implicit component of all senior capstone courses, including the five included in this study. All five courses included cultural diversity curriculum elements. Course A includes a unit on nourishing traditions and biocultural diversity where multicultural foods and traditions are the foci (A2). Course A has a learning outcome of expecting students to "Develop an understanding of how food issues impact diverse communities" (A2). Cultural food values, Native American perspectives, and indigenous traditions for food medicine, and ceremony are all critical elements of Course B; this represents a commitment to diversity of perspectives and cultural values. Further, Course B asks the students to discuss which Native American perspectives made the biggest impression on them (B2). Course D challenges students to "translate" valuable cultural lessons from their international experiences in environmental activism and community forestry practices for application to Portland non-profit organizations (D2). Students in Course D have lessons in the cultural heritage of their international service site, experience family home-stays, visit archaeological sites, and have daily language instruction (D2). Collectively, these course elements demonstrate a commitment to an informed cultural immersion experience whereby students gain a deep understanding, appreciation, and respect for the diverse culture in which their service 
takes place; they allow students to get to know "the smells and the noises" that make the culture unique (D1). Instructor D believes that study abroad courses are "ultimately part of the big sustainability circle" because they have students "go away to become better" and in this sense students are able to "close the loop" of learning. Course D asks students to come to class prepared to discuss "alternate perspectives" (D2). Course E incorporates diverse perspectives and considers diverse community demographics in course discussions on food security (E1; E2).

Critical discourse around inclusion and language usage occurs in Course C. Instructor $\mathrm{C}$ explained the rationale for this below:

The diversity of the human experience related to sustainability is all about inclusion. Students often come in saying 'We, we do this. We all want to have a hamburger. We all drive to McDonald's.' I want them to really consider who is "we"? They can do it in a local level. Who is "we" in Portland? Who has access to particular foods and who doesn't? Then they can make it broader by looking around the world. That's a total sustainability principle in the interconnectedness and access and inclusion theme. (C1)

To this end, students in Course $\mathrm{C}$ are challenged to reconsider the inclusivity of their language when using the term "we." This course establishes inclusion within the class but also challenges students to promote inclusion in society at large through questioning dominance, access, and equity issues impacting inclusion much like the critical dialogue Gruenewald (2003a) calls for. Tuitt (2009) posits that using diverse content and perspectives in class lets students know that their perspectives are welcomed; thus including diverse course content and perspectives helps create inclusive class environments.

Diversity sensitivity and cultural competency are important skills in community partnership and sustainability work. Cultural communication skills and diversity 
awareness and appreciation were learning goals or outcomes for many of the courses. Instructor B urges other instructors to honor the needs of the community partner and to first establish a relationship of trust and respect because many times instructors or university representatives do not have the cultural knowledge or sensitivity to best serve and work with diverse community organizations. Instructor B embodied this message when they stated, “...often times programs don't have the cultural competency to deliver the services. They know what they're good at, and they've identified a community that fits the protocol, but it doesn't honor the community in a culturally competent way" (B1). Gaining a cultural sensitivity to be able to work with and understand the experiences of diverse people is a learning outcome for Course $\mathrm{C}(\mathrm{C} 2)$. Course D includes learning goals for the students around learning about the culture of the United States and the international service site including food, language, customs, examining personal biases and prejudices related to non-United States cultures, increasing student awareness of poverty in the developing world, increasing students' ability to communicate across cultures and in diverse groups, and increase students' sensitivity to issues of diversity (D2). Instructor D proceeded to articulate that leaving one's own country and learning about other cultures helps one to learn about one's own culture (D1). Instructor E noted that their class "critically questions paradigms to include diverse perspectives...that we're not just accepting what is but we're thinking critically" (E1). Clearly, diversity and inclusion were foci of all five courses.

Sustainability is contingent upon all people being able to live peacefully together and "means people coming together to create good things" (B1). This requires global inclusion and appreciation of and respect for diverse perspectives, cultures, customs, 
foods, rituals, ceremonies, et cetera. Krapfel (1999) argues that ecological education must preserve and celebrate diversity and prevent the creation of a monoculture; education that values diversity and inclusion and requires cross-cultural collaboration approaches can ensure just that.

\section{Instructor Pedagogical Values, Sensitivity, and Intention Related to In-Class Community Development}

The preceding sections provide ample evidence for instructor values of connectedness and relationships, community and place, diversity and inclusiveness, cooperative, learner-centered, holistic learning, and student engagement, attendance, and participation. Collectively, these values contribute and reinforce the instructors' commitment to fostering in-class community development. Figure 1 depicts the relationship between these instructor values and the in-class community formation. The instructor pedagogical sensitivity and intention within these five courses is illustrated. A value of connectedness and relationships supports the instructors' desires for the students to develop relationships with and feel connected to their co-learners. Further, a commitment to community and place is expressed through building in-class community; local community engagement is an extension of the classroom community. In a strong community, all members ought to feel safe and honored and valued for their core identity; values of diversity and inclusion, thus, lead to a stronger in-class community. The inclusive techniques of sitting in a circle and consensus based decision making further bolster the in-class community. Further, the perspective of students that stresses cooperative learning and active student participation also leads to stronger class community through a co-learning and peer-based educational process. When students 
must work collaboratively and play an active role in their learning via group work, a more close-knit class community results. Figure 1 depicts the connections of the research themes covered earlier in this chapter. 


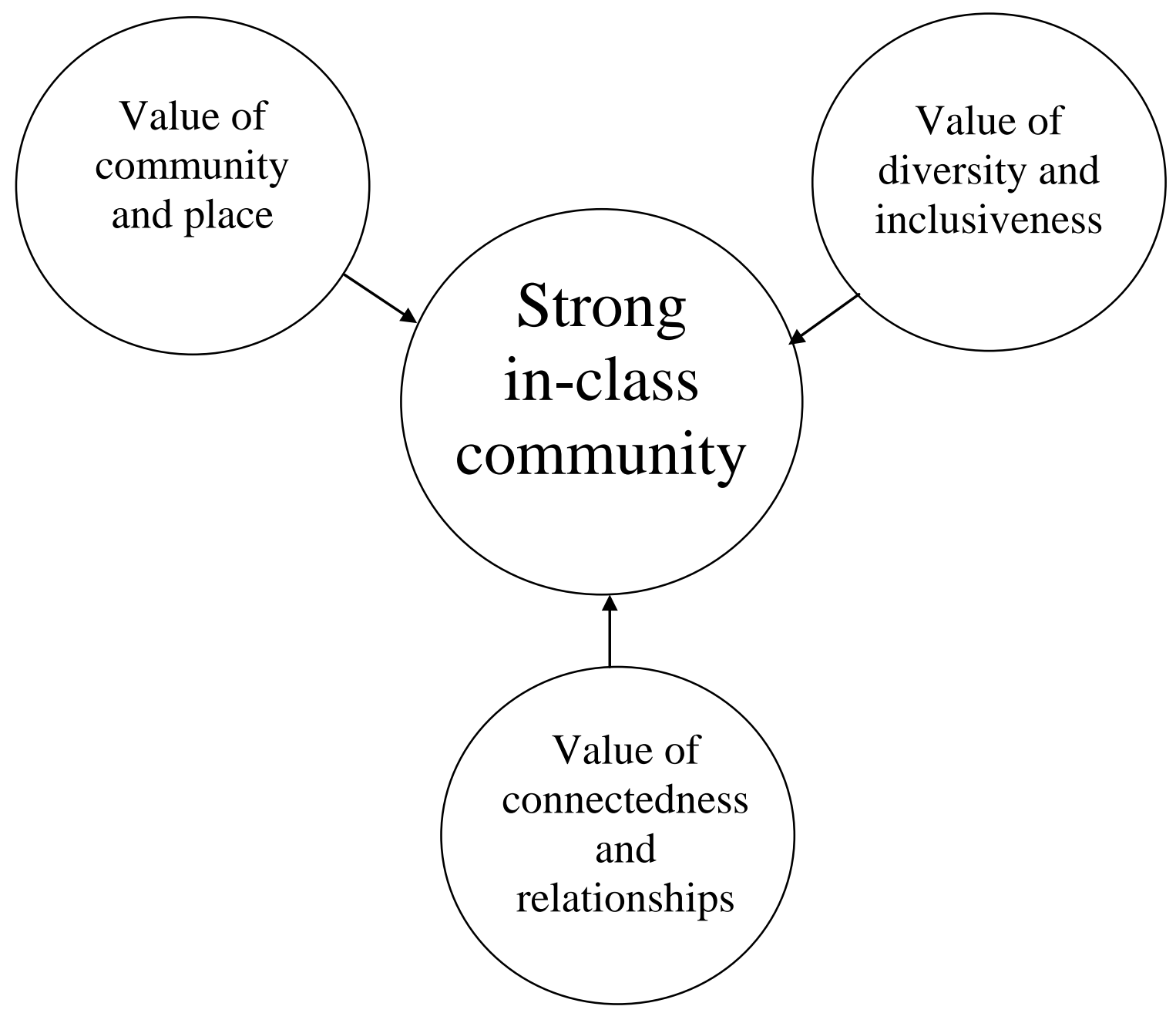

Figure 1. Instructor pedagogical values, sensitivity, and intention related to strong inclass community development. 


\section{Coupling Sustainability Education and Community-Based Learning}

This research provides convincing evidence for the use of community-based learning as a means to achieve more successful, meaningful, and relevant sustainability education. This study indicates that sustainability education and community-based learning ought to be coupled. Instructors of sustainability, community-based learning courses have understood values for connectedness and relationships, community and place, and diversity and inclusiveness. These values both contribute to and are reinforced by the instructors' pedagogical framework or model that includes use of reflection assignments as a key pedagogical tool, emphasis on active student participation and engagement, a perspective on students that values a collaborative, holistic, studentcentered learning process, and promotion of in-class community building among students. Figure 2 represents the ways that these emergent data themes are related. 


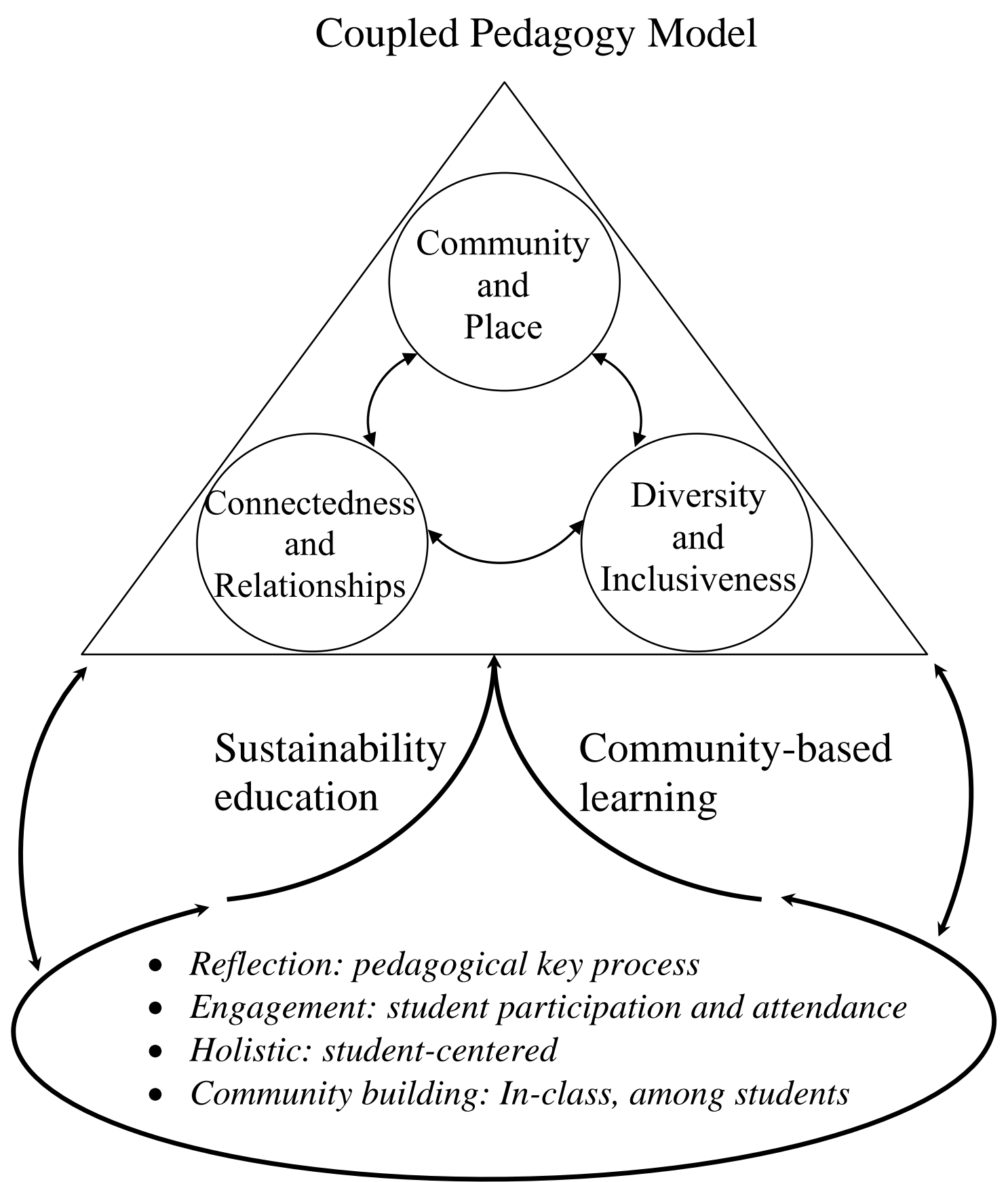

Figure 2. Pedagogical model of and values within the coupling of sustainability education and community-based learning 
All five instructors verbalized support for an evolving relationship between community-based learning and sustainability education based on the premise that community-based learning is an effective way to create learning experiences around sustainability. All five instructors provided compelling support for the coupling of sustainability education and community-based learning (A1; B1; C1; D1; E1). Many of the instructors noted that it does not make sense to separate or decouple communitybased elements from sustainability education and that many of the skills students need to successfully engage in sustainability work are also the same skills that students need to effectively participate in community work. This section summarizes the relationship between community-based learning and sustainability education revealed via the individual interviews.

Instructor $\mathrm{C}$ demonstrated support for the coupling of the two fields in stating, "I think if it's possible to do, community based learning is a great avenue towards really having an impactful educational experience around sustainability" (C1). While Instructor B noted that

I think they're [sustainability education and community-based learning] inseparable. I think the role of service is so fundamental in native leadership styles that you couldn't begin to separate them... They're [environmental education, Native American perspectives, and civic engagement] all connected. They go back to that sense of service, that sense of belonging, recognizing we are all connected, we are all related. Therefore how can we [the class] not be part of community engagement? (B1)

Because service, a sense of community and belonging, sustainability, and Native perspectives are so interconnected, it simply does not make sense to have a class about sustainability without also having community engagement. Being involved in and giving time to the community ensures that people know they are a part of something bigger than 
themselves (B1; E1). Sustainability "reinforces this ancient wisdom" that we are all related (B1). Reitenauer (2005) urges the use of service-learning as a way to facilitate the process of having students realize they are implicated in and part of their communities and have a connection to local issues.

Powerful support for utilizing community-based learning in sustainability education surfaced from the interview data. Instructor D epitomized this while describing the relationship between the two fields:

I do see them [community-based learning and sustainability education] linked, absolutely. I think you can do a very good community-based learning class, perhaps, and never mention the term sustainability. That doesn't mean the ideas behind sustainability or sustainability education won't be there. Probably you could do a course on sustainability that didn't include community-based learning. There probably are some examples here and in other universities across the country like that. For me, I can't conceive of how you'd do it. Here is why: I believe the community-based learning pedagogy is so strong, and that sustainability education is so human oriented, and that community-based learning is so strong on the human based orientation, to decouple them just doesn't make sense. It almost would be like trying to decouple the flour and the water you need to make a loaf of bread. I guess you could do it but I'm not really sure how. It's just better to have them coupled. (D1)

Community-based learning and sustainability education are linked in part because the sustainability ideals of inclusion, community, and human orientation undergird community-based learning. Instructor E provided a related yet unique perspective on the relationship between sustainability education and community-based learning:

It [community-based learning and sustainability education] really can't be separated. Without having a community context in some way, then what are we teaching sustainability for? It gives students a chance to...learn holistically, to practice what they're learning, to situate their learning in place, to think critically about what they're learning. All of those things are imbedded; they're all there. It gives students confidence. Students really feel confident that they've done something to affect change, or to create some kind of sustainable solution or process for somebody in the community. They have confidence to then take what they know, take what they've done and do something else similar or beyond. I 
think that's a really exciting thing. I think I'm coming to realize community-based learning, or ideally service-learning is the way to teach sustainability. I think it's so important. (E1)

Here, the point is made that it does not make sense to educate for sustainability if there is a not a community context for students to apply the sustainability knowledge to. The community-based element is necessary to allow students to practice and apply what they are learning, situate their learning in place, and gain a sense of agency and confidence to impact community change. Instructor $\mathrm{E}$ went as far as to say that community-based learning and service-learning are the ideal vehicles for sustainability education. Community-based learning provides the needed community and place contexts for sustainability education as noted in Instructor E's explanation:

One of the things I found in my dissertation work was that it's [linking of community-based learning and sustainability education] really important. Without community-based learning, or more specifically, I think, servicelearning, there is just limited amount of engagement and transformation really happening. I think service-learning, where students are really immersed in one particular context, really learning within that context, helps create the real transformation. You start to really see things differently, therefore actively want to make change in the future. I think it's essential. I think it's the direction all sustainability education needs to go. (E1)

Community context is absolutely imperative for transformative sustainability education, according to Instructor E. Instructor A expressed support for sustainability education that is rooted in the community by stating that "If all of our social institutions could be oriented around engagement in the community, we would have an amazing community" (A1); Instructor A noted that this change needs to happen on "every single level, in everything we do.” The coupling of sustainability education and community-based learning requires students to see the community differently and want to work for change in the future. Overwhelming support surfaced in this study for the coupling of 
community-based learning and sustainability education because of the more meaningful learning that can occur through their convergence. Further, evidence for the fact that the two fields cannot be separated was explained by the fact that community-based learning and sustainability education are linked tightly through their human based orientations and having similar ideals as a foundation. This research attests that all sustainability education should include community-based elements.

There was a general consensus within the interviews that a certain type of sustainability education could be completed without being community-based and that was a sustainability education that was focused on knowledge acquisition rather than skill development and personal and social transformation. This notion emerged when the instructors were asked if sustainability education can be done without it being community-based learning. This question elicited the following response from Instructor E, “I think it's helpful to have sustainability knowledge. I don't think knowledge is enough. I think it's important to learn some values that are associated with sustainability to understand some of the deeper purposes of the sustainability movement" (E1). The applied nature of community-based learning is central to it being a vehicle for deeper learning; "applied projects have a huge impact on people's understandings," according to Instructor C (C1). Instructor E stressed, "Process is so important" (E1). Instructor A noted the following:

I think on one level students can understand an aspect of it [sustainability] but the practice of sustainability, in order to teach that, it needs to be part of engaging with humanity. So much of it is ultimately back to that foundation of what is sustainability, understanding that we are part of the web of life. That can only be understood, you can't think about being part of the web. Yes, you can. You can think 'I am interconnected', but to experience your interconnection is entirely 
different. It's embodied knowledge versus facts. On one level yes, in the practice, no. (A1)

Skill cultivation requires different educational techniques than mere knowledge acquisition. Thinking about being a part of the web of life and actually experiencing it through a community-based experience is drastically different. Instructor C noted that he gives students opportunities to "actually get their hands dirty and see how much work it is to do farming" (C1). This provides a type of "embodied knowledge" that can only come from personal experience. Sustainability education is different because "It's personal, it's alive" (B1); it can only truly be personal and alive when it is experiential and community-based. The community-based pedagogy tends to allow both skill cultivation and value exploration; the community-based, experiential learning often is the component that allows learning to be more transformative. Instructor D commented,

They [community-based learning and sustainability education] absolutely have to evolve. They're coming together. I believe it is absolutely inevitable that these two formally disconnected strategies will come together more formally in the future, will continue to come more formally together. In other words, we talk about sustainability education, we're going to necessarily, I predict, talk more about community-based approaches. I may be creating a challenge, but I can't see currently, other than in class simulations, and readings, how you really get at the deepest levels of sustainability education. The kind of education I'm talking about are the personal transformations I like to see in students, personal transformations that move them significantly and substantively forward in terms of their own orientation toward the world. I can't see that kind of work happening without an opportunity to confront their own biases head on in challenging situations that are community-based. (D1)

Instructor D emphatically supports community-based learning as the way to create the deepest, most meaningful sustainability learning experiences that shift the way students view the world and allow them to "feel part of a larger system rather than...feeling a lack of hope." Instructor D was challenged to think of a way education could create personal 
transformations without being done in community-based settings (D1). Instructor E described similar views to Instructor D in terms of the transformative opportunities made possible by the community-based element. Instructor E stated,

I think you can [do sustainability education without community-based learning] but it's not nearly as, in my experience in teaching, it's not as transformative for students. If the goal is a transformational experience, which to me it is because students should not only learn information about sustainability, they should gain values and skills, and relationships to help them make decisions that will guide them towards a more sustainable place. If that is the goal, then community-based learning really needs to be a big part of all of the sustainability learning. (E1)

Instructor E asserted that community-based learning is needed to provide students with opportunities to gain skills and values in addition to knowledge. Community-based learning must be part of all sustainability learning if it is to be transformative. Many of the instructors feel that sustainability knowledge can be acquired without communitybased elements but that embodied, applied knowledge and cultivation of skills and values as well as transformative experiences are dependent upon a community-based learning experience being a part of sustainability education.

Sterling (2004) describes three orders of education related to sustainability: education about sustainability, education for sustainability, and education as sustainability. Education about sustainability is learning in a way that maintains the current mechanistic, transmissive educational paradigm that is based on content and knowledge transfer from the instructor to the student. Education for sustainability includes content but goes further to include values, skills, and reflection on the ideas of sustainability; the emphasis in education for sustainability is "learning for change" and includes critical and reflective thinking. Transformative learning occurs in education as sustainability due to a shift toward "learning as change." Education as sustainability 
stresses process and engages the whole person; learning is a continual process through practice and experience. This is transformative education. To this end, Eflin and Sheaffer (2011), Fagan (1996), Steiner and Posch (2007), Sterling (2004) and this study (A1; B1; D1; E1) attest that education about sustainability can occur without experiential, community-based elements but education for sustainability and certainly education as sustainability are simply not possible without a participatory, active process, such as community-based learning. Steiner and Posch (2007) corroborate these assertions related to the critical importance of community-based problem solving in sustainability education in stating, "Because of the dynamic of this process, students experience the process of sustainable development instead of purely memorizing its characteristics. The process of educating for sustainable development and practical applied sustainability therefore, becomes sustainable" (p. 877). Here, Steiner and Posch (2007) convey that only community-based sustainable education is in fact a sustainable process or form of education.

Other themes emerging from the interviews related to the relationship between sustainability and community-based learning were that being engaged in one's community is a sustainable practice and that there is considerable overlap between the skills needed to engage in community or civic affairs and the skills needed to participate in sustainable change. According to Instructor D, being focused on "human interaction to make a better place" is a commonality between sustainability and community-based learning. Instructor A commented that "Being engaged in your community is a sustainable practice.... They could be considered the same on one level. That community learning, learning through our community fosters sustainability" (A1). Community- 
based learning is a sustainable practice and fosters sustainability; therefore, coupling them is nearly unavoidable. Instructor E articulated the overlap in sustainability and community engagement skills in stating, "Absolutely. I see it [skills related to sustainability and skills related to good citizenship] really as the same thing.

Sustainability work is engaging. Civic work is engaging. It's doing, making change. Yes"

(E1). Instructor D provided more specific support for the overlap of skills here:

I think if you're good at, if you have an ability to thrive in community-based settings, or at least survive well enough in community-based settings, that presupposes you either will, or are currently, or have developed a certain set of skills. First and foremost are human interaction skills. How to speak well, present yourself well, be respectful, listen, ask good questions, be analytical, critical but with respect. You understand your own biases. You don't try to hide them. You're trying to work with them to transform them. Those are skills. Those are hardcore skills. Things that can be taught. The better you understand and have a grasp of those skills, the better, I believe, you'll be able to affect sustainability practices throughout your life, and affect others' sustainability practices at multiple levels the neighborhood level, the city level, regional, state, country, global levels. (D1)

Human interaction skills, communication skills, interpersonal skills, and respectful listening skills are essential for working in community-based settings and working for sustainability. Because sustainability work must take place within human systems, there is significant overlap in the skills needed for effecting change in the community and/or for sustainability. Instructor D further articulated this idea when they stated,

In general, if you're successful at engaging with community, then you're probably going to be more successful at understanding and effecting change around sustainability. There will be a positive relationship there. That is simply because, in my view, in the 21 st Century, most of sustainability is done in concert with human systems...In other words, if you're a better human because of communitybased learning, because you've had practice at being one, then you're probably going to be a better human at doing sustainability practices too, and vice versa. Whichever door you walk through, you're probably going to enter into a pretty similar living room, I believe. That living room is going to be the living room of human interaction to make a better place. (D1) 
This excerpt provides an argument that sustainability and community-based learning are essentially gateways or entryways for each other and will feed each other because of how related their goals are for creating a better community. To this end, an overlap in community engagement and sustainability skills makes logical sense.

The pedagogies of sustainability education and community-based learning should be intentionally coupled to provide the most optimal sustainability education experiences. Incorporating elements of sustainability into community work makes community engagement more meaningful and incorporating elements of community-based learning into sustainability education helps to complete sustainability education. Knowing sustainability principles and values makes work in the community more meaningful and more purposeful because people understand that they are part of a larger system. This positive relationship between sustainability education and community-based learning is partially due to the overlap in sustainability skills and community engagement skills. A limited amount of engagement and transformation happens without service-learning or community-based learning being intentionally included in sustainability education; it is much more powerful for students to participate and learn within local context. Including community-based elements in sustainability education allows the educational technique to model sustainability ideals and values in practice. As much as possible, communitybased learning ought to be incorporated into sustainability work.

\section{Conclusion}

The results described in this chapter provide deep insights into the research questions related to instructor perceptions on the relationship between community-based learning and sustainability education, if the community-based learning approach is 
beneficial in courses dealing with sustainability issues, and what pedagogical strategies or frameworks undergird courses that incorporate both sustainability education and community-based learning.

By coupling sustainability education and community-based learning, instructors value and prioritize connectedness and relationships, community and place, and diversity and inclusiveness; these values are evidenced by the instructors' stated course learning objectives, course structure, course assignments, course grading and evaluation, and/or pedagogical approaches in addition to their narrative descriptions of the rationale for their course approach. Further, the instructors in this study 1) utilize reflection as a way of engaging students in critical thinking, systems thinking, and personalizing sustainability; 2) develop intentional in-class community; 3) emphasize student class engagement; support cooperative, student-centered learning; and view their students holistically rather than as mere sponges who are to absorb and regurgitate knowledge presented in class.

When students were able to learn about sustainability with specific place-based and community interests, then the community gained, and student learning became relevant and meaningful according to the instructors. The findings have shown not only that community-based learning is a viable approach to sustainability education but that it may in fact be a critical way to do sustainability education. Because of the nature of sustainability, it is illogical to educate for sustainability if there is not relevancy provided in the form of a community context and agency cultivated through skill development and active, problem solving occurring via experiential learning. Without the communitybased learning or service-learning element, there would be a limited understanding and appreciation for sustainability among students. Because community building, 
collaboration, and community engagement are sustainable practices, community-based learning and sustainability education must be coupled for optimal learning, transformational impacts, and education as sustainability. 


\section{Chapter V}

\section{Recommendations and Conclusion}

This chapter expands upon the findings from the research by considering the significance and practical, pedagogical implications of the results. The recommendations based upon the findings of this study, institutional opportunities for implementation, suggestions for future research avenues, and a summary and conclusion are presented here.

The broad based implications of this study are that community-based learning and service-learning strategies can be employed in sustainability courses at the higher education level to ensure a significant amount of congruence between sustainability theory and practice as well as to allow for beneficial and transformative impacts to be felt for students and communities alike. This study also shows that education at all levels can benefit by being intentional with both the process of learning as well as the context of education. Sustainability education is more successful and meaningful when community engagement is an intrinsic part of the learning process. Furthermore, because there is such considerable overlap between the skills needed to engage successively in community and to do sustainability work, existing courses that include community-based learning or service-learning would benefit from including a distinct sustainability perspective or examining course content and community experiences through a sustainability lens. Similarly, existing courses that include sustainability content but do not yet utilize community-based methods would benefit by being restructured to thoughtfully incorporate community engagement. More tangible recommendations for higher education instructors and administrators can be found in the subsequent sections. 


\section{Recommendations for Higher Education Instructors}

This study reveals several values and priorities of the instructors as well as the orientation of instructors to both the learning process and their students as demonstrated through their course syllabi and interviews. Practitioners and educators in the sustainability education field must be intentional about and dedicated to providing community and local context for learning. Instructors successfully coupling communitybased learning and sustainability education have a perspective on students that values experiential learning, acknowledge the personal responsibility students must have for and active role they must play in their learning, value cooperative, peer-based learning groups, and understand the importance of multi-sensory learning that incorporates students' intellect and emotions. The values and priorities, connectedness and relationships, community and place, and diversity and inclusiveness, exhibited in courses and by instructors successfully coupling sustainability education and community-based learning led to various recommendations made here. The results of this study elicit the following recommendations for instructors in higher education who wish to link sustainability education and community-based learning:

- Value the process of learning as much as the content of education.

- Orient instructors as part of the process of learning and generation of meaning rather than outside of it.

- Encourage students to assume significant personal responsibility for their learning process and play an active role in their learning. 
- Acknowledge students holistically through striving to engage their five senses and their heads, hearts, and hands in the learning process. The following methods can be used to engage students' five senses:

- Hold class in the natural world or local community whenever possible.

- Assign projects or assignments that require immersion in the natural world.

- Promote creativity in the way assignments are allowed to be completed and presented in class such that art, poetry, music, song, dance, et cetera are options for students to express and convey their learning.

- Demonstrate value of connectedness and relationships:

- Stress the importance of relationship development between students and between students and the community to the overall goals of the course.

- Allow time for in-class community and relationship building.

- Hold class in the community and natural settings as much as possible to model a value for place and foster a connection to place.

- Assign projects that ask students to explore their relationships to elements of the community and world around them.

- Emphasize reflective practices in courses because they require students to explore connections and relationships; reflection is an ideal way to personalize topics of sustainability and also fuse the affective and cognitive domains.

- Consider using the concept of food as a way to introduce students to the interconnections between social, economic, political, and environmental 
systems as well as a as a means to personalize issues of sustainability; food is a ideal entry point to sustainability because it is a common human experience.

- Design courses and/or inquiry so that relationships between the content, readings, class activities, et cetera are acknowledged and made obvious to students to create a more holistic learning experience.

- Include learning outcomes related to developing relationship-building and collaboration skills in course syllabi.

- Honor the needs of the community partner through cultivating trusting, authentic relationships based on reciprocal exchanges.

- Demonstrate value of community and place:

- Allow time for in-class community and relationship building.

- View the community as the classroom and create permeable boundaries between the institutions of higher education and the community.

- Hold class in the community and natural settings as much as possible to model a value for place and foster a connection to place.

○ Include learning outcomes related to students' understanding their connection to place, community, and the earth's resources that sustain them in course syllabi.

- Assign projects that ask students to map or draw their bioregion and the resources provided by their bioregion that they rely on or interact with daily. 
Encourage students to consider how local problems and their solutions are specific and unique to locale yet connected to larger global issues through course discussion, reflective writing, or other mediums.

Abandon any perspective that attributes university faculty, staff, or students as "fixers" to community members or issues.

- Acknowledge that valuable, practical lessons can be learned through interacting with community members and agencies and not only via traditional mediums such as from university professionals or reading peerreviewed published literature.

- Consider respectful listening and story telling activities as potential opportunities for healing for populations that have been historically oppressed.

- Promote a collaborative, community-based approach to problem solving that incorporates the strengths of all.

- Demonstrate value for diversity and inclusiveness:

○ Honor diverse perspectives and cultural values in courses through selection of course readings, development of course learning outcomes, creation of course assignments, and seating of students in the classroom.

- Include as many issues of cultural, racial, ethnic, economic, age, ability, religious, sexual, gender, et cetera diversity as possible in course content.

○ Prompt students to include issues of diversity and culture in class discussions, written papers, and other assignments. 
- Ask student to think critically and challenge the status quo and dominant perspectives in course discussion and written work.

- Engage students in critical dialogue related to justice.

- Ensure inclusivity and an atmosphere of mutual respect and no judgment in the classroom (see also the recommendations for in-class community building below).

○ Include books, articles, art, poems, films, et cetera written or created by authors or artists of diverse backgrounds as part of the assigned course work.

- Provide space for students to share customs, rituals, or practices related to their identity or background as part of class whenever possible and relevant.

○ Include learning outcomes related to diversity sensitivity and cultural competency in course syllabi.

- Be intentional about in-class community building and creating safe learning spaces in order to promote inclusiveness, create a sense of belonging, cultivate relationship-building skills, and promote consistency in a value of community building both between class members and between class members and the local community with which the class is working. The following methods can be employed to achieve this:

○ Hold quick check-ins or icebreakers at the start of each class meeting. 
- Know the names of each student to ensure each student is a name and not a number; encourage the students to learn the names of each of their classmates.

$\circ$ Assign group projects and stress the importance of cooperative learning in the syllabus and in deed.

- Utilize consensus based decision making whenever possible.

- Hold class discussions and meetings in a circle orientation when possible to represent positional equity among class members.

All of the above recommendations will help to create more effective courses that couple sustainability education and community-based learning. Instructors should use as many of the recommendations as possible. The support of higher education administrators is crucial in creating an atmosphere that allows instructors the ability to consider and adopt these recommendations.

\section{Recommendations for Higher Education Administrators}

The values, priorities, and orientations of the instructors in this study appear to at least partially lead to their desire to both couple sustainability education and communitybased learning and to do it well. These could be an outcome of intrinsic or extrinsic influences or both. For optimal results both intrinsic and extrinsic factors would be at play in garnering instructor support of coupling community-based learning and sustainability education strategies. In addition to pressures from society itself, extrinsic pressures often come from the institution of higher education employing the instructor; higher education administrators have a large impact on the extrinsic pressures that instructors experience. The results of this study educe several recommendations for 
administrators in higher education who wish to further an agenda that allows coupling of community-based and sustainability education strategies:

- Value the process of learning as much as the content of education.

- Offer incentives and resources such as instructor trainings and course release time for instructors to create or restructure courses.

- Provide optional or mandatory instructor trainings on sustainability, sustainability education, and the impact of coupling community-based learning and sustainability education as well as instructor pedagogical support on how to execute community-based learning and sustainability education.

- Encourage instructors of existing community-based learning courses, senior capstones, and other culminating experiences that include community engagement to utilize a sustainability lens for their existing courses; encourage instructors of existing courses covering sustainability content to begin employing a communitybased learning approach.

- Consider including community engagement and sustainability related knowledge and skills as learning outcomes or objectives for the undergraduate general education curriculum.

- Do not wait until students' senior year to offer immersive community-based learning experiences.

- Create structures that allow small class size to provide the opportunity the deepest learning and more meaningful relationship building within the class. 
- Provide more room and time for course development in the workload of university instructors.

- Place a higher value on the quality of teaching in the promotion and tenure process.

- Work with the Education Department to incorporate sustainability education and community-based learning pedagogy in the pre-teaching training courses for future educators.

Higher education administrators are vital to creating a culture shift within academia that more readily values the process and relevancy of learning in postsecondary education in addition to sustainability teaching and learning. Adoption of any of the above recommendations will help to exert extrinsic motivators and pressures upon higher education instructors to couple community-based learning and sustainability education. There are numerous institutional barriers within higher education that will make integration and adoption of these recommendations challenging. These barriers as well as some promising opportunities are briefly reviewed and summarized in the next section.

\section{Potential Institutional Barriers and Opportunities for Recommendations}

The strong emphasis on research at many institutions of post-secondary education presents a major challenge and hurdle to the findings and recommendations described here. Boyer (1990) supports a scholarship of engagement and urges for a new paradigm for higher education that recognizes scholarly activity by university faculty outside of research and publication, including teaching and service. Boyer (1990), Gamson (2008), M. C. Taylor (2010), and Zemsky, Wegner, and Massy (2005), all question and critique the widespread faculty reward and promotion system that pushes faculty away from 
teaching and toward research. This system does not recognize the quality of undergraduate learning as a top institutional priority. The research culture also leads to college faculty being recruited predominantly according to their scholarly research rather than their teaching ability while prizing pure rather than applied research activities (Gamson, 2008). Because quality teaching and applied research are cornerstones to community-based learning and sustainability education, the research culture at many institutions detracts from the ability for a sustainability education agenda to be readily embraced. Furthermore, redesigning courses or creating new courses require restructuring or creating a syllabus, assignments, and readings, in addition to development of a strong community partnership; doing community-based learning and service-learning course design is a time intensive process (Battistoni, 2002; Eyler \& Giles, 1999; Reitenauer et al., 2005). Currently, many instructors do not have the time to devote to this process as a result of the priorities of the promotion and tenure process at most institutions. The promotion and tenure process, the publish or perish phenomenon, and priority on research over quality of teaching are all strong institutional barriers at many colleges and universities for implementing the recommendations presented here.

Jones, Selby, and Sterling (2010) identify three principal inhibiting conditions toward greater sustainability curriculum development at the postsecondary level. First, academic professionals have a propensity to guard their academic freedom and typically are so entrenched in their specialties that they are uncomfortable with the interdisciplinary teaching for which sustainability calls. Second, many academic staff consider themselves lacking the knowledge and skills to implement sustainability 
teaching and learning. Third, the ethos or culture of the institution may not be favorable for widespread sustainability education integration (Jones et al., 2010).

Aside from the research focus of many institutions, the feasibility of the implementation of the above recommendations is largely dependent upon institutional values, politics, and culture. Sustainability must be on an institution's agenda to make concerted progress in these areas. The culture of an institution largely dictates the campus politics as well as how readily the promotion and tenure process for faculty could be altered. All of these factors must be considered when trying to impact long-term change and a campus' ethos and values.

Culture is the social or normative glue based on shared values and beliefs that holds an organization or group of people together (Kuh \& Whitt, 1988). Culture conveys a sense of identity, enhances the stability of an organization's social system, facilitates a commitment to an entity other than itself, and helps guide and shape behavior (Kuh \& Whitt, 1988). The mere definition of culture evidences the need to take the culture of the institution into account when pushing for institutional shifts toward more sustainability education and community based-learning. Sustainability must be a value and part of the culture of an institution for these recommendations to be feasible or taken seriously. Some of the features of institutional culture such as historical roots, the personnel core, the founders and leaders, the social environment, artifactual manifestations such as customs, ceremonies, and rituals, and the core values and beliefs transmitted by norms (Kuh \& Whitt, 1988) represent entry points for impacting campus cultures. Shifting culture takes time and is a gradual process, particularly within colleges and universities 
(Kuh \& Whitt, 1988). Thus, the ability to increase a campus' receptivity to these recommendations will likely be a very slow process.

Even after sustainability is part of an institutional culture or agenda, the organizational structure must be understood so that organizational change can occur efficiently. Many institutions of higher education operate predominantly via vertical coordination or top-down management and decision-making, rather than horizontal or lateral coordination (Bolman \& Deal, 2008). This type of organizational structure makes it difficult to implement change when it is not the idea of upper management and administration. Furthermore, Sterling (2004) argues that the organizational and management structure under a mechanistic paradigm of education is controlled in a topdown fashion while the organizational and management structure under an ecological paradigm of education is democratic and participative. Institutions operating more under an ecological paradigm would likely have a management and organizational structure that is more receptive to change and sustainability education. Nonetheless, the organizational structure of an institution is a crucial factor and potential barrier for the implementation of the recommendations stemming from this study.

However, these recommendations are not totally unreasonable and overzealous. There is much acceptance of sustainability in higher education now and this acceptance continues to grow. A large number of institutions have started placing a higher priority on sustainability in recent years (AASHE, 2009). Despite the recession, AASHE membership grew by $17 \%$ in 2009 with institutions of higher education, the largest membership segment, growing by $23 \%$, from 591 members to 728 at the end of 2009 (AASHE, 2009). Further, AASHE saw a significant increase in registrants for 
sustainability curriculum workshops and in web visitors in 2009 compared to 2008 with a $23 \%$ increase in total page views (AASHE, 2009). AASHE was officially launched in 2006 and has seen steady growth in membership and interest among institutions of higher education since its launch date. The increase in AASHE activity evidences the growing acceptance for sustainability and sustainability education in higher education.

In addition, service-learning and civic education programs are also on the rise across the higher education landscape (Battistoni, 2002; Colby et al., 2003). The President's Higher Education Community Service Honor Roll, the Carnegie Classification, Campus Compact, American Association of Community Colleges, and the National Service-Learning Clearinghouse are all awards, recognitions, and organizations that support colleges and universities doing service-learning work that have emerged since the mid 1980s when there was a resurgence of interest in campus service and service-learning (Learn and Serve America's National Service-Learning Clearinghouse, 2008). Furthermore, a growing number of prospective college students, about $64 \%$, want information about a college's commitment to environmental and sustainability issues during the college selection process and about a quarter of students report that this information will strongly contribute to their assessment of a school (Princeton Review, 2010). Institutions of higher education will need to respond to the growing interest and priority prospective students are putting on sustainability course offerings and practices. Instructors and higher education administrators alike can capitalize on the momentum and energy that already exists around sustainability and service-learning in higher education. There is and will continue to be a growing need for strong pedagogical models 
that have the potential to prepare students with sustainability values, skills, and knowledge in addition to a sustainability and justice orientation toward the world.

\section{Suggestions for Further Research}

Because the results of this study are limited to five courses, five instructors, and

five syllabi at a single university, the options for future research projects and studies that expand this topic are vast. It would be valuable to conduct a similar study at several other institutions that vary by geographic region, population size of the local community, institutional type, and institutional size to compare and contrast the results collected. Additionally, it would be constructive to design a study to better characterize the type of student learning and community impact that occurs as a result of the values, priorities, and pedagogical framework common to courses that couple sustainability education and community-based learning that are presented here; this type of study ought to include interviews with students, community partners, and instructors. It would also be beneficial to conduct a study that serves to characterize the student learning outcomes and impacts of sustainability courses that both include and do not include community-based learning. Further, it would be interesting to explore what higher education instructors and administrators perceive to be the challenges or liabilities in implementing or institutionalizing the recommendations included in this chapter as well as their motivations for trying to employ sustainability education and community-based learning strategies. Along this line, it would be desirable to research potential educational policy changes that would provide room for more courses that coupled sustainability education and community-based learning. Another direction for future research is to focus on creating a best practices guide for coupling sustainability education and community- 
based learning based upon experiences and advice from instructors, administrators, students, and community partners.

\section{Summary and Conclusion}

As a result of the urgent need to preserve natural systems, biodiversity, and cultures, we must end irresponsible ecological, economic, and cultural practices; postsecondary educational institutions have a responsibility in achieving this, in addressing sustainability. Currently, higher education is largely unable to fulfill its civic mission adequately or address sustainability as a result of antiquated, mechanistic educational models that do not recognize teaching and learning as a top institutional priority or provide students with ample opportunities to reflect on their role in achieving a more sustainable world, imagine a world that is sustainable and livable, or develop the capacity to be agents for change.

This research provides a cogent argument for employing community-based learning as an ideal pedagogical strategy for providing optimal sustainability education. Daily life and local social and environmental problems must not be a side note to education, they should be education itself. Learning and knowing ought not be passive experiences. Student empowerment, agency, and skills cannot be effectively cultivated without the presence of active, experiential learning within community contexts. If higher education does not provide students with an education that includes sufficient doses of both relevancy and agency, we are doing a disservice to both the students and our communities; community-based learning provides relevancy and builds student agency. Relevancy and agency can be developed and enhanced via experiential, place-based 
education such as what occurs via the coupling of sustainability education and community-based learning.

Most often, the ideas and goals behind sustainability or sustainability education are present in all effective community-based learning classes, even if the term sustainability is not ever explicitly mentioned because of how much both fields stress being human oriented, building relationships, creating connections, and reducing inequality. In order to achieve the most meaningful and transformative learning experiences, community-based learning cannot be separated or decoupled from sustainability education. As the instructors in this study have indicated, being engaged in the community recognizes that we are part of something bigger than ourselves and improves the vitality of community. Effective skills related to sustainability work and effective skills related to civic engagement and good citizenship are very similar; both are about diversity sensitivity, communication, collaboration, being engaged, and making change. The concepts of connectedness and relationships, community and place, and diversity and inclusiveness are salient priorities in courses coupling sustainability education and community-based learning. Additionally, the instructors in this study emphasized collaborative learning, student personal responsibility, a holistic perspective on students, in-class community development, and student engagement. Further, employing a variety of reflective assignments as vehicles for both personalizing sustainability and challenging students to make connections between themselves and the course content and community experiences is an optimal strategy in sustainability courses. 
While the community-based learning and sustainability education fields are formally distinct and disconnected in higher education currently, it is likely that the two fields and strategies will more formally converge in the future as a result of overlap is skill base and human orientation, as well as the growing understanding of the interconnectedness between ecological and social community problems. However, it is important to note that not all community-based learning will or has to be about sustainability because of the emphasis of sustainability on environmental concerns and the interconnectedness between ecological, social, and economic systems. For example, tutoring or mentoring inner city school children may serve as an excellent forum for community-based learning for undergraduate elementary education major; however, it is not an example of sustainability education because of the absence of environmental concerns. While not all community-based learning will also be sustainability education, the most meaningful, relevant forms of sustainability education will include communitybased learning and community contexts.

Furthermore, if the goal of sustainability education is that students explore values, cultivate skills, and build relationships, in other words experience deeper levels of sustainability, community-based learning must be built into the learning experience. This study provides persuasive support for the notion that community-based learning is in fact an optimal way to teach sustainability. Teaching sustainability without community-based learning or service-learning is paradoxical because of the inherent values associated with sustainability and sustainability education. Without having a community context in some way, teaching sustainability loses significant meaning. Pedagogy should be living, and coupling sustainability education with community-based learning ensures that pedagogy 
is responsive and sensitive to local concerns, and best prepares students to deal with the growing number and complexity of issues that must be addressed in order to achieve a more sustainable, just, and livable future. Education that addresses sustainability must equip students to live well in place, embrace learning as a lifelong process, understand the complexity and interconnectedness of sustainability issues, and commit to sustainability as a lifestyle. Tilbury, Hamu, and Goldstein (2002) agree that sustainability education must move away from traditional educational models in order to create learning that takes place outside the walls of a school building and within the context of local community in stating, "In fact, sustainable development calls for additional and different processes than those traditionally thought of in education. The quest for sustainability demands new approaches to involve people, rather than convey just a body of knowledge" (p. 12). Simply put, the most effective forms of sustainability education readily employ community-based approaches and encourage sustainable community engagement as both a mindset and lifestyle. 


\section{References}

Allen-Gil, S., Walker, L., Thomas, G., Shevory, T., \& Shapiro, E. (2005). Forming a community partnership to enhance education in sustainability. International Journal of Sustainability in Higher Education, 6(4), 392-402.

Alvarez, A., \& Rogers, J. (2006). Going "out there": Learning about sustainability in place. International Journal of Sustainability in Higher Education, 7(2), 176-188.

Armstrong, J. C. (2005). En'owkin: decision making as if sustainability mattered. In M. K. Stone \& Z. Barlow (Eds.), Ecological literacy: Educating our children for a sustainable world (pp. 11-17). San Francisco: Sierra Club Books.

Association for the Advancement of Sustainability in Higher Education (AASHE). (2009). AASHE 2009 annual report. Association for the Advancement of Sustainability in Higher Education. Retrieved July 22, 2010 from http://www.aashe.org/highlights/press-releases/aashe-releases-2009-annual-report

Astin, A.W., \& Astin, H.S. (2000). Leadership reconsidered: Engaging higher education in social change. Ann Arbor, MI: W.K. Kellogg Foundation.

Barlow, Z., Marcellino, S. \& Stone, M. K. (2005). Leadership and the learning community. In M. K. Stone \& Z. Barlow (Eds.), Ecological literacy: Educating our children for a sustainable world (pp. 149-160). San Francisco: Sierra Club Books.

Barr, R. B. \& Tagg, J. (1995). From teaching to learning - A new paradigm for undergraduate education. Change, 27(6), 13-25.

Barth, M., Godemann, J., Rieckmann, M., \& Stoltenberg, U. (2007). Developing key competencies for sustainable development in higher education. International Journal of Sustainability in Higher Education, 8(4), 416-430.

Battistoni, R. M. (2002). Civic engagement across the curriculum: A resource book for service-learning faculty in all disciplines. Providence, RI: Campus Compact.

Berg, P. (2005). Finding your own bioregion. In M. K. Stone \& Z. Barlow (Eds.), Ecological literacy: Educating our children for a sustainable world (pp. 126134). San Francisco: Sierra Club Books.

Bloom, A. (1987). The closing of the American mind. New York: Simon and Schuster.

Bolman, L. G. \& Deal, T. E. (2008). Reframing organizations: Artistry, choice, and leadership. San Francisco: Jossey-Bass. 
Bowers, C. A. (1995). Educating for an ecologically sustainable culture: rethinking moral education, creativity, intelligence, and other modern orthodoxies. Albany, NY: SUNY Press.

Bowers, C. A. (1999). Changing the dominant cultural perspective in education. In G. A. Smith \& D. R. Williams (Eds.), Ecological education in action: On weaving education culture, and the environment (pp 161-178). Albany, NY: SUNY Press.

Bowers, C. A. (2000). Let them eat data: How computers affect education, cultural diversity, and the prospects of ecological sustainability. Athens: University of Georgia Press.

Boyer, E. L. (1987). College: The undergraduate experience in America. New York: Harper \& Row Publishers.

Boyer, E. L. (1990). Scholarship reconsidered: Priorities of the professoriate. Princeton, NJ: The Carnegie Foundation for the Advancement of Teaching.

Boyer, E. L. (1995). The basic school: A community for learning. Princeton, NJ: The Carnegie Foundation for the Advancement of Teaching.

Boyte, H. C. (2004). Everyday politics: Reconnecting citizens and public life. Philadelphia: University of Pennsylvania Press.

Boyte, H. C. (2008). The citizen solution. St. Paul: Minnesota Historical Society Press.

Brown, J. (2005). Meditations on an apple. In M. K. Stone \& Z. Barlow (Eds.), Ecological literacy: Educating our children for a sustainable world (pp. 184189). San Francisco: Sierra Club Books.

Burns, H. (2009). Education as sustainability: An action research study of the Burns model of sustainability pedagogy. Dissertation, Portland State University, Educational Leadership, Portland.

Butin, D. W. (2006). The limits of service-learning in higher education. The Review of Higher Education, 29(4), 473-498.

Cajete, G. (1994). Look to the mountain: An ecology of indigenous education. Skyland, NC: Kivaki Press.

Callenbach, E. (2005). Values. In M. K. Stone \& Z. Barlow (Eds.), Ecological literacy: Educating our children for a sustainable world (pp. 45-48). San Francisco: Sierra Club Books. 
Capra, F. (1996). The web of life: A new scientific understanding of living systems. New York: Doubleday, Anchor Books.

Capra, F. (2005). Speaking nature's language: Principles of sustainability. In M. K. Stone \& Z. Barlow (Eds.), Ecological literacy: Educating our children for a sustainable world (pp. 18-29). San Francisco: Sierra Club Books.

Carver, R. L. (1996). Theory for practice: A framework for thinking about experiential education. The Journal of Experiential Education, 19(1), 8-13.

Carver, R. L. (1997). Theoretical underpinnings of service learning. Theory into Practice, 36(3), 143-149.

Chávez, A. F. \& Guido-DiBrito, F. (1999). Racial and ethnic identity development. New Directions for Adult and Continuing Education, 84, 39-47.

City of Portland. (2010). Bureau of Planning and Sustainability. Portland Online. Retrieved July 20, 2010 from http://www.portlandonline.com/bps/index.cfm?

Cohen, B. (2007). Developing educational indicators that will guide students and institutions toward a sustainable future. In L.H. Litten \& D. G. Terkla (Eds.). New Directions for Institutional Research: Number 134. Advancing Sustainability in Higher Education (pp. 83-94). San Francisco: Jossey-Bass.

Colby, A., Ehrlich, T., Beaumont, E., \& Stephens, J. (2003). Educating citizens: Preparing America's undergraduates for lives of moral and civic responsibility. San Francisco: Jossey-Bass.

Collier, P. J. \& Williams, D. R. (2005). Reflection in action: The learning-doing relationship. In C. M Cress, P. J. Collier, V. L. Reitenauer \& Associates. (2005). Learning through serving: A student guidebook for service-learning across the disciplines (pp 83-99). Sterling, VA: Stylus Publishing, LLC.

Comnes, L. (2005). Revolution step-by-step: On building a climate for change. In M. K. Stone \& Z. Barlow (Eds.), Ecological literacy: Educating our children for a sustainable world (pp. 135-148). San Francisco: Sierra Club Books.

Corcoran, P. B. (2010). Sustainability education in higher education: Perspectives and practices across the curriculum. In P. Jones, D. Selby, \& S. Sterling (Eds.) (2010). Sustainability education: Perspectives and practice across higher education (pp xiii-Xv). London, UK: Earthscan.

Corney, G. \& Reid, A. (2007). Student teachers' learning about subject matter and pedagogy in education for sustainable development. Environmental Education Research, 13(1), 33-54. 
Correia, M. G. \& Bleicher, R. E. (2008). Making connections to teach reflection. Michigan Journal of Community Service Learning, 14(2), 41-49.

Cortese, A. D. (2003). The critical role of higher education in creating a sustainable future. Planning for Higher Education, 31(3), 15-22.

Cotton, D. R. E., Warren, M. F., Maiboroda, O., \& Bailey, I. (2007). Sustainable development, higher education, and pedagogy: a study of lecturers' beliefs and attitudes. Environmental Education Research, 13(5), 579-597.

Cotton, D. \& Winter, J. (2010). 'It's not just bits of paper and light bulbs': A review of sustainability pedagogies and their potential use in higher education. In P. Jones, D. Selby, \& S. Sterling (Eds.) (2010). Sustainability education: Perspectives and practice across higher education (pp 39-54). London, UK: Earthscan.

Cranton, P. (2002). Teaching for transformation. New Directions for Adult and Continuing Education, 93, 63-71.

Cress, C. M. (2005). What is service-learning?. In C. M Cress, P. J. Collier, V. L. Reitenauer \& Associates (Eds). (2005). Learning through serving: A student guidebook for service-learning across the disciplines (pp 7-16). Sterling, VA: Stylus Publishing, LLC.

DeLind, L. B. \& Link, T. (2004). Place as the nexus of a sustainable future: A course for all of us. In P. F. Barlett \& G. W. Chase (Eds.), Sustainability on campus: Stories and strategies for change (pp. 121-137). Cambridge, MA: Massachusetts Institute of Technology.

Dewey, J. (1902). “The school as social centre,” The Middle Works, 1899-1924, vol. 2. Carbondale: Southern Illinois University Press.

Dewey, J. (1916). Democracy and education. New York: The Free Press.

Dewey, J. (1938). Experience and education. New York: Macmillan.

Domask, J. J. (2007). Achieving goals in higher education: An experiential approach to sustainability studies. International Journal of Sustainability in Higher Education, 8(1), 53-68.

Dorado, S. \& Giles, Jr., D. E. (2004). Service-learning partnerships: Paths of engagement. Michigan Journal of Community Service Learning, 11(1), 25-36.

Eby, J. W. (1998). Why service-learning is bad. Retrieved June 22, 2011, from www.messiah.edu/external_programs/agape/service_learning/articles/wrongsvc.p df 
Edwards, A. R. (2005). The sustainability revolution: Portrait of a paradigm shift. Gabriola Island, BC: New Society Publishers.

Eflin, J. \& Sheaffer, A. L. (2011). Service-learning in watershed-based initiatives: Keys to education for sustainability in geography? Journal of Geography, 105(1), 3344.

Eyler, J. (2000). What do we need to know about the impact of service-learning on student learning? Michigan Journal of Community Service Learning, Special Issue (Fall), 11-17.

Eyler, J. \& Giles, D. E. (1999). Where's the learning in service-learning? San Francisco: Jossey-Bass.

Eyler, J., Giles, D. E., \& Schmiede, A. (1996). A practitioner's guide to reflection in service-learning: Student voices and reflections. Nashville, TN: Vanderbilt University Press.

Fagan, G. (1996). Community-based learning. In J. Huckle \& S. Sterling (Eds.), Education for sustainability (pp 136-148). London: Earthscan Publications Limited.

Felten, P., Gilchrist, L. Z., \& Darby, A. (2006). Emotion and learning: Feeling our way toward a new theory of reflection in service-learning. Michigan Journal of Community Service Learning, 12(2), 38-16.

Freire, P. (1970). Pedagogy of the oppressed. New York: Continuum Publishing.

Gadotti, M. (2008). What we need to learn to save the planet. Journal of Education for Sustainable Development, 2(21), 21-30.

Gamson, Z. F. (2008). The stratification of the academy. In J. H. Ballantine and J. Z. Spade (Eds.). Schools and society: A sociological approach to education (third edition) (pp 383-388). Victoria, AU: Wadsworth.

Gay, L. R., Mills, G. E., \& Airasian, P. (2009). Educational research: Competencies for analysis and application. $9^{\text {th }}$ edition. Upper Saddle River, NJ: Merrill Prentice Hall.

Geiger, R. L. (2002). Differentiation, hierarchy, and diversity: An overview of higher education in the United States. In R. McC.Adams (Ed.), Trends in American \& German higher education (pp 19-32). Cambridge: American Academy of Arts and Sciences. 
Giles, D. E. \& Eyler, J. (1994). The theoretical roots of service-learning in John Dewey: Toward a theory of service-learning. Michigan Journal of Community Service Learning, 1(1), 77-85.

Gruenewald, D. A. (2003a). The best of both worlds: A critical pedagogy of place. Educational Researcher, 32(4), 3-12.

Gruenewald, D. A. (2003b). Foundations of place: A multidisciplinary framework for place-conscious education. American Educational Research Journal, 40(3), 619654.

Harkavy, I. \& Blank, M. (2002). Community schools: A vision of learning that goes beyond testing. Education Week, April 17, 2002.

Hass, R. (2005). On watershed education. In M. K. Stone \& Z. Barlow (Eds.), Ecological literacy: Educating our children for a sustainable world (pp. 107-110). San Francisco: Sierra Club Books.

Hatcher, J. A., Bringle, R. G., \& Muthiah, R. (2004). Designing effective reflection: What matters to service-learning? Michigan Journal of Community Service Learning, 11(1), 38-46.

Hawken, P. (2007). Blessed Unrest. New York: Penguin Group.

Hollister, R. M., Wilson, N., Levine, P. (2008). Educating students to foster active citizenship. Association of American Colleges \& Universities Peer Review, Spring/Summer 2008, 18-21.

Hopkins, C. \& McKeown, R. (2001). Education for sustainable development: Past experience, present action and future prospects. Educational Philosophy and Theory, 33(2), 231-244.

hooks, b. (1994). Teaching to transgress: Education as the practice of freedom. New York: Routledge.

Illich, I. (1990). To hell with good intentions. In J. C. Kendall (Ed.), Combining service and learning: A resource book for community and public service (pp. 314-320). Raleigh, NC: National Society for Internships and Experiential Education.

Institute of Educational Sciences (2008). Retrieved December 20, 2010 from http://ies.ed.gov/

Jones, P., Selby, D., \& Sterling, S. (2010). Introduction. In P. Jones, D. Selby, \& S. Sterling (Eds.) (2010). Sustainability education: Perspectives and practice across higher education (pp 1-16). London, UK: Earthscan. 
Kaza, S. (1999). Liberation and compassion in environmental studies. In G. A. Smith \& D. R. Williams (Eds.), Ecological education in action: On weaving education culture, and the environment (pp 143-160). Albany, NY: SUNY Press.

Keen, C. \& Baldwin, E. (2004). Students promoting economic development and environmental sustainability: An analysis of the impact of involvement in a community-based research and service-learning program. International Journal of Sustainability in Higher Education, 5(4), 384-394.

Kiefer, J. \& Kemple, M. (1999). Stories from our common roots: Strategies for building an ecologically sustainable way of learning. In G. A. Smith \& D. R. Williams (Eds.), Ecological education in action: On weaving education culture, and the environment (pp 21-46). Albany, NY: SUNY Press.

Knapp, C. E. (2005). The "I-Thou" relationship, place-based education and Aldo Leopold. Journal of Experiential Education, 27(3), 277-285.

Knight, J. K. \& Wood, W. B. (2005). Teaching more by lecturing less. Cell Biology Education, 4(4), 298-310.

Krapfel, P. (1999). Deepening children's participation through local ecological investigations. In G. A. Smith \& D. R. Williams (Eds.), Ecological education in action: On weaving education culture, and the environment (pp 47-64). Albany, NY: SUNY Press.

Krasny, M. E. \& Tidball, K. G. (2010). Applying a resilience systems framework to urban environmental education. Environmental Education Research, 15(4), 465482.

Kuh, G. D. (2008). High-impact educational practices: What they are, who has access to them, and why they matter. Washington, DC: Association of American Colleges and Universities.

Kuh, G. D. \& Whitt, E. J. (1988). The invisible tapestry: Culture in American colleges and universities. ASHE-ERIC Higher Education Reports, 17(1). 1-154.

Lappé, F. M. (2007). Getting a grip: Clarity, creativity, and courage in a world gone mad. Cambridge, MA: Small Planet Media.

Largent, L. \& Horinek, J. B. (2008). Community colleges and adult service-learners: Evaluating a first-year program to improve implementation. New Directions for Adult and Continuing Education, 118, 37-48.

Learn and Serve America's National Service-Learning Clearinghouse. (2008). History of Service-Learning in Higher Education. National Service-Learning Clearinghouse. 
Retrieved April 23, 2011 from http://www.servicelearning.org/what_is_servicelearning/history_hesl

LeCompte, M. D. \& Schensul, J. J. (1999). Designing and conducting ethnographic research. Lanham, MD: AltaMira Press.

Lindholm, J. A. (2007). Spirituality in the academy: Reintegrating our lives and the lives of our students. About Campus, 12(4), 10-17.

Longo, N. V. (2007). Why community matters: Connecting education with civic life. State Albany, NY: University of New York Press.

Louv, R. (2005). Last child in the woods: Saving our children from nature-deficit disorder. Chapel Hill, NC: Algonquin Book of Chapel Hill.

Margolin, M. (2005). Indian pedagogy: a look at traditional California Indian teaching techniques. In M. K. Stone \& Z. Barlow (Eds.), Ecological literacy: Educating our children for a sustainable world (pp. 67-79). San Francisco: Sierra Club Books.

McKeown, R. (2002). Education for Sustainable Development Toolkit, version 2. http://www.esdtoolkit.org. Knoxville: University of Tennessee, Waste Management Research and Education Institute.

McKeown, R. (2003). Working with K-12 schools: Insights for scientists. BioScience, 53(9), 870-875.

Merkel, J. \& Litten, L. H. (2007). The sustainability challenge. In L.H. Litten \& D. G. Terkla (Eds.). New Directions for Institutional Research: Number 134. Advancing Sustainability in Higher Education (pp. 7-36). San Francisco: Jossey-Bass.

Meadows, D. (2005). Dancing with systems. In M. K. Stone \& Z. Barlow (Eds.), Ecological literacy: Educating our children for a sustainable world (pp. 193205). San Francisco: Sierra Club Books.

Mezirow, J. (1991). Transformative dimensions of adult learning. San Francisco: JosseyBass.

Michael, P. (2005). Helping children fall in love with the earth: Environmental education and the arts. In M. K. Stone \& Z. Barlow (Eds.), Ecological literacy: Educating our children for a sustainable world (pp. 111-125). San Francisco: Sierra Club Books. 
Mitchell, T. D. (2008). Traditional vs. critical service-learning: Engaging the literature to differentiate two models. Michigan Journal of Community Service Learning, $14(2), 50-65$.

Moore, J. (2005). Seven recommendations for creating sustainability education at the university level: A guide for change agents. International Journal of Sustainability in Higher Education, 6(4), 326-339.

Moravec, M., Williams, A., Aguilar-Roca, N., \& O’Dowd, D. K. (2010). Learn before lecture: A strategy that improves learning outcomes in a large introductory biology class. CBE Life Sciences Education, 9(4), 473-481.

Morrison, J. (2003). U.S. higher education in transition. On the Horizon, 11(1), 6-10.

Morrow, S. (2005). Quality and trustworthiness in qualitative research in counseling psychology. Journal of Counseling Psychology, 52(2), 250-260.

Murphy, T. (2010). Conversations on engaged pedagogies, independent thinking skills and active citizenship. Issues in Educational Research, 20(1), 39-46.

Nardone, C. F. \& Lee, R. G. (2011). Critical inquiry across disciplines: Strategies for student-generated problem posing. College Teaching, 59(1), 13-22.

National Leadership Council for Liberal Education \& America's Promise. (2007). College learning for the new global century. Washington, DC: Association of American Colleges and Universities.

Niesenbaum, R. A. \& Gorka, B. (2001). Community-based eco-education: Sound ecology and effective education. Journal of Environmental Education, 33(1), 12-16.

Orr, D. W. (1992). Ecological literacy: Education and the transition to a post-modern world. Albany, NY: State University of New York Press.

Orr, D. W. (2004a). Earth in mind: On education, environment, and the human prospect. Washington, DC: Island Press.

Orr, D. W. (2004b). Foreword. In S. Sterling, Sustainable education: Revisioning learning and change (pp 7-9). Schumacher Briefings no. 6. Devon: Green Books. Ltd.

Orr, D. W. (2004c). The nature of design: Ecology, culture, and human intention. New York: Oxford University Press. 
Otto, E. \& Wohlpart, A. J. (2009). Creating a culture of sustainability: Infusing sustainability into the humanities. Journal of Education for Sustainable Development, 3(2), 231-235.

Pascarella, E. T. \& Terenzini, P. T. (2005). How college affects students: (Vol. 2) A third decade of research. San Francisco: Jossey-Bass.

Perry, J. L. \& Katula, M. C. (2001). Does service affect citizenship? Administration \& Society, 33(3), 330-365.

Portland State University Institutional Assessment Council. (2009). Campus-wide learning outcomes. Portland State University. Retrieved October 1, 2009 from http://www.iac.pdx.edu/content/campus-wide-learning-outcomes-0

Portland State University References. (2010). We've got great references. Portland State University. Retrieved July 13, 2010 from http://www.pdx.edu/references

Portland State University University Studies. (2009). Senior capstone. Portland State University. Retrieved October 31, 2009 from http://www.pdx.edu/unst/seniorcapstone

Prentice, M. (2002). Institutionalizing service learning in community colleges. American Association of Community Colleges Research Brief. Retrieved from ERIC database. (ED465399)

Prentice, M., \& Robinson, G. (2010). Improving student learning outcomes with service learning. Washington, DC: American Association of Community Colleges.

Princeton Review. (2010). 2010 College Hopes \& Worries Survey Report. The Princeton Review. Retrieved April 3, 2011 from http://www.princetonreview.com/collegehopes-worries.aspx

Putnam, R. D. (2000). Bowling alone: The collapse and revival of American community. New York: Simon \& Schuster.

Putnam, R. D. \& Feldstein, L. M. (2003). Better together: Restoring the American community. New York: Simon \& Schuster.

Reitenauer, V. L. (2005). Becoming community: moving from I to we. In C. M Cress, P. J. Collier, V. L. Reitenauer \& Associates. (2005). Learning through serving: A student guidebook for service-learning across the disciplines (pp 33-44). Sterling, VA: Stylus Publishing, LLC.

Reitenauer, V. L, Spring, A, Kecskes, K. J., Kerrigan, S. M., \& Cress, C. M. (2005). Building and maintaining community partnerships. In C. M Cress, P. J. Collier, V. 
L. Reitenauer \& Associates. (2005). Learning through serving: A student guidebook for service-learning across the disciplines (pp 17-32). Sterling, VA: Stylus Publishing, LLC.

Roehling, P. T., Kooi, T. L. V., Dykema, S., Quisenberry, B., \& Vandlen, C. (2011). Engaging the Millennial Generation in class discussion. College Teaching, 59(1), $1-6$.

Ruby, A. (2008). Reshaping the university in an era of globalization. In J. H. Ballantine and J. Z. Spade (Eds.). Schools and society: A sociological approach to education (third edition) ( $\mathrm{pp}$ 436-440). Victoria, AU: Wadsworth.

Saltmarsh, J. (2007). Dewey's dream: universities and democracies in an age of education reform: civic society, public schools, and democratic citizenship. Michigan Journal of Community Service Learning, 14(1), 65-70.

Sandy, M. \& Holland, B. A. (2006). Different worlds and common ground: community partner perspectives on campus-community partnerships. Michigan Journal of Community Service Learning, 13(1), 30-43.

Sarkissian, W., Hofer, N., Shore, Y., Vajda, S., \& Wilkinson, C. (2009). Kitchen table sustainability: Practical recipes for community engagement with sustainability. London: Earthscan.

Sauvé, L. (2005). Currents in environmental education: Mapping a complex and evolving pedagogical field. The Canadian Journal of Environmental Education, 10, 11-37.

Schrader, D. E. (2004). Intellectual safety, moral atmosphere, and epistemology in college classrooms. Journal of Adult Development, 11(2), 87-101.

Scott, W. \& Gough, S. (2003). Sustainable development and learning: framing the issues. New York: Taylor and Francis (Routledge).

Senge, P., Smith, B., Kruschwitz, N., Laur, J., \& Schley, S. (2008). The necessary revolution: How individuals and organizations are working together to create a sustainable world. New York: Doubleday.

Smith, G. A. (2002). Place-based education: Learning to be where we are. Phi Delta Kappan 83(8), 584-594.

Smith, G. A. (2007). Place-based education: breaking through the constraining regularities of public school. Environmental Education Research, 13(2), 189-207.

Smith, G. A. \& Williams, D. R. (1999). Introduction: Re-engaging culture and ecology. In G. A. Smith \& D. R. Williams (Eds.), Ecological education in action: On 
weaving education culture, and the environment (pp 1-18). Albany, NY: SUNY Press.

Smith, M. C. (2008). Does service learning promote adult development? Theoretical perspectives and directions for research. New Directions for Adult and Continuing Education, 118, 5-15.

Snyder, G. (1995). The rediscovery of Turtle Island. In G. Snyder (Ed.), A place in space: Ethics, aesthetics, and watersheds: New and selected prose. Washington, D.C.: Counterpoint.

Sipos, Y., Battisti, B., \& Grimm, K. (2008). Achieving transformative sustainability learning: Engaging head, hands, and heart. International Journal of Sustainability in Higher Education, 9(1), 68-86.

Sobel, D. (2004). Place-based education: Connecting classrooms and communities. Great Barrington, MA: The Orion Society.

Steiner, G. \& Posch, A. (2006). Higher education for sustainability by means of transdisciplinary case studies: An innovative approach for solving complex, realworld problems. Journal of Cleaner Production, 14, 877-890.

Sterling, S. (2004). Sustainable education: Revisioning learning and change. Schumacher Briefings no. 6. Devon: Green Books. Ltd.

Stone, M. K. (2005). Sustainability: A new item on the lunch menu. In M. K. Stone \& Z. Barlow (Eds.), Ecological literacy: educating our children for a sustainable world (pp. 227-240). San Francisco: Sierra Club Books.

Strauss, A., \& Corbin, J. (1998). Basics of qualitative research: Techniques and procedures for developing grounded theory (2nd ed.). Thousand Oaks, CA: Sage.

Stuteville, R. \& Ikerd, J. (2009). Global sustainability and service-learning: paradigms for the future. International Journal of Organizational Analysis, 17(1), 10-22.

Svanström, M., Lozano-García, F. J., \& Rowe, D. (2008). Learning outcomes for sustainable development in higher education. International Journal of Sustainability in Higher Education, 9(3), 339-351. doi: 10.1108/14676370810885925.

Taylor, E. W. (2006). The greening of the adult education academy. In S. B. Merriam, B.C. Courtenay, R. M. Cervero (Eds.), Global issues and adult education: Perspectives from Latin America, Southern Africa, and the United States (pp. 254-264). San Francisco: Jossey-Bass. 
Taylor, M. C. (2010). Crisis on campus: A bold plan for reforming our colleges and universities. New York: Random House, Inc.

Taylor, M. L. (2006). Generation next comes to college: 2006 updates and emerging issues. A collection of papers on self-study and institutional improvement: Focusing on the needs and expectations of constituents: Understanding and supporting all types of learners, 2(2), 28-55.

Tennant, N. \& Pogson, P. (1995). Learning and change in the adult years: A developmental perspective. San Francisco: Jossey-Bass.

Tilbury, D., Hamú, D. \& Goldstein, W. (2002). Education. Earth Year Report on the World Summit. International Union for Conservation of Nature, Gland, Switzerland.

Tuitt, F. A. (2009). Standing on the outside looking in: Implications for practice. In. M. F. Howard-Hamilton, C. L. Morelon-Quanoo, S. D. Johnson, R. Windle-Wagner, \& L. Santigue (Eds.), Standing on the outside looking in: Underrepresented students in advanced degree programs (pp. 224-256). Sterling, VA: Stylus.

UNESCO. (2005, October). United Nations decade of education for sustainable development (2005-2014): Guidelines and recommendations for reorienting teacher education to address sustainability. Retrieved September 15, 2008, from UNESCO Documents and Publications: http://unesdoc.unesco.org/images/0014/001433/143370E.pdf

Waldstein, F. A. \& Reiher, T. C. (2001). Service-learning and students' personal and civic development. The Journal of Experiential Education, 24(1), 7-13.

Wals, A. E. J \& Blewitt, J. (2010). Third-wave sustainability in higher education: Some (inter)national trends and developments. In P. Jones, D. Selby, \& S. Sterling (Eds.) (2010). Sustainability education: Perspectives and practice across higher education (pp 55-74). London, UK: Earthscan.

Westheimer, J. \& Kahne, J. (2004). What kind of citizen? The politics of educating for democracy. American Educational Research Journal, 41(2), 237-269.

White, C. R. (1993). A model for comprehensive reform in general education: Portland State University. Retrieved from http://www.pdx.edu/unst/program-documents

Williams, D. R. \& Taylor, S. (1999). From margin to center: Initiation and development of an environmental school from the ground up. In G. A. Smith \& D. R. Williams (Eds.), Ecological education in action: On weaving education culture, and the environment (pp 79-102). Albany, NY: SUNY Press. 
Yeh, T. L. (2010). Service-learning and persistence of low-income, first generation college students: An exploratory study. Michigan Journal of Community Service Learning, 16(2), 50-65

Zaferatos, N. C. (2007). Sustainable planning education as intercultural service learning: Kefalonia program in sustainable community development. Journal of Education for Sustainable Development, 1(2), 199-208.

Zemsky, R., Wegner, G. R., and Massy, W. F. (2005). Remaking the American university: Market-smart and mission-centered. New Brunswick, NJ: Rutgers University Press. 


\section{Appendix A: Interview Themes for Individual Interviews}

The following themes will be covered in your individual interview:

- Your current relationship, role, and responsibilities with PSU and the senior capstone program

- How you define sustainability and sustainability education

- The content of your senior capstone course related to sustainability issues, themes, processes, learning outcomes, skills, knowledge, and/or values

- The ability for sustainability and community-based learning to complement or enhance each other

- The connection between sustainability themes, knowledge, skills, or values and the community-based learning element

- Types of sustainability and community engagement activities the students engage in during your course

- Community-based learning as an approach for sustainability education

- Best practices for connecting community-based learning and sustainability

- The relationship between sustainability education and community-based learning

- The ability for sustainability education and community-based learning to prepare students to successfully engage in their communities 


\section{Appendix B: Informed Consent Form for Individual Interviews}

You are invited to participate in a research study conducted by Emily Bowling, a graduate student from Portland State University's Educational Leadership and Policy graduate program in Leadership in Ecology, Culture, and Learning (LECL). The researcher has designed this study to explore and better understand best practices for connecting sustainability course themes in community based learning courses, such the senior capstone courses, at the higher education level. This study is being conducted in partial fulfillment of the requirements for a master's degree, and it is under the supervision of Dr. Dilafruz Williams. You were selected as a possible participant in this study because of your affiliation with the senior capstone program and knowledge of or experience with sustainability and community-based learning.

If you decide to participate, you will be asked to engage in a 45 to 60 minute interview that will be audio taped and take place in your office or another location of convenience to you. The interview will be conducted to learn about how you link sustainability with community-based learning. You will also need to review and sign this consent form. There are very limited risks known for participating in this study. However, while participating in this study, it is possible that participants may experience psychological discomfort. If this occurs, your decision to discontinue participation for any reason will be immediately honored and respected. You may not receive any direct benefit for participation in this study; however your participation may help increase knowledge that may benefit university instructors teaching community based learning courses.

Any information that you provide and can be linked to you in this study will be kept confidential. The principal investigator will keep this information confidential, and your identity will be coded and pseudonyms will be used in the final publication unless you agree otherwise. Due to the nature and specificity of the questions being asked in this study, it is possible that your identity could be determined even with the use of pseudonyms. However, the information being collected in the questions is not of a very sensitive nature and minimal risk exists for the participants. The researcher will be happy to provide you with the interview questions prior for your review while you consider your participation in the study. The digital recordings will be erased after note taking and transcription, and all identifying information will be removed. Data storage procedures will include keeping the data and transcripts on a personal computer that is password protected. Any information that is acquired based upon participant interviews will be made available to you for final review and editing.

Your participation is voluntary. You do not have to participate in this study and this decision will not affect your relationship Portland State University or the Educational Leadership and Policy Department. You may withdraw from this study at any time without affecting your relationship with Portland State University.

If you have concerns or problems with your participation in this study or your rights as a research subject, please contact the Human Subjects Research Review Committee, Office 
of Research and Sponsored Projects, 600 Unitus Building, Portland State University, (503) 725-4288 or 1-877-480-4400. If you have questions about the study itself, please contact the researcher Emily Bowling at (503) 725-2459 or bowlinge@pdx.edu.

Your signature indicates that you have read and understand the above information and agree to take part in this study. Please understand that you may withdraw your consent at any time without penalty, and that by signing, you are not waiving any legal claims, rights, or remedies. The researcher will provide you with a copy of this form for your own records.

Signature:

Date:

Printed Name:

Your signature below indicates that you give permission for your name to be used in reports and publications associated with this research. You will be given the opportunity to review and approve any quotations or information that is linked to your name before any report or publication submissions are made.

Signature:

Date:

Printed Name: 


\section{Appendix C: Individual Interview Guide for Semi-Structured Interviews}

Thank you for participating in this interview. You can withdraw from this study at any time.

1) Describe your current relationship and role with Portland State University (PSU). How long have you been in this role?

2) Briefly explain your duties and responsibilities in your position with PSU.

3) How many senior capstone courses have you taught? What were the titles?

4) Briefly describe the course content of your "sustainability" senior capstone course.

5) Explain the term "sustainability" as you understand it.

6) Explain the term "sustainability education" as you understand it.

7) Elaborate on how the course content includes issues or themes of sustainability.

8) Why did you choose to include sustainability issues in your senior capstone course and particularly in a community-based learning course?

9) Have you incorporated the following into your course, and if so, how?

a. sustainability processes,

b. sustainability learning outcomes,

c. sustainability skills,

d. sustainability knowledge, and/or

e. sustainability values.

10) What is your perception on how sustainability and community-based learning are linked?

11) Do you see the sustainability piece and community-based learning piece of your course complementing or enhancing each other?

a. Why/why not?

b. If yes, in what ways?

12) How do you connect sustainability themes, knowledge, skills, or values to the community-based learning element? (What activities, projects, or assignments do you employ? Which are most effective?)

13) What are the types of community engagement activities students do and how do they fit together with the sustainability piece? 
14) What are the types of sustainability activities students do and how do they fit together with the community engagement piece?

15) How are the community engagement and sustainability pieces distinct? How do they overlap?

16) In your opinion, does knowledge about sustainability enhance a student's ability to successfully engage in the community?

a. If yes, how?

17) In your opinion, does knowledge about or ability to engage in the community enhance a student's ability to successfully engage in sustainability work?

a. If yes, how?

18) Is the community-based learning approach beneficial in courses dealing with sustainability issues?

a. If yes, why?

b. To what degree?

19) What tools, tips, or best practices do you have to offer for connecting communitybased learning with sustainability?

20) Would you be able to teach sustainability education/about sustainability issues without community-based learning? Explain.

21) Would you like to see community-based learning and sustainability education coevolve to better prepare students to engage successfully in their communities?

a. If so, how?

22) How would you sum up the relationship between sustainability education and community-based learning?

23) Would you like to add anything else?

Thank you. 